\title{
Modelagem hidrodinâmica e de qualidade da água como ferramenta para avaliação de enquadramento de corpos d'água
}

\author{
Modelling unsteady flow and water quality as a tool for \\ assessing and managing water bodies
}

Arthur Humberto Rocha Ferreira ${ }^{1}$ (D), Danieli Mara Ferreira ${ }^{1}$ (D), Cristovão Vicente Scapulatempo Fernandes ${ }^{1}$ (D)

1Universidade Federal do Paraná - UFPR, Curitiba, PR. Brasil. E-mails: arthur.rocha@outlook.com.br, danielimaraferreira@gmail.com, cris.dhs@ufpr.br

\begin{abstract}
Como citar: Ferreira, A. H. R., Ferreira, D.M., \& Fernandes, C. V. S. (2021). Modelagem hidrodinâmica e de qualidade da água como ferramenta para avaliação de enquadramento de corpos d'água. Revista de Gestão de Água da América Latina, 18, e20.

https://doi.org/10.21168/rega.v18e20
\end{abstract}

RESUMO: O Enquadramento de corpos de água em classes de usos, em acordo com a Lei 9.433/1997, representa um importante instrumento de gestão de recursos hídricos, na medida em que estabelece não só um olhar para a classificação de classes em acordo com concentrações limite de parâmetros de qualidade da água, mas estabelecendo estratégias para a definição de metas futuras de classificação para o rio. Essas metas são importantes para que o gestor tenha noção dos efeitos das alterações de uso da terra na bacia e processos de urbanização, e para que possa basear sua tomada de decisão, tendo uma relação sustentável entre meio ambiente e usos da água e terra. Tradicionalmente, os estudos de enquadramento levam em consideração aspectos de emissão e transporte não considerando variações espaciais e temporais. Este trabalho apresenta uma abordagem alternativa, em que a análise em regime nãopermanente é considerada para poder integrar aspectos de emissão em Bacias, sua propagação em rios e a integração com a dinâmica de reservatórios. Neste contexto, avalia-se a aplicabilidade do modelo hidrodinâmico e de qualidade da água HEC-RAS para os rios da união da Bacia do Rio Paranapanema, como ferramenta adicional à gestão de recursos hídricos e enquadramento de corpos de água, considerando a dinâmica espacial e temporal. Destaca-se a implementação do modelo para todo o rio Paranapanema, incluindo a representação do sistema lótico-lêntico, considerando as cinco usinas hidrelétricas a fio d'água e os três reservatórios em operação entre os estados de São Paulo e Paraná. Os parâmetros de qualidade da água considerados foram Demanda Biológica de Oxigênio (DBO), Nitrogênio Total (NT), Fósforo Total (PT) e Oxigênio Dissolvido (OD). Os resultados indicaram capacidade em estimar a frequência de conformidade com os limites de classe para os cenários, em especial NT e DBO, compatível com a dinâmica temporal e espacial, mas com resultados limitados pelos coeficientes cinéticos constantes do modelo e tamanho da área de estudo. A principal contribuição é que resultados confirmam a aplicabilidade da metodologia e da utilização de um modelo de domínio público para incorporação, o HEC-RAS, em ampla escala em bacias hidrográficas.

Palavras-chave: Gestão de Recursos Hídricos; Modelagem em Regime Não-Permanente; HEC-RAS; Reservatórios em Cascata.

ABSTRACT: Part of the management of water resources in Brazil is controlled by the Enquadramento, in accordance with Law 9,433/1997, a tool that defines classes for rivers, based on limit concentrations of water quality parameters, acting as a basis for defining future goals for the river and its basin. These goals can relate land use in the basin and urbanization processes to water quality, which must be guaranteed for the most demanding current and future uses, and crucial for the decision-making on the basin to be based on a sustainable relationship between the environment and the uses of water and land. Traditionally, this type of studies take into account aspects of pollutants emission and transport without considering spatial and temporal variations. This work presents an alternative approach, in which the analysis in the unsteady regime is considered, so it is possible to integrate aspects of emission in Basins, its propagation in rivers and the integration with reservoir dynamics. In this context, the applicability of the hydrodynamic and water quality model HEC-RAS for the rivers Paranapanema and Itararé are evaluated, as an additional tool to the management of the water resources in the river basin, considering the spatial and temporal dynamics. The implementation of the model for the entire Paranapanema River stands out, including the

Recebido: Julho 22, 2021. Revisado: Setembro 26, 2021. Aceito: Outubro 11, 2021. 
representation of the lotic-lentic system, considering the five run-of-river hydroelectric plants and the three reservoirs in operation between the states of São Paulo and Paraná. The water quality parameters considered were Biological Oxygen Demand (BOD), Total Nitrogen (NT), Total Phosphorus (PT) and Dissolved Oxygen (DO). The results indicated the ability of the model to estimate the frequency of compliance with the classes, as presented in the Enquadramento, for multiple scenarios and compatible with the temporal and spatial dynamics. The NT and BOD results stood out, while the other parameters were more strongly limited by the kinetic coefficients approach of the HEC-RAS model and the size of the study area, which challenged the calibration process. The main contribution is that the results confirm the applicability of the methodology and the use of the HEC-RAS, on a large hydrographic basin with a series of cascade-reservoirs.

Keywords: Water Resources Management; Unsteady Flow Modelling; HEC-RAS; Cascade Reservoirs.

\section{INTRODUÇÃO}

O desenvolvimento econômico, social e ambiental de uma bacia hidrográfica são os pilares para o crescimento sustentável, que é condicionado ao adequado planejamento visando atenuar os efeitos de emissões poluentes. Setores produtivos como a pecuária, agricultura e indústria tem o protagonismo econômico, mas também são responsáveis pelos impactos no meio ambiente no local com o aumento no lançamento de agrotóxicos, fertilizantes, químicos e poluentes em geral, além de desmatamento e alterações no uso da terra. 0 equilíbrio entre essas variáveis é um grande desafio, cuja solução demanda o adequado planejamento e gestão sustentável de uso da terra e de recursos hídricos.

Dentro deste contexto, a Lei 9.433/97 instituiu a Política Nacional de Recursos Hídricos (PNRH) com o objetivo de garantir o uso de recursos hídricos em quantidade e qualidade adequada aos seus usos, e assegurar sua disponibilidade para as gerações atuais e futuras. Os fundamentos são: bem de domínio público, recurso escasso e limitado, dotado de valor econômico e cuja gestão deve atender a distintos usos. Também define os mecanismos de governança através dos Comitês de Bacias Hidrográfica, de forma descentralizada e com a participação do poder público, usuários e a Sociedade Civil. Dos 5 instrumentos previstos em lei, destacam-se para esse estudo: planos de recursos hídricos - planos diretores que visam fundamentar e orientar a implementação da PNRH, outorga de uso instrumento administrativo que visa controlar o uso da água para garantir sua disponibilidade, e o enquadramento de corpos de água. Este tem como objetivo definir classes para os rios, que devem ser atribuídas de forma a garantir que a qualidade da água do rio seja suficiente para seu uso mais exigente, além de diminuir custos de combate à poluição com ações preventivas (Brasil, 1997).

Os principais instrumentos normativos associados ao enquadramento são a Lei 9.984/200, resolução CONAMA 357 (Brasil, 2005) e a resolução CNRH 91/2008. Essa separa os corpos hídricos por tipo, como água doce, salina e salobra, ambientes lóticos e lênticos, além de apresentar as classes para cada tipo. Cada classe define valores limite para uma série de parâmetros, cujos valores devem ser obedecidos nas condições de vazão de referência. A resolução também indica que possíveis interações entre os parâmetros devem ser observadas, não podendo causar alterações no comportamento do ecossistema local, assim como alterar os usos preponderantes previstos. No entanto, a resolução não detalhas critérios para a definição da vazão de referência, apenas que é responsabilidade do Comitê da Bacia Hidrográfica.

Em geral, conforme apresentado por Bitencourt et al. (2019), as metas de enquadramento são obtidas a partir do cálculo das concentrações de constituintes avaliadas no cenário da vazão de referência, em geral, a Q7,10 (vazão mínima de 7 dias de duração e tempo de recorrência de 10 anos) ou Q95 (vazão com tempo de permanência igual a 95\%). Essa abordagem simula uma situação frequente e que não considera a variação temporal de vazões e de concentração de poluentes. Em aplicações de modelagem, essa estratégia implica em menor tempo computacional e utilização de modelos de qualidade da água em regime permanente (Bitencourt et al., 2019).

Mais recentemente, com a necessidade de se avaliar o enquadramento de corpos de água considerando o efeito dinâmico de bacias hidrográficas, influenciado por características do uso da terra e do regime hidrológico, modelos em regime não-permanente para a gestão de recursos hídricos passaram a ser utilizados (Ferreira et al., 2016, 2019; Ferreira, 2019). Essa dinâmica é intensificada em cenários urbanos e com rios controlados por reservatórios (Ferreira, 2021). Fica evidente que estes aspectos, que interferem diretamente na dinâmica de transporte de constituintes, podem ter um impacto significativo nas estratégias de implementação dos instrumentos de gestão de recursos hídricos (Ferreira, 2021; Ferreira et al., 2016). 
Adicionalmente, outros estudos voltados a aplicações de modelagem na gestão de recursos hídricos apontam a importância de considerar as interações rio-reservatórios e a variação temporal. Tendo como área de estudo a bacia do Rio Tietê, Tercini \& Méllo Júnior (2016) desenvolveram um modelo em regime permanente unidimensional, aplicado a 83 quilômetros de rio e um reservatório, considerando 12 cenários que variam o nível do reservatório, vazão de descarga e concentração de entrada de demanda biológica de oxigênio DBO. A conclusão obtida é que o reservatório tem grande influência nos processos dinâmicos associados aos parâmetros de qualidade da água à jusante do barramento, sendo influenciados pela carga de DBO afluente, nível do reservatório e vazão descarregada.

O impacto gerado pela carga de DBO afluente e nível do reservatório indicam a importância da modelagem integrada de bacia e rio. Luo et al. (2020) apontam os efeitos da urbanização e alterações de uso no solo nos rios da região estudada, indicando que os impactos gerados pelo processo de crescimento urbano têm menor impacto nos corpos hídricos e equilíbrio da fauna que as alterações relacionadas a agricultura, agropecuárias e afins. Essa pesquisa também indicou resultados diferentes para as estações seca e úmida, com resultados piores para a estação seca (inverno), destacando a importância da consideração da variação temporal. Resultados semelhantes àqueles apresentados por Moura et al., (2013), que analisou a distribuição de fitoplâncton ao longo do Rio Contas, rio controlado por uma série de reservatórios, também observando a redução na variação das concentrações dos parâmetros associados a qualidade da água, processo chamado de homogeneização, e aumento de algas durante o período seco.

Estabelecida a importância da relação entre alterações no uso de solo e qualidade da água, ressalta-se que as formas de as integrar são avaliando os dados observados, ou usando modelos em regime não-permanente. A pesquisa desenvolvida por da Silva et al. (2019) estudou os dados disponíveis para o Rio Jauru, entre os anos de 1990 e 2013, abrangendo inclusive a construção de um dos seis reservatórios do rio. Esse tipo de abordagem permitiu concluir relações de causaconsequência, como a forma com que as características físicas dos reservatórios influenciam os parâmetros de qualidade da água, mas não permite simular cenários diferentes. Para a simulação de cenários diferentes requer-se o desenvolvimento de modelos em regime não permanente, como desenvolvido por Wang et al., (2016), que avaliou o impacto de projetos de represamento e desvio no transporte de água e poluentes para o Rio Hianjiang (China), e como esses impactariam a classificação do rio. Esse estudo também aponta a regularização das vazões, mas ao contrário dos outros indica que as obras de represamento e desvio implicariam em queda de qualidade da água, fazendo com que o Rio não atendesse mais os critérios mínimos de sua classe.

Dentro deste contexto, no que concerne a aplicação para o enquadramento de corpos de água, Ferreira et al. (2016) propõe o uso de curvas de permanência como alternativa a abordagem baseada em vazões de referência, usando como base a bacia do Rio Iguaçu, na Região Metropolitana de Curitiba (PR). 0 estudo indicou a versatilidade da abordagem em regime não-permanente, trazendo melhor compreensão sobre a variação temporal das vazões e concentrações dos poluentes e os potenciais impactos para melhor avaliar as estratégias de implementação do Enquadramento de corpos de água.

Dentro desse contexto, o presente estudo integra simulações em regime não-permanente, aplicadas a gestão de recursos hídricos. Mais particularmente, destaca uma representação de sistema ambiental que considera a integração Rio-Reservatório para a Bacia Hidrográfica do Rio Paranapanema, com $929 \mathrm{~km}$ de extensão e $100.800 \mathrm{~km}^{2}$ de área de bacia hidrográfica. A principal contribuição deste artigo é de apresentar estas reflexões através de uma aplicação de modelo hidrodinâmico e de qualidade da água como ferramenta de auxílio a gestão e tomada de decisão. Os resultados são avaliados por curvas de permanência e comparados com os limites de classe (Brasil, 2005) utilizando cenários de referência com aporte de poluentes crescentes (Universidade Federal do Paraná, 2020a). Optou-se por aplicar o modelo HEC-RAS 5.0.7, programa de acesso público e com extensa aplicação em estudos de escoamento de águas superficiais (Che \& Mays, 2017; Correia, 2018; Fleischmann et al., 2019; Vijay et al., 2018). Adicionalmente, para complementação de referencial bibliográfico é apresentada uma tabela resumo para a revisão bibliográfica do tema, permitindo categorizar o objetivo de cada estudo, diferenciais, modelos usados, cujo conteúdo é apresentado no item 4 do material suplementar.

\section{MATERIAIS E MÉTODOS}

Usaram-se como base os dados disponibilizados na plataforma HidroWeb (Agência Nacional de Águas, 2020), e pelas instituições Departamento de Água e Energia Elétrica (DAEE-SP), Instituto Água 
e Terra (IAT) e Companhia Ambiental do Estado de São Paulo (CETESB). Os dados de vazão, medidos em intervalo diário, passaram pelas etapas de obtenção, processamento e seleção, nas quais se definiu o ano base de 2012, por ter a maior quantidade de dados disponíveis. Para as condições de contorno do modelo hidrodinâmico, usaram-se as estações com dados disponíveis para 2012, enquanto para qualidade da água usaram-se aquelas com dados disponíveis para o período 2000 - 2017 e localizadas nas entradas e saídas dos reservatórios, denominadas "estações de referência" (Universidade Federal do Paraná, 2019).

\section{Modelagem Hidrodinâmica}

As simulações foram conduzidas em regime não-permanente na direção longitudinal (1D), baseando-se nas equações de Saint-Venant. Essa abordagem permite avaliar a influência da variação temporal no sistema, um dos objetivos da pesquisa, para um esquema de escoamento compatível com aquele observado em rios. Cabe destacar que representações em Sistemas 2D são indicados para usos mais específicos (J

eppson, 2010), usualmente em situações em que o foco está nas característica de escoamento e qualidade da água entre as margens, exigindo mais dados, esforço computacional e tempo de desenvolvimento. Aplicou-se o modelo em regime 1D para todas as simulações, sendo que os trechos de reservatórios são representados como seções de rios mais largas e controlados pelas vazões de descarga das barragens, ao contrário da abordagem tradicional, que usualmente simula de forma separada os reservatórios e considera seu início e fim como condições de contorno.

Essa abordagem é vista em estudos de otimização de operação de reservatórios (Che \& Mays, 2017), onde usa-se o HEC-RAS para simular o volume de água e descargas de reservatório; assim como em estudos de rompimento de barragem (Goodell, 2005), onde também se usa o programa para simular o volume contido na barragem e o hidrograma gerado pelo seu rompimento - no entanto, nenhum dos casos explora características de qualidade da água.

Desenvolvidas no século XIX, as equações de Saint-Venant (Equações 1 e 2) permitem simular o comportamento hidrodinâmico de rios. Sendo equações diferencias sem soluções exatas, requerem métodos numéricos para sua solução, além das condições iniciais e de contorno (U.S. Army Corps of Engineers, 2016):

$$
\begin{aligned}
& \frac{\partial A}{\partial t}+\frac{\partial Q}{\partial x}=q \\
& \frac{\partial Q}{\partial t}+\frac{\partial V Q}{\partial x}+g A\left(\frac{\partial z}{\partial x}+S_{f}\right)=0
\end{aligned}
$$

Onde: $\mathrm{t}=$ tempo $[\mathrm{s}] ; \mathrm{Q}=$ Vazão $\left[\mathrm{m}^{3} / \mathrm{s}\right] ; \mathrm{A}=$ Área da seção transversal $\left[\mathrm{m}^{2}\right] ; \mathrm{q}=$ Contribuição lateral por unidade de distância $\left[\mathrm{m}^{3} / \mathrm{s} . \mathrm{m}\right] ; \mathrm{g}=$ Aceleração da gravidade $\left[\mathrm{m} / \mathrm{s}^{2}\right] ; \mathrm{S}_{\mathrm{f}}=$ Inclinação da linha de energia [-]; V = Velocidade [m/s]; $\mathrm{z}=$ Elevação da superfície [m].

A solução das equações de Saint-Venant não é um processo simples, envolvendo o desenvolvimento de programas ou o uso de ferramentas prontas. Optou-se nesse caso pelo uso do programa HEC-RAS, ferramenta de modelagem hidrodinâmica e de qualidade da água de domínio público, com módulo de integração com dados georreferenciados (SIG) e ampla base de usuários. As Equações 1 e 2 são resolvidas usando o esquema numérico de diferenças finitas implícito de 4 pontos, conhecido como box scheme (U.S. Army Corps of Engineers, 2016).

\section{Modelagem de Qualidade da Água}

Com os resultados da simulação hidrodinâmica, é possível desenvolver as simulações de qualidade da água, que tem como base a equação Advecção - Dispersão - Reação (ADR) (Brunner, 2016).

$$
\frac{\partial}{\partial t} V \varnothing=-\frac{\partial}{\partial x}(Q \varnothing) \Delta x+\frac{\partial}{\partial x}\left(\Gamma \mathrm{A} \frac{\partial \phi}{\partial x}\right) \Delta x \pm S
$$


Onde:

$\mathrm{V}=$ Volume $\left[\mathrm{m}^{3}\right] ; \varnothing=$ Temperatura da Água $\left({ }^{\circ} \mathrm{C}\right)$ ou concentração $\left[\mathrm{kg} / \mathrm{m}^{3}\right] ; \mathrm{Q}=$ Vazão $\left[\mathrm{m}^{3} / \mathrm{s}\right] ; \Gamma=$ Coeficiente de dispersão [m²/s]; A = Área da seção transversal $\left[\mathrm{m}^{2}\right] ; \mathrm{S}=$ Fontes e sumidouros $[\mathrm{kg} / \mathrm{s}]$.

A equação ADR avalia a concentração do poluente baseado nos dados de escoamento da célula computacional e nas taxas de conversão dos poluentes, que podem ser negativas (decaimento) ou positivas (acumulação). Essa é calculada individualmente para cada nutriente simulado, dependendo da concentração e taxas de conversão de outros nutrientes, temperatura, taxa de oxidação, etc. (Brunner, 2016). Além desses processos de transformação, o termo $S$, calculado por equações únicas para cada fração, inclui cargas pontuais e difusas que o sistema recebe ao longo do escoamento. Na versão utilizada do HEC-RAS, considerou-se os processos que simulam oxigênio dissolvido (OD), demanda bioquímica de oxigênio (DBO), fósforo e nitrogênio, interpretados como fósforo total (PT) e nitrogênio total (NT), cujas equações são apresentadas no item 1 do material suplementar.

0 ciclo de nitrogênio representa as transformações pelas quais o elemento passa em contato com a água: frações dissolvidas de Nitrogênio Orgânico (OrgN), Amônia $\left(\mathrm{NH}_{4}\right)$, Nitrito $\left(\mathrm{NO}_{2}\right)$ e Nitrato $\left(\mathrm{NO}_{3}\right)$, apresentados nos resultados como a soma das frações, denominada Nitrogênio Total (NT). No ciclo de fósforo, são contabilizadas as frações dissolvidas de Fósforo Orgânico (OrgP) e ortofosfato $\left(\mathrm{PO}_{4}\right)$; Fósforo Total (PT) é considerado como a soma dessas frações. 0 termo $\Gamma$ da Equação 3 representa a dispersão, forma como os poluentes são misturados na água pelos efeitos do fluxo turbulento e diferenças de velocidade. A equação ADR é resolvida usando o método explícito QuicketUltimate (Brunner, 2016).

\section{Área de Estudo}

Separando parte da fronteira entre os estados Paraná e São Paulo, a bacia do Paranapanema tem $100.800 \mathrm{~km}^{2}$ de área e abriga uma população de 4,2 milhões de pessoas, além de dois rios de domínio da união - Rio Paranapanema, com $929 \mathrm{~km}$ de comprimento, e Itararé, com $220 \mathrm{~km}$. Os rios são caracterizados pela influência de usinas hidrelétricas, que totalizam oito ao longo do Rio Paranapanema, e das quais cinco são a fio d'água. Os três reservatórios com barragens são Jurumirim, Chavantes e Capivara, sendo que o reservatório de Chavantes fica logo após a junção dos rios e é único ao longo da calha do Rio Itararé. A área de estudo é representada pela Figura 1, que ilustra as variações de altitude do Modelo de Elevação de Terreno (MDE) e posição das estações usadas no modelo hidrodinâmico, e pela Figura 2, que localiza as estações de referência usadas para calibração e avaliação dos resultados de qualidade da água.

\section{Características do Modelo Hidrodinâmico}

Um dos desafios para o desenvolvimento e utilização de modelos como o proposto, baseado no HEC-RAS, parte da demanda de dados necessários para sua adequada implementação. No que concerne aos dados de geometria, para melhor traduzir as características do relevo local para inclinação do canal e área das seções transversais, foram utilizadas um total de nove seções transversais medidas, disponibilizadas no banco de dados HidroWeb (Agência Nacional de Águas, 2020); estas foram complementadas com a geração de outras seções transversais a partir de um arquivo de Modelo de Elevação de Terreno (MDE) da região nos trechos sem medições disponíveis. Esse uniu as elevações da bacia, com resolução de 30 metros, com as batimetrias dos oito reservatórios da bacia hidrográfica, com resolução de 25 metros, permitindo a geração de mais seções transversais (Figura 1). 0 trecho de rio com seções transversais geradas a partir da batimetria doa reservatório tem comprimento de 556,8 km, sendo que comprimento total do trecho simulado é de 720,5 km. Esse método se mostra eficaz (Fleischmann etal., 2019) mas dependente da resolução dos dados disponíveis, condição que nesse caso é contornada pelo grande porte do Rio Paranapanema, com quase $1 \mathrm{~km}$ de largura em sua foz, e com a geração das seções transversais majoritariamente nos trechos de reservatório. Esses dados mostram boa precisão pois as elevações dos reservatórios vêm das batimetrias, dado mais preciso que as elevações de terreno geradas via satélite.

A condição de contorno de montante controla a entrada de água do modelo, para a qual usou-se os hidrogramas diários observados para o ano de 2012. Como condição de contorno interna, usou-se a diferença entre as vazões diárias observadas nas estações indicadas na Figura 1, gerando uma série de dados diários que representa as interações do rio com o ambiente ao seu redor - contribuição lateral causada por chuva, afluentes, pontos de captação de água, entre outros. As descargas das barragens são representadas como condições de contorno internas, na forma de vazões média diárias, 
dado obtido nas estações localizadas nas saídas dos reservatórios - 64215080, 64270090 e 64516080 (Figura 1). As simulações nos reservatórios seguem o mesmo método proposto para os rios, sendo tratados como trechos de rio com seções transversais maiores e controlados pelo fluxo de água afluente e vazões de descarga definidas para a barragem a jusante.

A condição de contorno de jusante é a profundidade normal, calculada a partir da equação de Manning e função da inclinação do fundo do canal no ponto e coeficiente de rugosidade. Essa inclinação foi obtida a partir da elevação e distância entre as duas últimas estação HidroWeb no rio, e tem valor de $0,027 \%$. Como condição inicial, que define os valores de início para solução das equações de SaintVenant, usou-se os dados referentes ao primeiro dia do período considerado (01/01/2012), com término no dia 31/12/2012. 0 menor intervalo de tempo que gerou simulações estáveis foi 2 minutos, com seções transversais interpoladas para cada 200 metros, e coeficiente de rugosidade de Manning $=0,02 \mathrm{~m}^{-1 / 3}$. S. A faixa de valores sugeridos pela literatura para o coeficiente de Manning é entre 0,02 e $0,05 \mathrm{~m}^{-1 / 3}$. S (Chapra, 1997; Jeppson, 2010). Esse valor foi definido como o inicial, baseado em valores de apresentados em (Chapra, 1997; Ferreira et al., 2020) para as simulações e calibração, que não foi necessária por conta dos bons resultados iniciais.

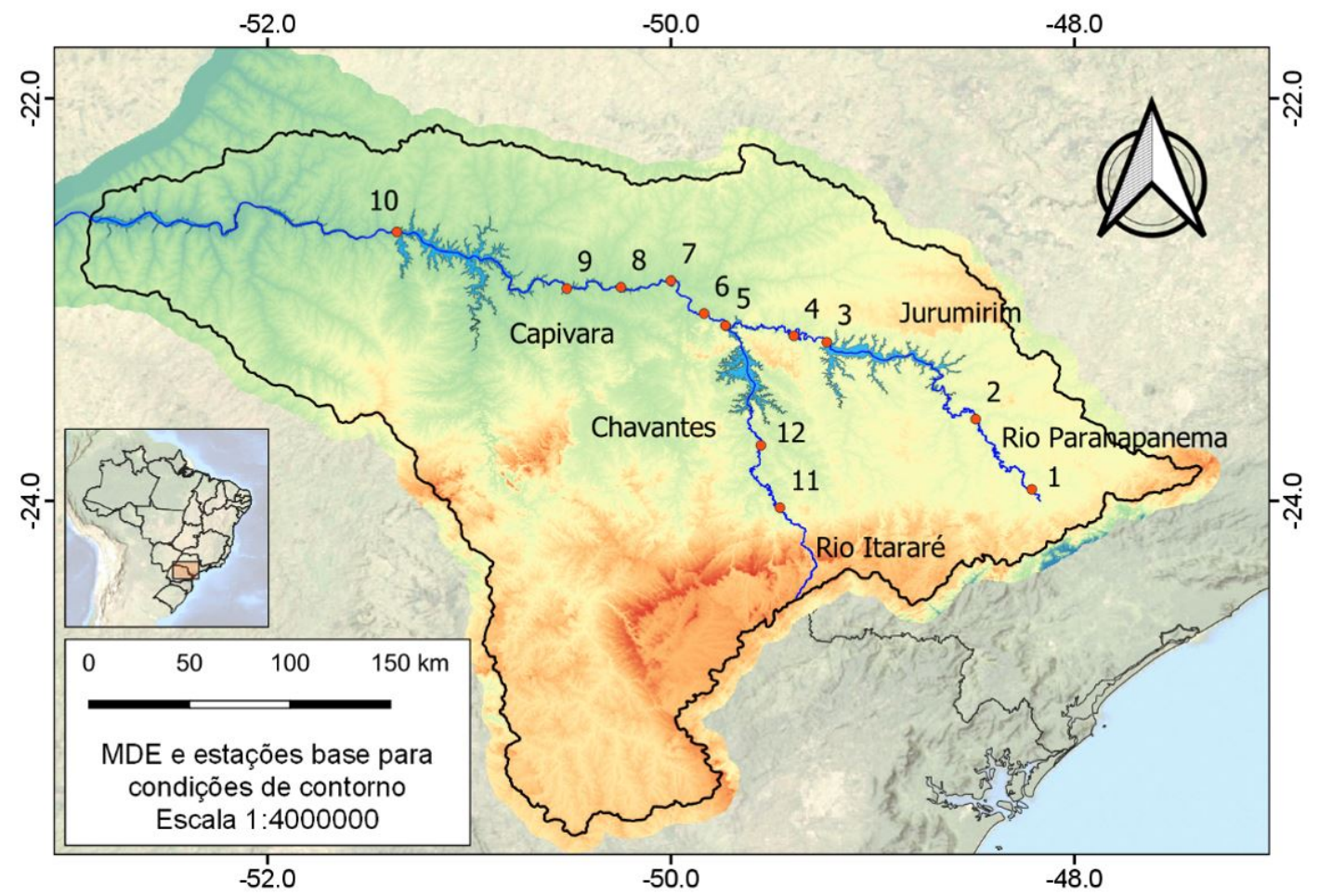

Figura 1 - mapa base do MDE e estações usadas para gerar as condições de contorno do modelo hidrodinâmico, onde os números correspondem às estações: $1=64005000 ; 2=64080000 ; 3=64215080 ; 4=64220050 ; 5=64270080$; $6=64278080 ; 7=64332080 ; 8=64345075 ; 9=64345080 ; 10=64516080 ; 11=64231000 ; 12=64247000$.

\section{Características do Modelo de Qualidade da Água}

Para solução da equação ADR e simulações de qualidade da água, usaram-se cargas de DBO, PT e NT geradas por ottobacia, representando a forma com que os diferentes usos de solo contribuem com poluentes que chegam ao rio, na forma de cargas diárias anuais constantes distribuídas em 123 trechos (Universidade Federal do Paraná, 2019), expandidos para 6 cenários referentes aos anos 2025 e 2035, com aumento de aporte de cargas estagnado, tendencial e acelerado (Tabela 1 - adaptado de (Universidade Federal do Paraná, 2020a). Esses trechos foram compatibilizados com aqueles usados para geração das contribuições laterais do modelo hidrodinâmico, permitindo gerar séries de concentrações de entrada desses poluentes. Fez-se então a mistura dessas cargas na vazão com tempo de permanência de $50 \%\left(Q_{50}\right)$ do trecho avaliado, resultando na concentração de entrada diária constante para o cenário base. A condição de contorno de montante são séries sintéticas para cada fração de poluente avaliado, na forma de concentrações diárias geradas a partir do método autorregressivo de primeira ordem e do conjunto histórico de monitoramento, como apresentado por 
Ferreira et al. (2019). Como condição inicial usou-se os dados referentes ao primeiro dia do período considerado, 01/01/2012. Os coeficientes de aumento no aporte de carga para os cenários futuros são apresentados na Tabela 1, aplicados aos 123 trechos base de acordo com sua localização. Os detalhes do método são apresentados no item 2 do material suplementar.

Tabela 1 - Coeficiente de aumento no aporte de cargas nos cenários futuros, onde: UGRH = Unidade de Gestão de Recursos Hídricos, UPH = Unidade de Planejamento Hídricos.

\begin{tabular}{c|c|c|c|c|cc}
\hline \multirow{2}{*}{ UGRH/UPH } & \multicolumn{2}{c}{ Cenário Tendencial } & \multicolumn{2}{c}{ Cenário Acelerado } & \multicolumn{2}{c}{ Cenário Estagnado } \\
\cline { 2 - 7 } & $\mathbf{2 0 2 5}$ & $\mathbf{2 0 3 5}$ & $\mathbf{2 0 2 5}$ & $\mathbf{2 0 3 5}$ & $\mathbf{2 0 2 5}$ & $\mathbf{2 0 3 5}$ \\
\hline Alto Paranapanema & 1,53 & 1,99 & 1,77 & 2,75 & 1,37 & 1,62 \\
\hline Médio Paranapanema & 1,63 & 2,27 & 1,97 & 3,63 & 1,43 & 1,74 \\
\hline Pontal do Paranapanema & 1,57 & 2,17 & 1,90 & 3,53 & 1,37 & 1,63 \\
\hline Norte Pioneiro & 1,55 & 2,18 & 1,93 & 3,83 & 1,35 & 1,61 \\
\hline Tibagi & 1,34 & 1,83 & 1,63 & 3,17 & 1,21 & 1,40 \\
\hline Piraponema & 1,47 & 1,94 & 1,74 & 3,09 & 1,33 & 1,54 \\
\hline
\end{tabular}

A resolução espacial é de 1000 metros, enquanto o intervalo de tempo não é definido diretamente. A resolução temporal é calculada de forma dinâmica a cada passo de tempo, variando conforme os coeficientes de dispersão do rio e dos coeficientes de Peclet e Courant da célula para cada passo de tempo (Brunner, 2016). A calibração foi conduzida de forma a aproximar a mediana das séries diárias geradas àquela do conjunto dos dados históricos, tendo como base as estações indicadas na Figura 2, em um processo de tentativa e erro. Este processo abrangeu as frações de nitrogênio, fósforo na forma de ortofosfato dissolvido, OD e DBO, atuando nas taxas de reação e sedimentação. A temperatura não foi simulada, assumindo valor constante de $20{ }^{\circ} \mathrm{C}$, assim como os coeficientes de dispersão, que tiveram valor fixo de $20 \mathrm{~m}^{2} / \mathrm{s}$. Os valores usados para os coeficientes cinéticos, assim como a faixa de valores de referência recomentados, são apresentados no item 1 do material suplementar.

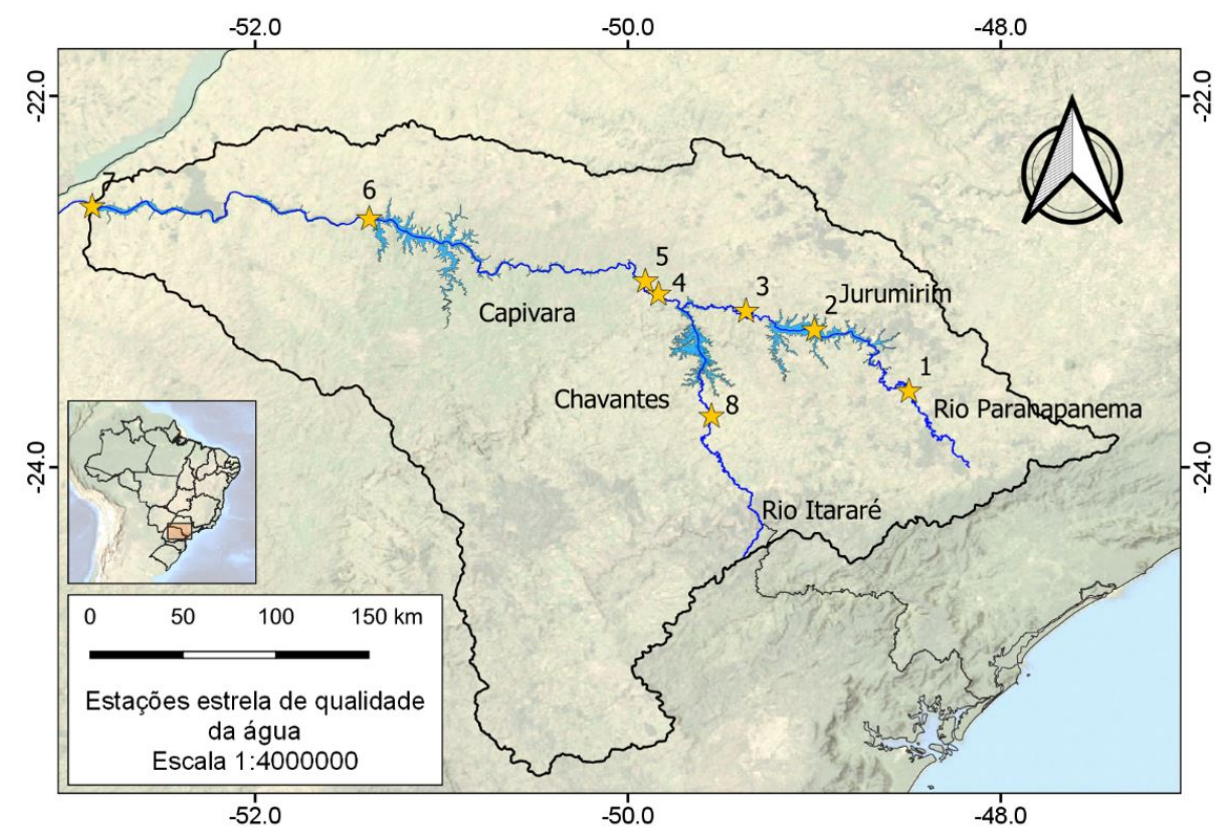

Figura 2 - localização da bacia, rios, reservatórios e estações de referência, onde os números das estações correspondem às estações Hidroweb e código alternativo CETESB: $1=64081000$ / PARP 02100; $2=64214000 /$ JURU 02500; 3 = 64219000; 4 = 64278080; $5=64326000 /$ PARP02500; $6=64516900 /$ PARP 02750; $7=64571100 /$ PARP02900; $8=64245200 /$ ITAR 02500 . 


\section{RESULTADOS E DISCUSSÃO}

\section{Análise Hidrodinâmica}

Os resultados são expressos pela comparação dos hidrogramas e curvas de permanência para a estação 64332080 (Figuras 3 e 4), considerada representativa por estar em uma seção de rio após a junção dos rios Paranapanema e Itararé, e a $54 \mathrm{~km}$ da barragem de Chavantes; e para a estação 64080000 (Figuras 5 e 6), localizada na cabeceira do Rio Paranapanema e não sem receber a influência do remanso do reservatório de Jurumirim. Os resultados para as demais estações, destacando os coeficientes de Nash-Sutcliffe (NS) entre os dados observados e simulados, são apresentados na Tabela 2 e indicados no item 3.1 do material suplementar.

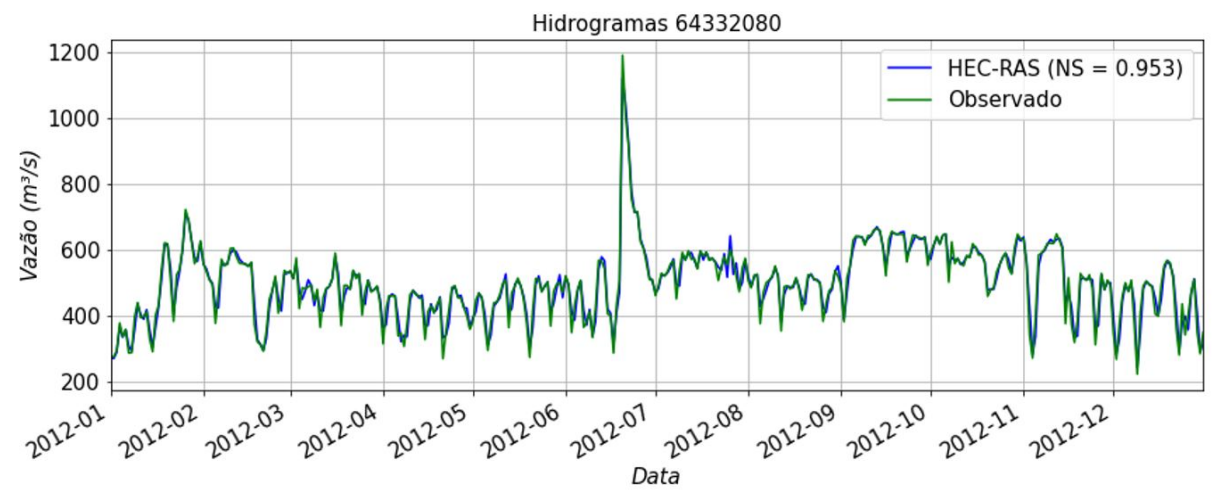

Figura 3 - Comparação entre hidrogramas observado e simulado para a estação 64332080.

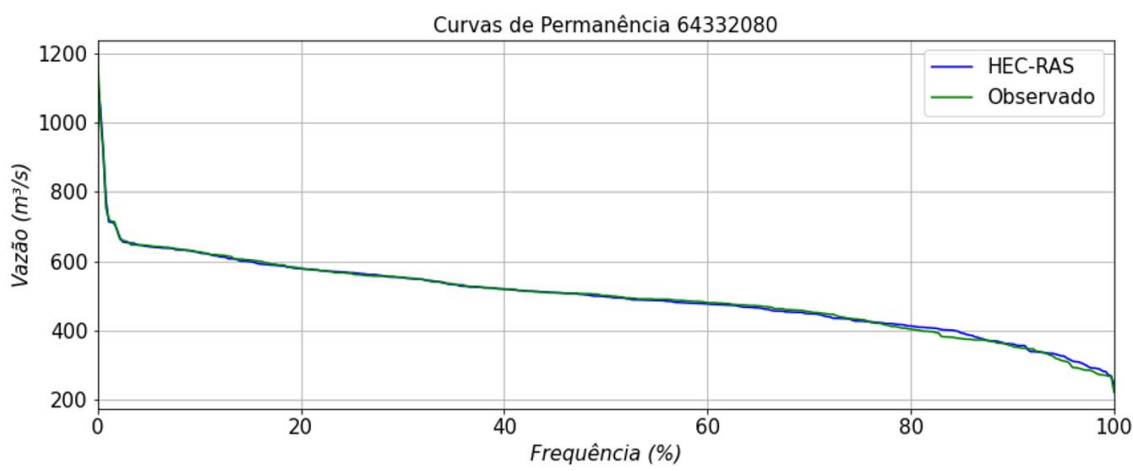

Figura 4 - Comparação entre as curvas de permanência das vazões observadas e simuladas para a estação 64332080.

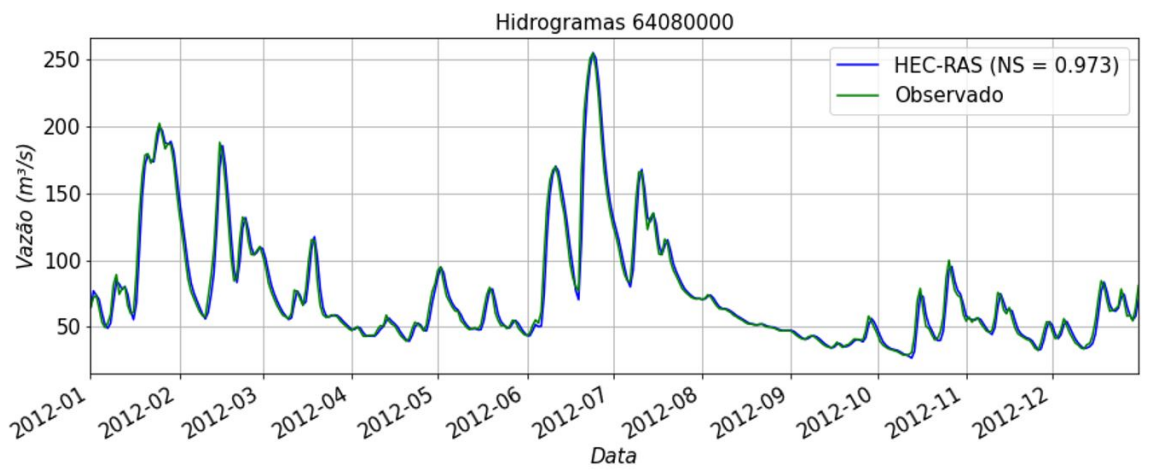

Figura 5 - Comparação entre hidrogramas observado e simulado para a estação 64080000 


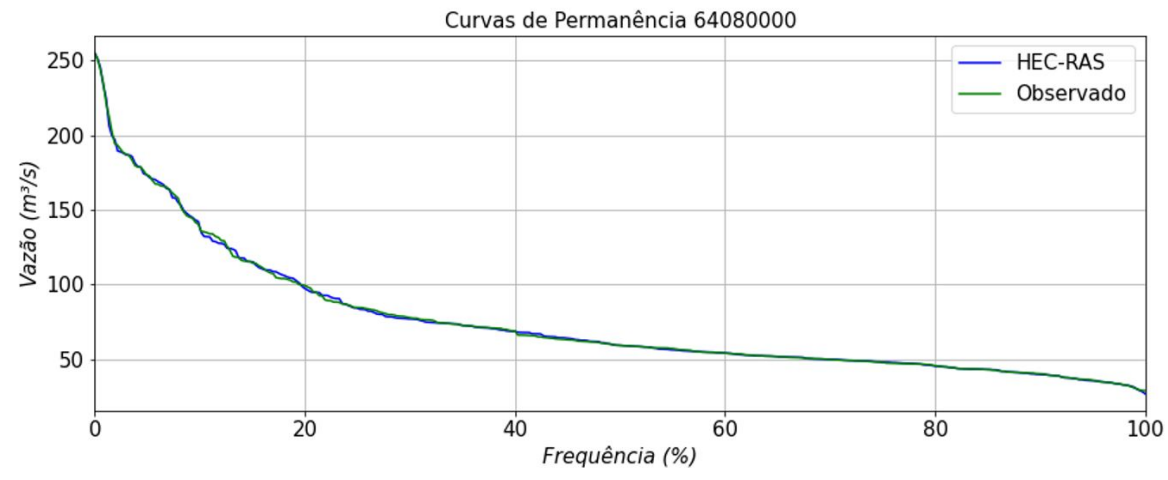

Figura 6 - Comparação entre as curvas de permanência das vazões observadas e simuladas para a estação 64080000.

Tabela 2 - Coeficientes de Nash-Sutcliffe (NS) para as hidrogramas simulados e observados.

\begin{tabular}{c|c|c|c|c|c|c|c|c}
\hline Estação & $\mathbf{6 4 0 8 0 0 0 0}$ & $\mathbf{6 4 2 2 0 0 5 0}$ & $\mathbf{6 4 2 4 7 0 0 0}$ & $\mathbf{6 4 2 7 8 0 8 0}$ & $\mathbf{6 4 3 3 2 0 8 0}$ & $\mathbf{6 4 3 4 5 0 7 5}$ & $\mathbf{6 4 3 4 5 0 8 0}$ \\
\hline Nash-Sutcliffe (NS) & 0,973 & 0,994 & 0,984 & 0,992 & 0,953 & 0,905 & 0,860 \\
\hline
\end{tabular}

A estação 64332080, com os resultados expressos na Figura 3, representa um trecho com escoamento controlado pela barragem de Chavantes, após a junção dos rios. As vazões diárias simuladas são próximas das observadas $(\mathrm{NS}=0,953)$, incluindo os picos, comportamento observado também nas outras estações.

Os resultados das simulações hidrodinâmicas utilizando o modelo HEC-RAS foram considerados satisfatórios, em acordo com a Tabela 2 para as sete estações de referências, indicando a eficiência do modelo em propagar as vazões e representar adequadamente a geometria dos rios e reservatórios. Esses resultados complementam os de Ferreira (2019), que utilizou o mesmo método para estimar as contribuições laterais em seu estudo do Rio Iguaçu, no trecho da Bacia do Alto Iguaçu, com vazões diárias simuladas próxima aquelas observadas, inclusive nos picos. Esses picos também indicam a influência dos reservatórios nos hidrogramas a jusante, sujeitos às regras de operação de vazões descarregadas. Estações sem essa influência, como a 64080000, com seus hidrogramas de vazões medidas e simuladas ilustrados na Figura 5, tem variações de valores menos bruscas.

Comparando-se os hidrogramas apresentadas nas Figuras 3 e 5, nota-se um dos efeitos dos reservatórios no escoamento indicado por outros estudos (Guo et al., 2020; Poff et al., 2007): a regularização das vazões. As curvas de permanência das estações 64332080 (Figura 4) e 64247000 (Figura 6) apresentam uma variação aproximadamente linear. Resultados similares para as demais estações estão indicados no item 3.1 do material suplementar.

Esse comportamento reflete as regras de operação das usinas hidrelétricas e consequentes vazões de descarga dos reservatórios, e do efeito de regularização de vazões, típico de aproveitamento de queda energética com reservatórios em cascata.

\section{Análise de Qualidade da Água}

Os resultados para as simulações de qualidade da água são representados pelas curvas de permanência para os parâmetros Demanda Bioquímica de Oxigênio (DBO), Fósforo Total (PT), Nitrogênio Total (NT) e Oxigênio Dissolvido (OD) para as estações 64326000 (Figura 7), por estar logo após a junção dos rios e 64571100 (Figura 8), por estar na foz do Rio Paranapanema e 64245200 (Figura 9), representando o Rio Itararé.

Adicionalmente, apresenta-se os resultados para a estação 64326000 considerando os resultados para os cenários futuros (Figura 10 - Universidade Federal do Paraná, 2020b), destacando-se os limites de classe definidos na resolução CONAMA no 357/2005 (Brasil, 2005). Para o parâmetro NT, os limites foram arbitrados para fins de comparação, dado que a norma não define valores únicos de referência; para PT, assumiu-se os limites compatíveis a ambientes intermediários entre sistema lêntico e lótico, enquanto OD e DBO utilizam-se dos valores especificados para regime fluvial (Ferreira, 2021).

As curvas de permanência foram construídas ordenando a concentração do poluente de forma decrescente, indicando a frequência de tempo que determinada concentração é excedida. OD tem as 
concentrações ordenadas de forma crescente para que valores de permanência maiores continuem indicando os valores mais críticos, portanto indicando a frequência de tempo em que determinada concentração de oxigênio dissolvido é atingida. Os resultados de qualidade da água são apresentados na integra no item 3.2 do material suplementar.
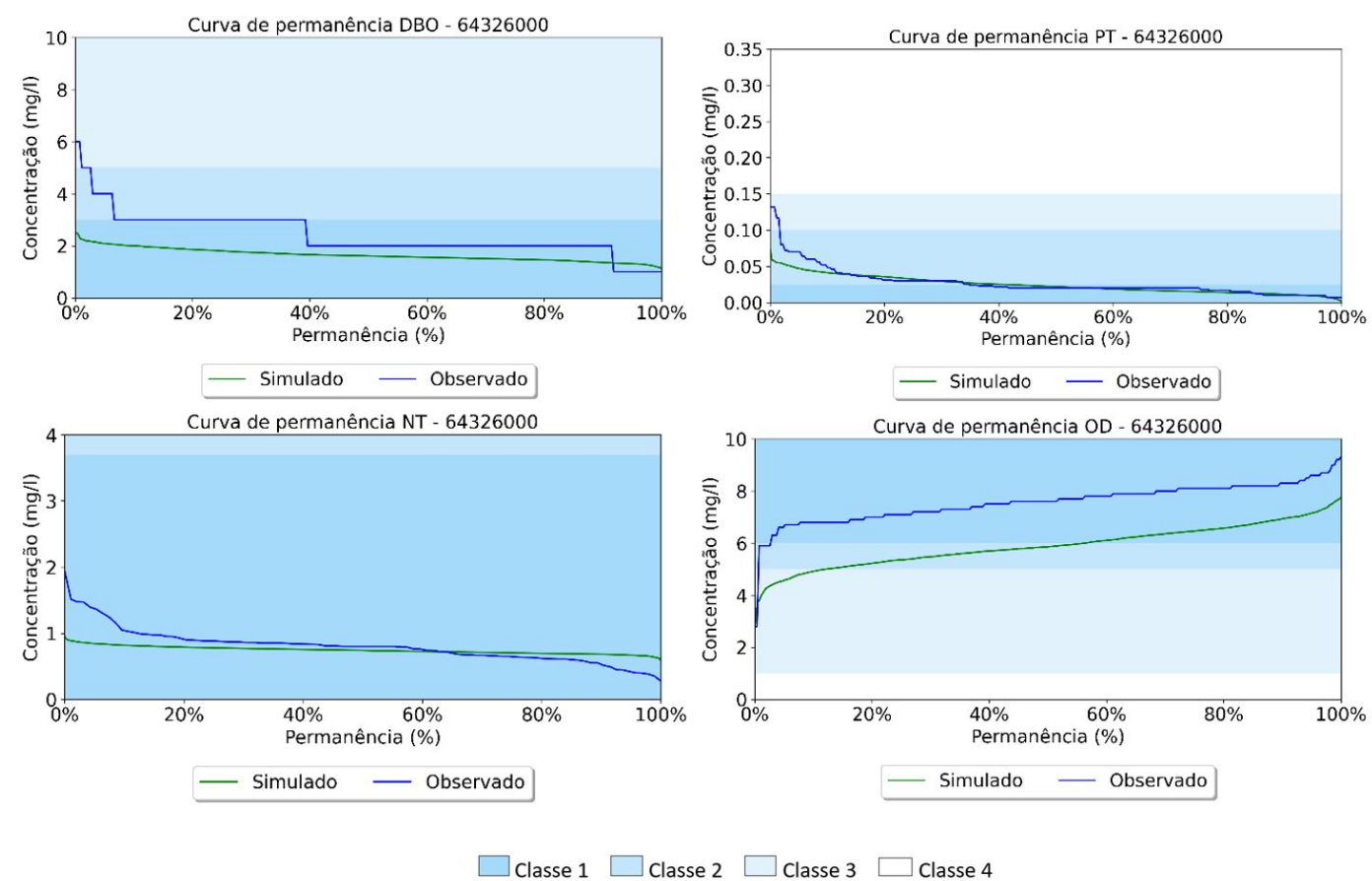

Figura 7 - Resultados das simulações de qualidade da água para a estação 64326000 e comparação com os dados observados.
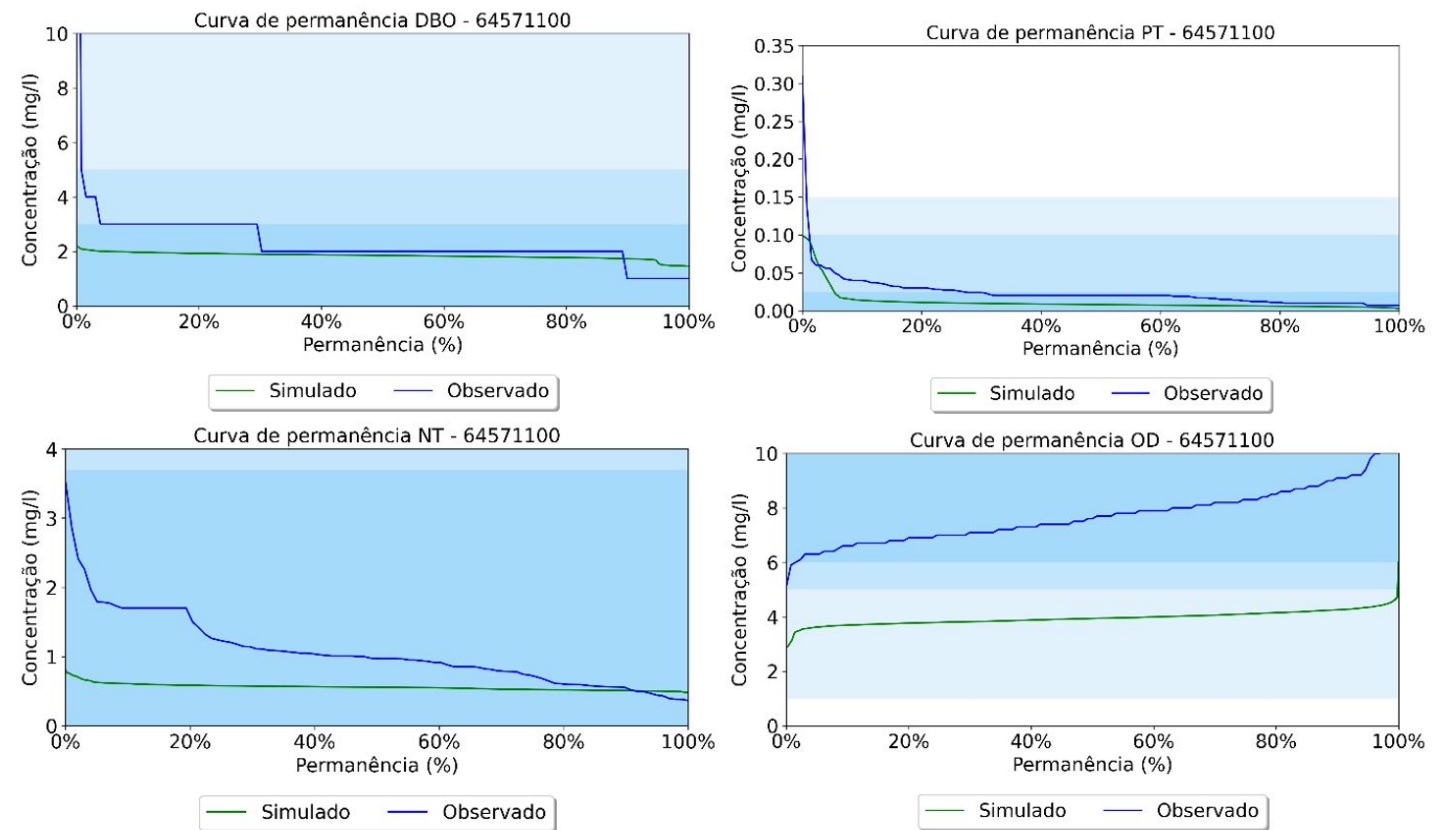

$\square$ Classe $1 \square$ Classe $2 \square$ Classe 3 $\square$ Classe 4

Figura 8 - Resultados das simulações de qualidade da água para a estação 64571100 e comparação com os dados observados. 

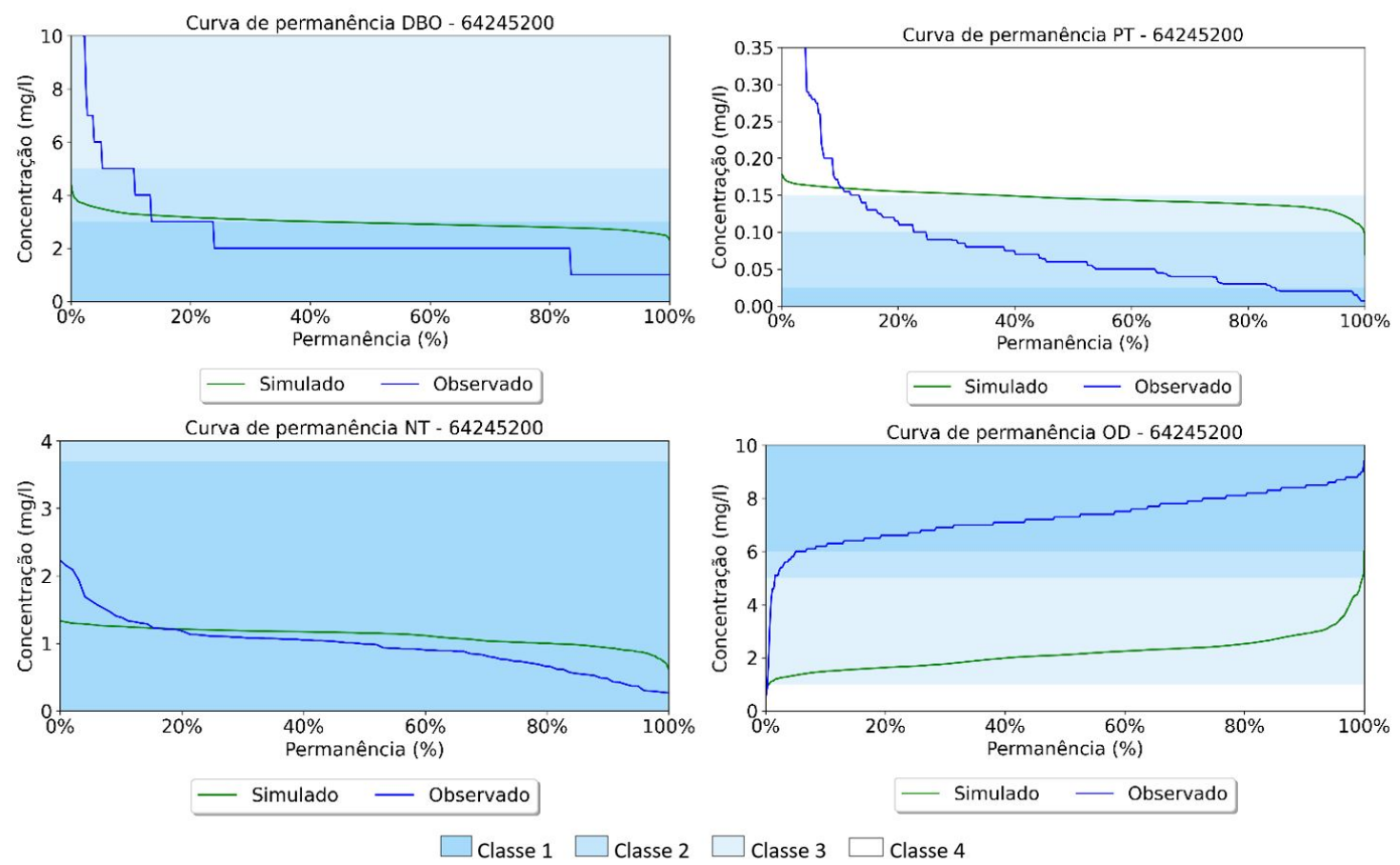

Figura 9 - Resultados das simulações de qualidade da água para a estação 64245200 (Rio Itararé e comparação com os dados observados.

O parâmetro DBO teve resultados mais próximos dos observados, com concentrações dentro dos limites de classe 2 para a estação 64245000 e de classe 1 para as estações 64326000 e 64571100. Nota-se que os valores de permanência nos extremos das curvas de permanência das concentrações observadas, menores que $5 \%$ e maiores à $95 \%$, tendem a ser mais distante dos observados, comportamento atribuído a natureza dos valores das séries históricas, que podem não representar a variação esperada no período de análise. Ressalta-se que a comparação com as concentrações observadas também é limitada pela frequência de dados disponível, normalmente medidos com intervalo de meses, e por limitações nos próprios processos usados em laboratório para avaliar as concentrações.

Uma das questões mais significativas na análise apresentada está associada aos processos analíticos utilizados e formalmente registrados nos bancos de dados oficiais. Claramente os valores apontam para medições dentro do limite de detecção, explicando a repetição dos valores de concentração igual a 2 e $3 \mathrm{mg} / \mathrm{L}$ para DBO, por exemplo. No que concerne a utilização do modelo HECRAS para as simulações de qualidade da água nas condições de regime não permanente, fica evidente o desafio de uma adequada calibração, de forma a melhor representar os processos físicos, químicos e biológicos e de transporte dos poluentes (Benedini \& Tsakiris, 2013).

As simulações de NT também geraram curvas de permanência similares às observadas, com exceção da estação 64571100, que tem concentrações simuladas menores que as observadas. Esse comportamento é atribuído principalmente à sua posição, na exutória da área de estudo logo após uma sequência de reservatórios a fio d'água, representados como seções largas de rio, que tendem a reduzir as concentrações dos poluentes.

De forma análoga, as concentrações de NT na cabeceira dos rios tiveram seus valores superestimados. Esses resultados são corroborados pelo estudo apresentado por Cunha-Santino et al. (2017), que avaliaram o impacto de uma série de 23 reservatórios em cascata na bacia do Rio JuquiáGuaçu, concluindo que esses tendem a acumular poluentes e reduzir suas concentrações nos trechos a jusante de rio.

Do mesmo modo, há estudos que avaliam como a operação pode influenciar as concentrações de poluentes ao longo do sistema, como sugerido por Chen et al. (2019) em sua análise de PT ao longo do Rio Lancang (China), e por Wang et al. (2018) em seu estudo do rio Han, que focou no desenvolvimento de uma estratégia de operação para reduzir o impacto dos reservatórios. Ambos os estudos concluíram que é possível operar os reservatórios de forma a reduzir os impactos, tanto no equilíbrio ecológico quanto nas concentrações de fósforo exportadas. 
A diferença entre os resultados e os dados observados de PT são maiores que para os outros parâmetros, sugerindo que o método aplicado no HEC-RAS não seja eficiente em representar seus fenômenos de transporte e transformação (Brunner, 2016). Entretanto, os resultados foram bons para a estação 64326000, indicando que o método proposto de simulação integrada rio - reservatório pode replicar as concentrações observadas, mas limitados pela calibração baseada com coeficientes cinéticos constantes usada no modelo.

Um dos objetivos e diferenciais desse trabalho foi avaliar o comportamento de um modelo integrado rio - reservatório, com uma geometria e conjuntos de condições de contorno para dois rios extensos. Entretanto, a versão utilizada do modelo HEC-RAS não permite definir coeficientes de transformação (cinética de reações químicas) diferentes dentro da mesma simulação, implicando no uso de coeficientes de calibração únicos para toda a geometria (Brunner, 2016). É possível que essa característica limite a capacidade do modelo em representar o comportamento de qualidade da água, uma vez que esses coeficientes podem variar ao longo dos mais de $1.000 \mathrm{~km}$ de rio, limitação que outros autores contornam ao desenvolver simulações por trechos de rio. Tercini \& Méllo Júnior (2016), por exemplo, analisaram o impacto de um reservatório na qualidade da água em trechos a jusante de rio, calibrando por trecho, obtendo resultados que indicam o efeito dos reservatórios em reduzir a concentração de poluentes.

Os resultados de OD também exibiram diferença significativa entre as concentrações simuladas e observadas, comportamento que pode ser atribuído a sua complexidade de modelagem (Mannina \& Viviani, 2010). Além de estar diretamente relacionado com as reações bioquímicas que o HEC-RAS simula, é possível que o sistema seja mais sensível a alguma dessas variáveis, de forma que os dados disponíveis e o método aplicado limitem os resultados gerados (Brunner, 2016).

A modelagem hidrodinâmica e de qualidade da água utilizando o modelo HEC-RAS apresenta um potencial de aplicação para problemas de Gestão de Recursos Hídricos muito desafiador. A representação da geometria dos reservatórios e aportes laterais de carga, além da correta representação dos processos de transporte e reações dos poluentes usando coeficientes cinéticos constantes, não limitaram a sua utilização, mas indicam a necessidade de aprimoramento dessas condições de contorno.

Considerando essa limitação e a metodologia aplicada que propõe avaliar o impacto de uma representação com geometria que integre trechos de rios e reservatórios, os resultados foram condizentes com o comportamento físico esperado. As simulações foram capazes de replicar a conformidade com os limites de classe dos rios Paranapanema e Itararé mas, para uma representação mais próxima das condições de qualidade da água indicadas pelo monitoramento, seria necessário aplicar um modelo que varie os coeficientes cinéticos, ou simular trechos mais curtos.

\section{Análise para a Gestão de Recursos Hídricos}

A partir da simulação apresentada e calibrada para o ano de 2012, denominada cenário base (B12), aplicou-se os cenários de crescimento de aporte de cargas aos rios de acordo com o desenvolvimento da bacia (Universidade Federal do Paraná, 2020b), dando origem às simulações para os cenários estagnado, tendencial e acelerado para 2025 (E25, T25 e A25) e 2035 (E25, T25 e A25), apresentados na Figura 10 para a estação 64326000. Os resultados completos para todos os cenários indicados na Tabela 1 são apresentados no item 3.3 do material suplementar.

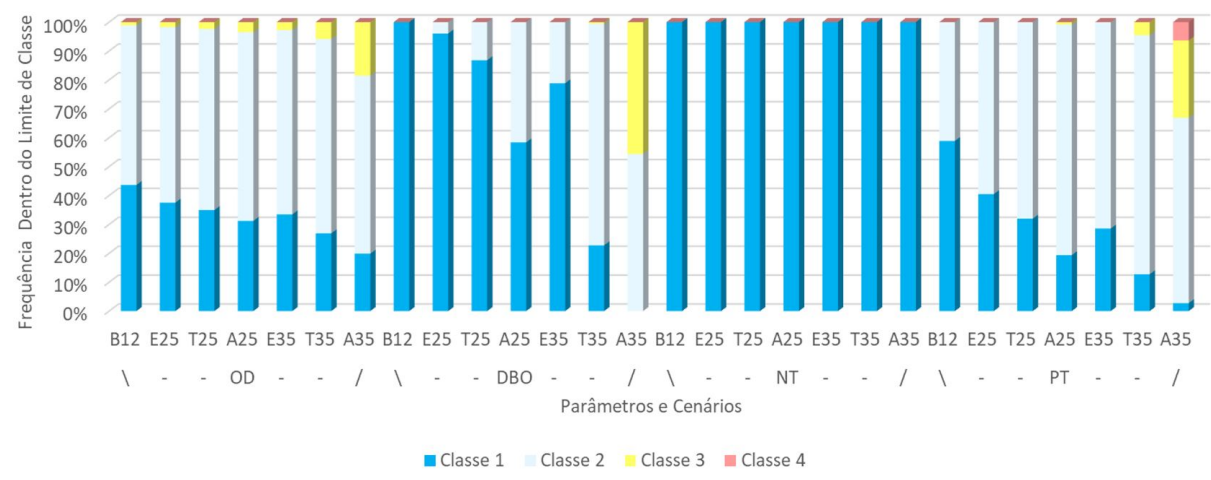

Figura 10 - Frequência em cada classe para a estação 64326000, para dados observados (OBS) e simulados para os cenários base (B12), estagnado, tendencial e acelerado para os anos de 2025 (E25, A25 e T25) e 2035 (E35, T35 e A35). 
Os resultados apresentados na Figura 10 indicam a frequência que cada parâmetro atinge os limites de classe nos cenários propostos, para a estação 64326000. Essa visualização permite avaliar o impacto do aumento das concentrações de entrada de poluentes nos cenários futuros na conformidade com a classe proposta para o rio (1, 2, 3 ou 4), resultado apresentado no formato de curvas de permanência na Figura 11.
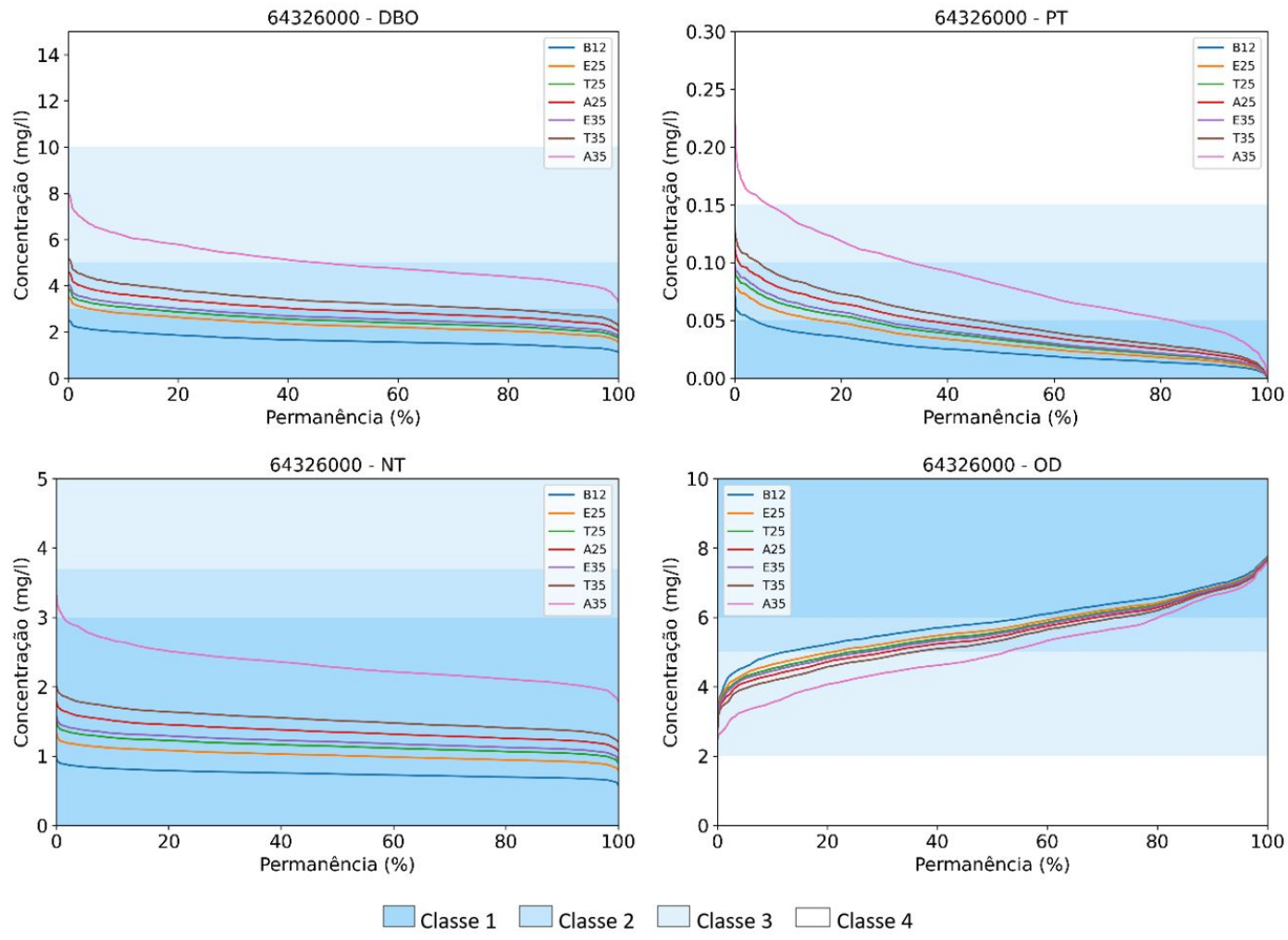

Figura 11 - Curvas de permanência de DBO, PT, NT e OD da estação 64326000, para os resultados dos cenários base (B12), estagnado, tendencial e acelerado para os anos de 2025 (E25, A25 e T25) e 2035 (E35, T35 e A35).

Os resultados apresentados nas Figuras 10 e 11 permitem entender o impacto do aumento de aporte de cargas na conformidade ao enquadramento do Rio Paranapanema. Para o trecho avaliado, nesse caso a região logo após a junção dos rios Paranapanema e Itararé, o aumento nas concentrações de entrada dos poluentes reduziria a frequência com que esse atingiria os limites de classe 1, mas se mantendo dentro dos limites da classe 2 para DBO, NT e PT para mais de 95\% do tempo para todos os cenários, menos A35, que sugere frequência de 46\% do tempo em classe 3 para DBO.

Adicionalmente, esta análise pode ser utilizada para auxiliar o Comitê de Bacia, indicando quais parâmetros são mais críticos e sensíveis, assim como a forma com que o desenvolvimento da bacia pode alterar em cenários futuros a conformidade com a classe estabelecida para o rio, permitindo quantificar as reduções de carga necessárias para atender as concentrações limite das classes no futuro. Tomando como exemplo o parâmetro DBO e a estação 64326000, pode-se notar pela Figura 10 que o ponto teve concentrações dentro dos limites de classe 1 para quase $100 \%$ do tempo; mas que caso o cenário avançado se concretize, essa frequência de permanência dentro do limite de classe 1 cai para $55 \%$ no ano de 2025 , e $0 \%$ no ano de 2035 , se mantendo durante cerca de $50 \%$ do tempo dentro do limite de classe 2 . Com essas informações, o comitê pode avaliar se esses $50 \%$ do tempo no ano de 2035, com concentrações de DBO acima do limite de classe 2, é uma condição satisfatória para atender os seus usos mais exigentes.

Tomando como base o trecho da estação 64326000, OD se mostrou menos sensível que os demais parâmetros, com menos diferença entre as curvas, sendo que as variações de DBO, NT e PT nos cenários analisados indicam qual variável deveria receber mais atenção para que o rio se mantivesse em conformidade com a classe proposta. As concentrações dos três poluentes indicam permanência em classe 1 para o cenário base, sendo que NT também se mantém dentro dos limites propostos pela classe 1 para os demais cenários, portanto não sendo a variável mais crítica. Por outro lado, as curvas 
de permanência de PT e DBO assinalam possibilidade de não cumprimento das concentrações limite para classe 3 durante mais de $20 \%$ do tempo, caso o cenário A35 se concretize, indicando que o controle desses poluentes requer mais atenção.

\section{CONSIDERAÇÕES FINAIS}

A gestão integrada de recursos hídricos e a implementação dos instrumentos previstos em lei, requerem uma base técnica que permita integrar os efeitos de emissão de poluentes e os mecanismos de transporte em rios e reservatórios. Este trabalho compila estas questões com foco no enquadramento de corpos de água e a integração rio-reservatório, para melhor representação dos comportamentos hidrodinâmico e de qualidade da água em dois rios, Paranapanema e Itararé, totalizando mais de mil quilômetros de comprimento, em uma bacia de $100.800 \mathrm{~km}^{2}$. A consideração dos efeitos hidrodinâmicos permitiu estabelecer um modelo integrado como ferramenta de subsídio ao enquadramento, complementando o trabalho de Ferreira et al. (2016). Os resultados avaliam a variação na concentração de poluentes no rio ao longo do tempo, comparando os resultados com as curvas de permanência históricas dos pontos observados. Essa avaliação foi ampliada para cenários futuros de aumento de cargas, quantificando os efeitos de alterações socioeconômicas e de uso do solo futuras e seus impactos na qualidade da água nos rios.

Esses resultados viabilizam indicar a frequência com que os pontos avaliados atingem as concentrações limite para atender seus usos mais exigentes. Em termos práticos, a aplicação deste método permite definir as metas progressivas para atendimento aos cenários estabelecidos dentro do horizonte de planejamento de um plano de bacia. Nesse caso manter os rios Paranapanema e Itararé em classes compatíveis com seus usos mais exigentes, e associar esse objetivo com os resultados obtidos nos cenários futuros da modelagem em regime não-permanente. Esses dados possibilitam ao gestor planejar estratégias de controle nas emissões de poluentes na bacia, baseando-se em dados quantitativos vindos de uma abordagem de modelagem mais representativa que a tradicional baseada em vazões de referência.

Esse resultados corroboram estudos anteriores, como o proposto por Ferreira et al. (2019), que aplicam de permanência como ferramenta adicional para gestão, tendo como diferencial a simulação integrada rio-reservatório de um sistema com reservatórios em cascata, baseando-se na ferramenta HEC-RAS (Brunner, 2016; U.S. Army Corps of Engineers, 2016).

\section{REFERÊNCIAS BIBLIOGRÁFICAS}

Agência Nacional de Águas - ANA. (2020). Hidroweb. Recuperado em 1 de julho de 2021, de http://www.snirh.gov.br/hidroweb/serieshistoricas

Benedini, M., \& Tsakiris, G. (2013). Water quality modelling for rivers and streams (Vol. 70). Switzerland: Springer.

Bitencourt, C., Fernandes, C., \& Gallego, C. (2019). Panorama do enquadramento no Brasil: uma reflexão crítica. Revista de Gestão de Água da América Latina, 16(1), 9.

Brasil. (1997). Lei no 9.433/1997. Política Nacional de Recursos Hídricos. Diário Oficial [da] República Federativa do Brasil, Brasília.

Brasil. (2005). Resolução CONAMA no 357, de 17 de março de 2005. Diário Oficial [da] República Federativa do Brasil, Brasília.

Brunner, G. W. (2016). HEC-RAS River analysis system user's manual. Davis: U.S. Army Corps of Engineers, Hydrologic Engineering Center [s.l: s.n.].

Chapra, S. (1997). Surface water-quality modeling (1st ed., Vol. 1). McGraw-Hill Science/Engineering/Math.

Che, D., \& Mays, L. W. (2017). Application of an optimization/simulation model for real-time flood-control operation of river-reservoirs systems. Water Resources Management, 31(7), 2285-2297.

Chen, X., Xu, B., Zheng, Y., \& Zhang, C. (2019). Nexus of water, energy and ecosystems in the upper Mekong River: a system analysis of phosphorus transport through cascade reservoirs. The Science of the Total Environment, 671, 1179-1191.

Correia, R. (2018). Utilização de dados topo-batimétricos para a modelagem hidrodinâmica 1D com apoio de um sistema de informações geográficas: estudo de caso do Rio Paraguai (Dissertação de mestrado). Universidade Federal do Paraná, Curitiba. 
Cunha-Santino, M. B., Fushita, Â. T., \& Bianchini Junior, I. (2017). A modeling approach for a cascade of reservoirs in the Juquiá-Guaçu River (Atlantic Forest, Brazil). Ecological Modelling, 356, 48-58.

Ferreira, A. H. R. (2021). Integração rio-reservatório: estratégia para enquadramento dinâmico utilizando o modelo HEC-RAS (Dissertação de mestrado). Universidade Federal do Paraná, Curitiba.

Ferreira, D. M. (2019). Integrated analysis for modeling of flow and transport of contaminants in riversintegrated analysis for modeling of flow and transport of contaminants in rivers (Tese de doutorado). Universidade Federal do Paraná, Curitiba.

Ferreira, D. M., Fernandes, C. V. S., \& Kaviski, E. (2016). Curvas de permanência de qualidade da água como subsídio para o enquadramento de corpos d'água a partir de modelagem matemática em regime não permanente. Revista Brasileira de Recursos Hidricos, 21(3), 479-492.

Ferreira, D. M., Fernandes, C. V. S., Kaviski, E., \& Fontane, D. (2020). Transformation rates of pollutants in rivers for water quality modelling under unsteady state: A calibration method. Journal of Hydrology, 585, 124769.

Ferreira, D., Fernandes, C. V. S., Kaviski, E., \& Fontane, D. (2019). Water quality modelling under unsteady state analysis: strategies for planning and management. Journal of Environmental Management, 239, 150-158.

Fleischmann, A., Paiva, R., \& Collischonn, W. (2019). Can regional to continental river hydrodynamic models be locally relevant? A cross-scale comparison. Journal of Hydrology X, 3, 100027.

Goodell, C. R. (2005). Dam break modeling for tandem reservoirs: a case study using HEC-RAS and HEC-HMS. In World Water Congress 2005: Impacts of Global Climate Change - Proceedings of the 2005 World Water and Environmental Resources Congress (pp. 402)

Guo, X., Zhu, X., Yang, Z., Ma, J., Xiao, S., Ji, D., \& Liu, D. (2020). Impacts of cascade reservoirs on the longitudinal variability of fine sediment characteristics: a case study of the Lancang and Nu Rivers. Journal of Hydrology, $581,124343$.

Jeppson, R. (2010). Open channel flow: numerical methods and computer applications (1st ed.). Routledge.

Luo, Z., Shao, Q., Zuo, Q., \& Cui, Y. (2020). Impact of land use and urbanization on river water quality and ecology in a dam dominated basin. Journal of Hydrology, 584, 124655.

Mannina, G., \& Viviani, G. (2010). A hydrodynamic water quality model for propagation of pollutants in rivers. Water Science and Technology, 62(2), 288-299.

Moura, A., Severiano, J. S., Tavares, N. K. A., \& Dantas, E. W. (2013). The role of a cascade of reservoirs and seasonal variation in the phytoplankton structure in a tropical river. Brazilian Journal of Biology $=$ Revista Brasileira de Biologia, 73(2), 291-298.

Poff, N. L. R., Olden, J. D., Merritt, D. M., \& Pepin, D. M. (2007). Homogenization of regional river dynamics by dams and global biodiversity implications. Proceedings of the National Academy of Sciences of the United States of America, 104(14), 5732-5737.

Silva, A. C. C., Fantin-Cruz, I., Lima, Z. M., \& Figueiredo, D. M. (2019). Cumulative changes in water quality caused by six cascading hydroelectric dams on the jauru river, tributary of the pantanal floodplain. Revista Brasileira de Recursos Hidricos, 24, e18.

Tercini, J. R. B., \& Méllo Júnior, A. V. (2016). Modelo de simulação de OD e DBO integrando rio e reservatório aplicado ao rio Tietê. Revista Brasileira de Recursos Hidricos, 21(2), 338-346.

U.S. Army Corps of Engineers - USACE. (2016). HEC-RAS river analysis system hydraulic reference manual version 5.0. Washington.

Universidade Federal do Paraná - UFPR. (2019). Relatório consolidado de modelagem hidrodinâmica e de qualidade das águas superficiais em rios de domínio da união e seus reservatórios na UGRH Paranapanema (Nota Técnica, No. 2). Curitiba. Recuperado em 1 de julho de 2021, de https://sites.google.com/view/paranapanema-openmodels/home?authuser=1

Universidade Federal do Paraná - UFPR. (2020a). Relatório consolidado de modelagem hidrodinâmica e de qualidade das águas superficiais em rios de domínio da união e seus reservatórios na UGRH Paranapanema (Nota Técnica, No. 3). Curitiba. Recuperado em 1 de julho de 2021, de https://sites.google.com/view/paranapanema-openmodels/home?authuser=1

Universidade Federal do Paraná - UFPR. (2020b). Relatório consolidado de modelagem hidrodinâmica e de qualidade das águas superficiais em rios de domínio da união e seus reservatórios na UGRH Paranapanema (Nota Técnica, No. 4). Curitiba. Recuperado em 1 de julho de 2021, de https://sites.google.com/view/paranapanema-openmodels/home?authuser=1 
Vijay, R., Gupta, R., \& Dash, S. (2018). Modelling approach for water quality assessment of Pili River using HECRAS. Journal of Indian Water Works Association, 44(1), 24-30.

Wang, H., Lei, X., Yan, D., Wang, X., Wu, S., Yin, Z., \& Wan, W. (2018). An ecologically oriented operation strategy for a multi-reservoir system: a case study of the Middle and Lower Han River Basin, China. Engineering, $4(5), 627-634$.

Wang, Y., Zhang, W., Zhao, Y., Peng, H., \& Shi, Y. (2016). Modelling water quality and quantity with the influence of inter-basin water diversion projects and cascade reservoirs in the Middle-lower Hanjiang River. Journal of Hydrology, 541, 1348-1362.

\section{Contribuições dos autores:}

Arthur Humberto Rocha Ferreira: análise dos dados, desenvolvimento das simulações, criação dos mapas, discussões conceituais, redação do artigo.

Danieli Mara Ferreira: orientação do projeto, discussões conceituais, redação do artigo, revisão do artigo.

Cristovão Vicente Scapulatempo Fernandes: elaboração do projeto, discussões conceituais, orientação do projeto, revisão do artigo. 


\section{MATERIAL SUPLEMENTAR}

Apresenta-se nesse anexo o Material Suplementar do artigo Modelagem Hidrodinâmica e de Qualidade da Água como Ferramenta para avaliação de Enquadramento de Corpos d'água. Esse documento é segmentado de forma a apresentar as seguintes informações:

\section{Sumário}

1. Equações e coeficientes cinéticos das simulações de qualidade da água no HEC-RAS ........ 2

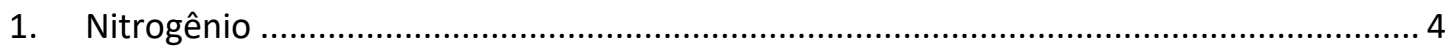

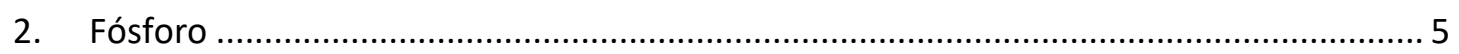

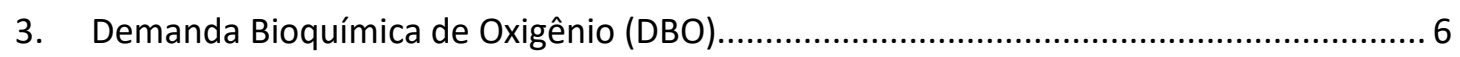

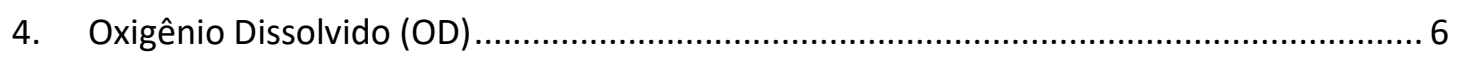

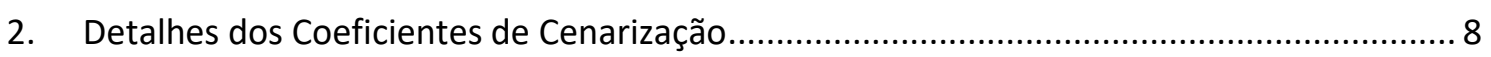

3. Resultados Completos das Modelagens Hidrodinâmicas e de Qualidade da Água .............. 11

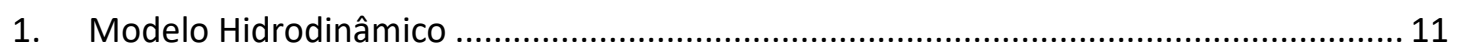

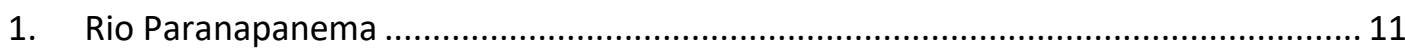

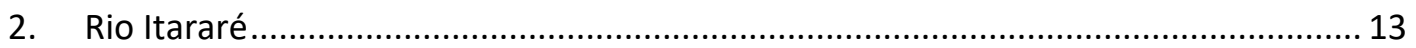

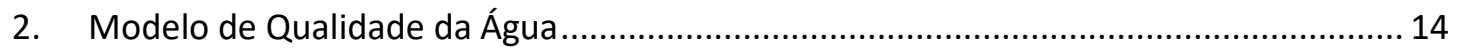

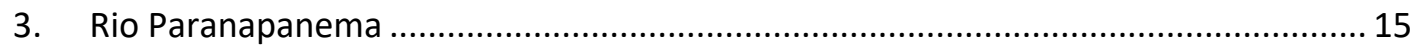

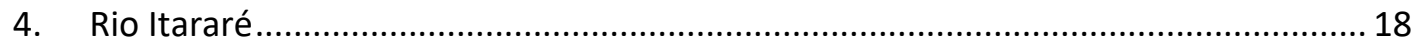

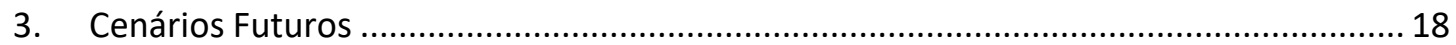

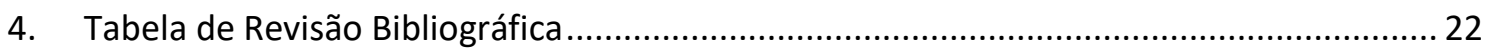




\section{Equações e coeficientes cinéticos das simulações de qualidade da água no HEC-RAS}

Entre os termos da equação ADR (equação 1), o termo "S" representa a taxa de variação na concentração da variável, causada por sedimentação e fenômenos de reação. Enquanto os demais termos a direita da equação são relativos a advecção e dispersão, ambos em função de escoamento, o termo " $\mathrm{S}$ " é função das reações químicas dos elementos, assim como taxas de entrada, saída e sedimentação. Como cada elemento se relaciona de forma única com os demais, conforme apresentado na Figura 1, tem-se uma equação para elemento, apresentadas entre as equações 2 e 8 para OD, DBO, frações de nitrogênio e fósforo.

$$
\frac{\partial}{\partial t} V \emptyset=-\frac{\partial}{\partial x}(Q \emptyset) \Delta x+\frac{\partial}{\partial x}\left(\Gamma A \frac{\partial \emptyset}{\partial x}\right) \Delta x \pm S
$$

Onde:

$\mathrm{V}=$ Volume da célula computacional $\left[\mathrm{m}^{3}\right] ; \varnothing=$ Concentração $\left[\mathrm{kg} / \mathrm{m}^{3}\right] ; \mathrm{Q}=$ Vazão $\left[\mathrm{m}^{3} / \mathrm{s}\right]$; $\Gamma=$ Coeficiente de dispersão $\left[\mathrm{m}^{2} / \mathrm{s}\right] ; A=$ Área da seção transversal $\left[\mathrm{m}^{2}\right] ; \mathrm{S}=$ Fontes e sumidouros - $[\mathrm{kg} / \mathrm{s}]$.

Figura 1- Relação entre os parâmetros de qualidade da água simulados no HEC-RAS, coeficientes cinéticos e de transporte após calibração. FONTE: O Autor (2021).

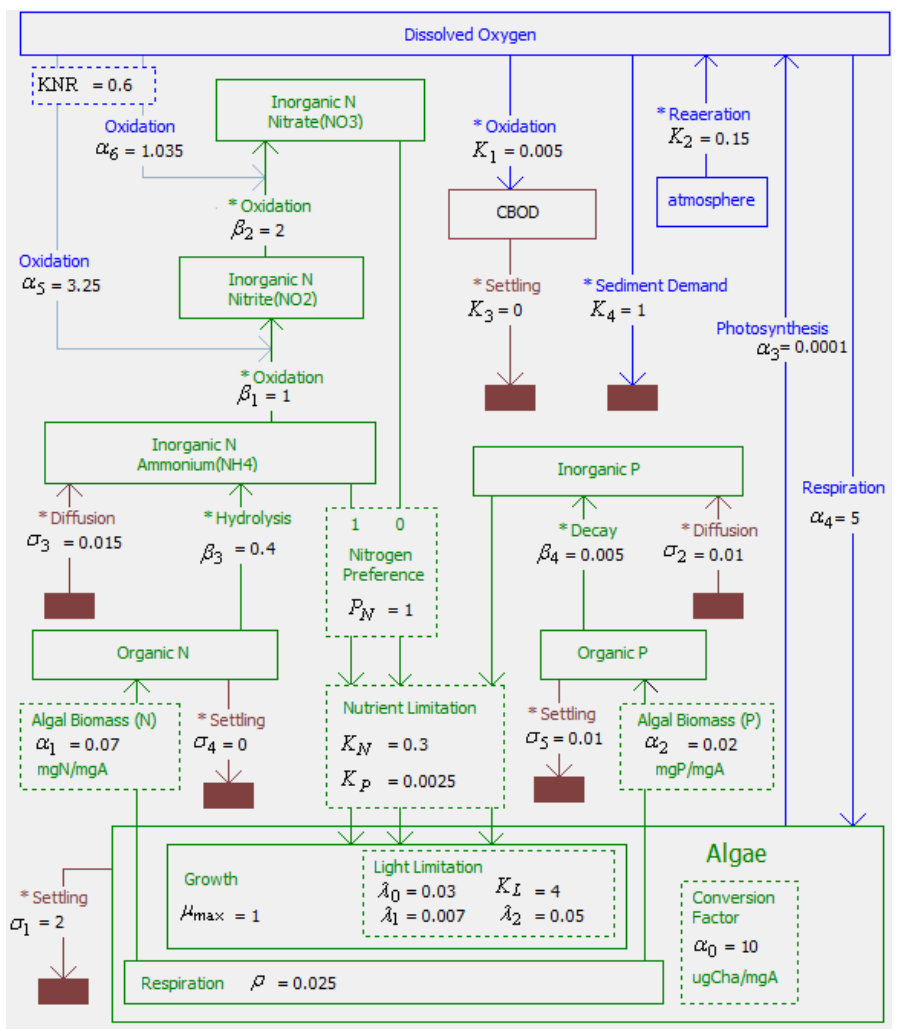


Os valores de referência indicados pelo software, baseados na literatura, e os usados nas simulações após a calibração são apresentados na Tabela 1.

Tabela 1 - Coeficientes cinéticos usados nas simulações e valores de referência sugeridos.

\begin{tabular}{|c|c|c|c|c|}
\hline SÍMBOLO & DESCRIÇÃO & UNIDADE & $\begin{array}{l}\text { SUGERIDO } \\
\text { QUAL2E }\end{array}$ & $\begin{array}{l}\text { USADO NA } \\
\text { SIMULAÇÃO }\end{array}$ \\
\hline$\rho$ & Taxa de respiração das algas & $d^{-1}$ & $0,05-0,5$ & 0,025 \\
\hline$\propto_{1}$ & $\begin{array}{c}\text { Fração da biomassa de algas } \\
\text { que é nitrogênio }\end{array}$ & - & $0,07-0,09$ & 0,07 \\
\hline$\propto_{2}$ & $\begin{array}{l}\text { Fração da biomassa de algas } \\
\text { que é fósforo }\end{array}$ & $m g P m g A^{-1}$ & $0,01-0,02$ & 0,02 \\
\hline$\propto_{3}$ & $\begin{array}{l}\text { Produção de } \mathrm{O} 2 \text { por unidade } \\
\text { de alga }\end{array}$ & $\mathrm{mgO}_{\mathrm{mgAL} \mathrm{d}}{ }^{-1}$ & $1,4-1,8$ & 0,0001 \\
\hline$\propto_{4}$ & $\begin{array}{c}\text { Consumo de } \mathrm{O} 2 \text { por unidade } \\
\text { de alga }\end{array}$ & $\mathrm{mgO} \mathrm{mgAL} \mathrm{d}^{-1}$ & $1,6-2,3$ & 5 \\
\hline$\propto_{5}$ & $\begin{array}{c}\text { Produção de } \mathrm{O} 2 \text { por unidade } \\
\text { de } \mathrm{NH}_{4} \text { oxidada }\end{array}$ & $\mathrm{mgO} \mathrm{mgN} \mathrm{d}^{-1}$ & $3-4$ & 3,25 \\
\hline$\propto_{6}$ & $\begin{array}{c}\text { Consumo de } \mathrm{O} 2 \text { por unidade } \\
\text { de } \mathrm{NO}_{2} \text { oxidada }\end{array}$ & $\mathrm{mgO} \mathrm{mgN} \mathrm{d}^{-1}$ & $1,00-1,14$ & 1,035 \\
\hline$\beta_{1}$ & $\begin{array}{c}\text { Conversão de amônia para } \\
\text { nitrito }\end{array}$ & $d^{-1}$ & $0,1-1,0$ & 1 \\
\hline $\boldsymbol{\beta}_{2}$ & $\begin{array}{l}\text { Conversão de nitrito para } \\
\text { nitrato }\end{array}$ & $d^{-1}$ & $0,2-2,0$ & 2 \\
\hline $\boldsymbol{\beta}_{3}$ & $\begin{array}{c}\text { Conversão de OrgN para } \\
\text { amônia }\end{array}$ & - & $0,02-0,4$ & 0,4 \\
\hline $\boldsymbol{\mu}$ & $\begin{array}{l}\text { Taxa de crescimento local das } \\
\text { algas }\end{array}$ & $d^{-1}$ & $1-3$ & 1 \\
\hline$\rho$ & Taxa de respiração das algas & $d^{-1}$ & $0,05-0,50$ & 0,025 \\
\hline$\sigma_{1}$ & Taxa de sedimentação - algas & $M d^{-1}$ & $0,10-2,0$ & 2 \\
\hline$\sigma_{2}$ & Fonte bentônica de ortofosfato & $\mathrm{mgP} \mathrm{m} \mathrm{m}^{-2} \mathrm{~d}^{-1}$ & $0,001-0,100$ & 0,01 \\
\hline$\sigma_{3}$ & Fonte bentônica de amônia & $m g N m^{-2} d^{-1}$ & - & 0,015 \\
\hline$\sigma_{4}$ & Sedimentação de OrgN & - & $0,001-0,100$ & 0 \\
\hline KNR & $\begin{array}{l}\text { Coeficiente de inibição de } \\
\text { nitrificação de primeira ordem }\end{array}$ & $\mathrm{mgO} \mathrm{L^{-1 }}$ & $0,6-0,7$ & 0,6 \\
\hline $\mathrm{K}_{1}$ & Taxa de desoxigenação de DBO & $d^{-1}$ & $0,02-3,40$ & 0,005 \\
\hline $\mathrm{K}_{2}$ & Taxa de reaeração diária & $d^{-1}$ & $0-100$ & 0,15 \\
\hline $\mathrm{K}_{3}$ & $\begin{array}{c}\text { Taxa de perda de DBO por } \\
\text { sedimentação }\end{array}$ & $d^{-1}$ & $-0,36-0,36$ & 0 \\
\hline $\mathrm{K}_{4}$ & $\begin{array}{l}\text { Taxa de consumo de oxigênio } \\
\text { pelo sedimento }\end{array}$ & $\mathrm{mg} O \mathrm{~m}^{2} \mathrm{~d}^{-1}$ & $>0$ & 1 \\
\hline
\end{tabular}

Apresenta-se a seguir as equações que definem as taxas de variação nas concentrações das frações de nitrogênio, fósforo, oxigênio e DBO (BRUNNER; CEIWRHEC, 2016). 


\section{Nitrogênio}

\section{Nitrogênio Orgânico Dissolvido - OrgN}

A equação 2 simula a taxa de variação de concentração de $\operatorname{OrgN}$, sendo que os termos a direita representam, respectivamente: respiração das algas, hidrolise (OrgN para NH4) e sedimentação.

$$
\operatorname{Org}_{\text {fontes/sumidouros }}=\propto_{1} \rho A L-\beta_{3} \operatorname{Org} N-\sigma_{4} \operatorname{OrgN}
$$

Onde:

OrgN = Taxa de conversão do nitrogênio orgânico $\left[\mathrm{kg} \mathrm{s}^{-1}\right]$;

$\propto_{1}=$ Fração da biomassa de algas que é nitrogênio [mgN mgA ${ }^{-1}$;

$\rho=$ Taxa de respiração das algas $-\left[\mathrm{d}^{-1}\right]$;

$\beta_{3}=$ Conversão de OrgN para amônia [ - ];

$\sigma_{4}=$ Sedimentação de OrgN [ - ];

$\mathrm{AL}=$ Concentração de algas $\left[\mathrm{kg} \mathrm{m}^{-3}\right]$;

\section{Nitrogênio Amoniacal - $\mathrm{NH}_{4}$}

A equação 3 simula a taxa de variação de concentração de $\mathrm{NH}_{4}$, sendo que os termos a direita representam, respectivamente: hidrolise (OrgN para $\mathrm{NH}_{4}$ ), difusão dos organismos bentônicos, oxidação $\left(\mathrm{NH}_{4}\right.$ para $\left.\mathrm{NO}_{2}\right)$ e consumo das algas.

$\mathrm{NH}_{\text {fontes/sumidouros }}$

$$
=\beta_{3} \operatorname{OrgN}+\frac{\sigma_{3}}{d}-\beta_{1}\left(1-\exp ^{-K N R . D O X}\right) N H 4-F_{1} \propto_{1} \mu A L
$$

Onde:

$\beta_{3}=$ Conversão de OrgN para amônia [ - ];

$\beta_{1}=$ Conversão de amônia para nitrito $\left[\mathrm{d}^{-1}\right]$;

$\sigma_{3}=$ Fonte bentônica de amônia $\left[\mathrm{mgN} \mathrm{m}^{-2} \mathrm{~d}^{-1}\right]$;

$\mathrm{d}=$ profundidade média do canal [m];

$\mu=$ taxa de crescimento local das algas $\left[\mathrm{d}^{-1}\right]$;

$\propto_{1}=$ Fração da biomassa de algas que é nitrogênio [mgN mgA ${ }^{-1}$;

KNR = Coeficiente de inibição de nitrificação de primeira ordem [mgO L-1];

DOX = Concentração de oxigênio dissolvido $\left[\mathrm{mgO} \mathrm{L}^{-1}\right]$;

F1 = Fração de absorção pelas Algas [-];

$\mathrm{AL}=$ Concentração de algas $\left[\mathrm{kg} \mathrm{m}^{-3}\right]$.

Nitrito $-\mathrm{NO}_{2}$ 
A equação 4 simula a taxa de variação de concentração de $\mathrm{NO}_{2}$, sendo que os termos a direita representam a oxidação dos poluentes ( $\mathrm{NH}_{4}$ para $\mathrm{NO}_{2}$ e $\mathrm{NO}_{2}$ para $\mathrm{NO}_{3}$ ).

$$
\begin{aligned}
& \text { NO2 } 2_{\text {fontes/sumidouros }} \\
& \qquad \beta_{1}\left(1-\exp ^{-K N R . D O X}\right) N H 4-\beta_{2}(1-\exp -\text { KNR.DOX })
\end{aligned}
$$

Onde:

$\beta_{1}=$ Conversão de amônia para nitrito $\left[\mathrm{d}^{-1}\right]$;

$\beta_{2}=$ Conversão de nitrito para nitrato $\left[\mathrm{d}^{-1}\right]$;

KNR = Coeficiente de inibição de nitrificação de primeira ordem [mgOL-1];

$\mathrm{DOX}=$ Concentração de oxigênio dissolvido [mgO L-1].

\section{Nitrato $-\mathrm{NO}_{3}$}

A equação 5 simula a taxa de variação de concentração de $\mathrm{NO}_{3}$, sendo que os termos a direita representam, respectivamente, oxidação $\left(\mathrm{NO}_{2}\right.$ para $\left.\mathrm{NO}_{3}\right)$ e consumo das algas.

$$
\begin{aligned}
& \text { NO3 }_{\text {fontes/sumidouros }} \\
& \qquad \beta_{2}\left(1-\exp ^{-K N R . D O X}\right) N H 2-\left(1-F_{1}\right) \propto_{1} \mu A L
\end{aligned}
$$

Onde:

$\beta_{2}=$ Conversão de nitrito para nitrato $\left[\mathrm{d}^{-1}\right]$;

KNR = Coeficiente de inibição de nitrificação de primeira ordem [mgOL-1 ${ }^{-1}$;

DOX = Concentração de oxigênio dissolvido [mgO L-1];

F1 = Fração de absorção pelas Algas [-];

$\propto_{1}=$ Fração da biomassa de algas que é nitrogênio [mgN mgA-1];

$\mu=$ taxa de crescimento local das algas $\left[\mathrm{d}^{-1}\right]$;

$\mathrm{AL}=$ Concentração de algas $\left[\mathrm{kg} \mathrm{m}^{-3}\right]$.

\section{Nitrogênio Total - NT}

O nitrogênio total é a soma das frações apresentadas $\left(\mathrm{OrgN}, \mathrm{NH}_{4}, \mathrm{NO}_{2}, \mathrm{NO}_{3}\right)$ e é a forma base para análise dos dados, incluindo obtenção e análise dos resultados das simulações.

\section{Fósforo}

A simulação de fósforo no HEC-RAS utilizada as frações fósforo orgânico dissolvido (OrgP) e ortofosfato inorgânico dissolvido (PO4), ambas formas dissolvidas do material, sendo que sua principal forma de entrada de fósforo em rios é a particulada. Considera-se que as frações de ortofosfato inorgânico $\left(\mathrm{PO}_{4}\right)$ são representativas da concentração de fósforo total, parâmetro cujas taxas de variações de concentrações o 
HEC-RAS simula segundo a equação 6 (FERNANDES et al., 2020;KNAPIK, 2014;KOZAK, 2016). Os termos a direita da equação representam, respectivamente: decaimento (OrgP para PO4), difusão dos organismos bentônicos e consumo das algas.

$$
P O 4_{\text {fontes/sumidouros }}=\beta_{4} \operatorname{OrgP}+\frac{\sigma_{2}}{d}-\propto_{2} \mu A L
$$

Onde:

$\sigma_{2}=$ Fonte bentônica de ortofosfato $\left[\mathrm{mgP} \mathrm{m}^{-2} \mathrm{~d}^{-1}\right]$;

$\propto_{2}=$ Fração da biomassa de algas que é fósforo [mgP mgA ${ }^{-1}$;

$\mathrm{d}=$ profundidade média do canal [m];

$\mu=$ taxa de crescimento local das algas $\left[\mathrm{d}^{-1}\right]$;

$\mathrm{AL}=$ Concentração de algas $\left[\mathrm{kg} \mathrm{m}^{-3}\right]$.

\section{Demanda Bioquímica de Oxigênio (DBO)}

A simulação de DBO é descrita no HEC-RAS por um decaimento de primeira ordem (equação 7).

$$
D B O_{\text {fontes } / \text { sumidouros }}=K_{1} D B O-K_{3} D B O
$$

Onde:

$\mathrm{DBO}=$ Concentração de $\mathrm{DBO}\left[\mathrm{mgDBO} \mathrm{L}^{-1}\right]$;

$\mathrm{K}_{1}$ = taxa de desoxigenação de $\mathrm{DBO}\left[\mathrm{d}^{-1}\right]$;

$K_{3}=$ Taxa de perda de DBO por sedimentação $\left[d^{-1}\right]$.

\section{Oxigênio Dissolvido (OD)}

A taxa de variação de concentração de OD é simulada pelo HEC-RAS usando a equação 7 , sendo que os termos da direita representam, respectivamente: reaeração, fotossíntese e respiração, demanda de oxigênio de DBO, demanda de oxigênio do sedimento, oxidação da amônia e oxidação do nitrito. 
$O D_{\text {fontes/sumidouros }}$

$$
\begin{aligned}
& =K_{2}\left(O_{s a t}-O D\right)+A L\left(\propto_{3} \mu-\propto_{4} \rho\right)-K_{1} . D B 0-\frac{K_{4}}{d} \\
& -\propto_{5} \beta_{1} N H 4-\propto_{6} \beta_{2} N O 2
\end{aligned}
$$

Onde:

$\mathrm{O}_{\text {sat }}=$ Concentração de saturação do oxigênio dissolvido $-\left[\mathrm{mgOLd}^{-1}\right]$;

$\propto_{3}=$ Produção de $\mathrm{O}_{2}$ por unidade de alga - [mgO mgAL d ${ }^{-1}$;

$\propto_{4}=$ Consumo de $\mathrm{O}_{2}$ por unidade de alga - [mgO mgAL d ${ }^{-1}$;

$\propto_{5}=$ Produção de $\mathrm{O}_{2}$ por unidade de $\mathrm{NH}_{4}$ oxidada - [mgO mgN d ${ }^{-1}$;

$\propto_{6}=$ Consumo de $\mathrm{O}_{2}$ por unidade de $\mathrm{NO}_{2}$ oxidada - [mgO mgN d${ }^{-1}$;

$\mathrm{DBO}=$ Concentração de DBO $\left[\mathrm{mgDBO} \mathrm{L}^{-1}\right]$;

$\mathrm{K}_{1}=$ taxa de desoxigenação de DBO $\left[\mathrm{d}^{-1}\right]$;

$\mathrm{K}_{2}=$ Taxa de reaeração diária $\left[\mathrm{d}^{-1}\right]$;

$\mathrm{K}_{4}=$ Taxa de consumo de oxigênio pelo sedimento [mg O $\mathrm{m}^{2} \mathrm{~d}^{-1}$;

$\beta_{1}=$ Taxa de oxidação da amônia [ $\left.\mathrm{d}^{-1}\right]$;

$\beta_{2}=$ Conversão de amônia para nitrito $\left[\mathrm{d}^{-1}\right]$;

$\mathrm{d}=$ Profundidade média do canal $[\mathrm{m}]$. 


\section{Detalhes dos Coeficientes de Cenarização}

A função dos coeficientes de cenarização é simular o aumento no aporte de poluentes, tanto na forma de cargas pontuais quanto difusas, conforme cenários futuros que representam o crescimento econômico da bacia, apresentados na Tabela 2. Esses coeficientes foram estimados para cada uma das Unidade de Gestão (UGHs) da bacia, conforme descrito por (FERNANDES et al., 2020)

Tabela 2 - Coeficientes de aumento no aporte de cargas de acordo com cenários de crescimento econômico para os anos de 2025 e 2035

\begin{tabular}{|c|c|c|c|c|c|c|}
\hline \multirow{2}{*}{ UGRH/UPH } & \multicolumn{2}{|c|}{ Cenário Tendencial } & \multicolumn{2}{l|}{ Cenário Acelerado } & \multicolumn{2}{l|}{ Cenário Estagnado } \\
\cline { 2 - 7 } & 2025 & 2035 & 2025 & 2035 & 2025 & 2035 \\
\hline Alto Paranapanema & 1,53 & 1,99 & 1,77 & 2,75 & 1,37 & 1,62 \\
\hline Médio Paranapanema & 1,63 & 2,27 & 1,97 & 3,63 & 1,43 & 1,74 \\
\hline Pontal do Paranapanema & 1,57 & 2,17 & 1,90 & 3,53 & 1,37 & 1,63 \\
\hline Norte Pioneiro & 1,55 & 2,18 & 1,93 & 3,83 & 1,35 & 1,61 \\
\hline Tibagi & 1,34 & 1,83 & 1,63 & 3,17 & 1,21 & 1,40 \\
\hline Piraponema & 1,47 & 1,94 & 1,74 & 3,09 & 1,33 & 1,54 \\
\hline
\end{tabular}

A conversão do aumento de carga dos cenários para as concentrações que efetivamente são inseridas como condição de contorno no HEC-RAS foi feita convertendo os trechos de rio para os quais as cargas foram geradas para trechos coincidentes com aqueles usados como condição de contorno nas simulações hidrodinâmicas (contribuição lateral) conforme ilustrado na Figura 2. 
Figura 2 - Relação dos pontos base usados na estimativa de carga e pontos base para estimativa da contribuição Lateral, onde: $1-64005000 ; 2-64080000 ; 3=64215080 ; 4=64220050$; $5=64270080 ; 6=64278080 ; 7=64332080 ; 8=64345075 ; 9=64345080 ; 10=64516080 ; 11=$ 64231000; 12 =64247000. Fonte: $\mathrm{O}$ Autor (2021), Fernandes et al. (2020).

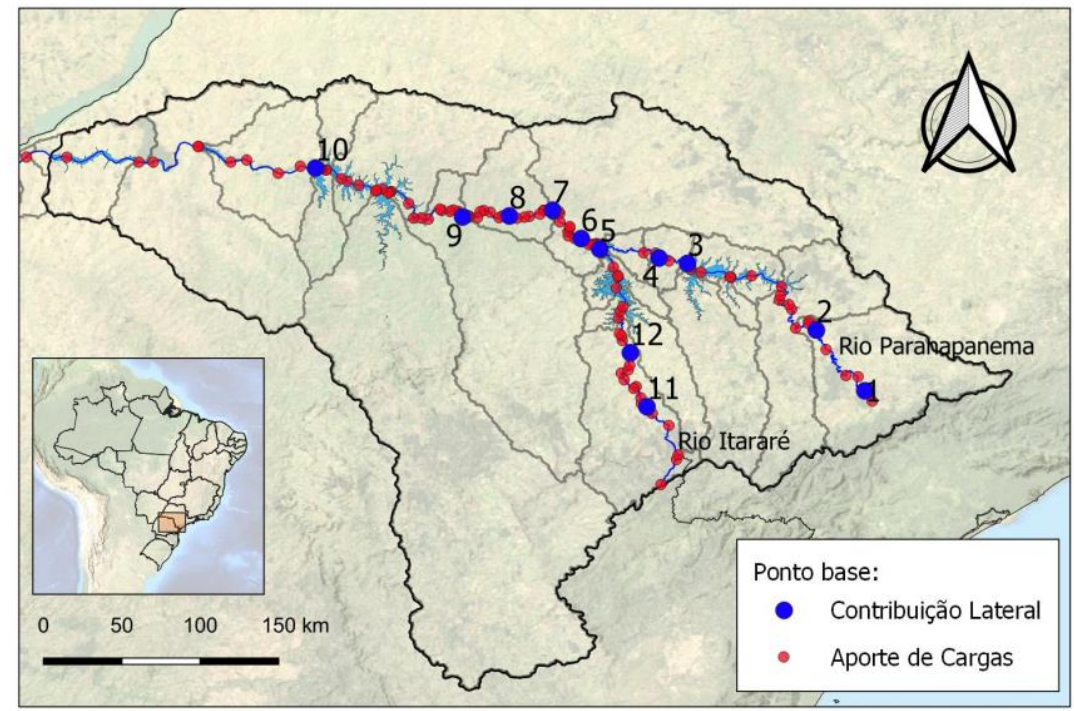

Essa abordagem possibilitou gerar o aporte de cargas no rio, de acordo com as UGHs e cenários apresentados na Tabela 2. O aporte total das cargas poluentes por trecho para o cenário base (2012) é apresentado na Tabela 3.

Tabela 3 - Aporte de cargas de DBO, PT e NT por trecho.

Trecho Carga DBO ( $\mathrm{kg} / \mathrm{dia}) \quad$ Carga PT $(\mathrm{kg} / \mathrm{dia}) \quad$ Carga NT $(\mathrm{kg} / \mathrm{dia})$

\begin{tabular}{c|ccc}
\hline-1 & $1.120,16$ & 35,84 & 508,14 \\
$1-2$ & $16.384,21$ & 851,52 & $5.841,00$ \\
$2-3$ & $31.185,87$ & $1.827,21$ & $12.084,12$ \\
$3-4$ & $1.833,74$ & 72,69 & 727,35 \\
$4-5$ & $23.561,06$ & $1.348,42$ & $9.616,71$ \\
$5-6$ & 835,73 & 28,52 & 339,94 \\
$6-7$ & $23.311,04$ & 871,04 & $10.032,52$ \\
$7-8$ & $4.902,74$ & 447,31 & $1.589,11$ \\
$8-9$ & $32.573,84$ & $1.763,59$ & $12.215,31$ \\
$9-10$ & $116.919,05$ & $7.918,17$ & $44.523,62$ \\
$10-$ & $55.244,67$ & $2.025,76$ & $18.414,51$
\end{tabular}

As cargas de poluentes foram diluídas na mediana da série de vazões referente a contribuição lateral no trecho, resultado portanto em uma concentração constante de entrada de DBO, NT e PT para cada trecho. Os valores da Q50 e concentrações de entrada do cenário base (2012) de cada trecho são apresentadas na Tabela 4. 
Tabela 4- Concentrações de entrada de DBO, NT e PT

\begin{tabular}{|c|c|c|c|c|c|c|c|c|c|c|}
\hline & $1-2$ & $2-3$ & $3-4$ & $4-5$ & $5-6$ & $6-7$ & $7-8$ & $8-9$ & $9-10$ & $10-$ \\
\hline $\begin{array}{l}\text { Concentração } \\
\text { de DBO (mg/L) }\end{array}$ & 4,30 & 1,69 & 2,15 & 2,72 & 1,21 & 2,49 & 4,05 & 8,57 & 2,10 & 1,32 \\
\hline $\begin{array}{l}\text { Concentração } \\
\text { de NT (mg/L) }\end{array}$ & 1,53 & 0,65 & 0,85 & 1,11 & 0,49 & 1,07 & 1,31 & 3,21 & 0,80 & 0,44 \\
\hline $\begin{array}{l}\text { Concentração } \\
\text { de PT (mg/L) }\end{array}$ & 0,22 & 0,10 & 0,09 & 0,16 & 0,04 & 0,09 & 0,37 & 0,46 & 0,14 & 0,05 \\
\hline $\mathrm{Q} 50\left(\mathrm{~m}^{3} / \mathrm{s}\right)$ & 44,06 & 213,56 & 9,88 & 100,31 & 8,00 & 108,50 & 14,00 & 44,00 & 644,00 & 482,70 \\
\hline
\end{tabular}




\section{Resultados Completos das Modelagens Hidrodinâmicas e de Qualidade da Água}

Apresenta-se os resultados dos modelos hidrodinâmico e de qualidade da água, visando melhor contextualizar a capacidade do modelo em replicar as séries de vazões e concentrações de poluentes.

\section{Modelo Hidrodinâmico}

Os resultados do modelo hidrodinâmico são apresentados na forma de curva de permanência para todas as estações com séries de vazões disponíveis para o ano de 2012, apresentadas na Figura 2, menos as estações de montante pois seus hidrogramas foram usados como condição de contorno.

1. Rio Paranapanema

Figura 3 - Comparação dos resultados do modelo hidrodinâmico com a série de vazões observadas na 64080000.

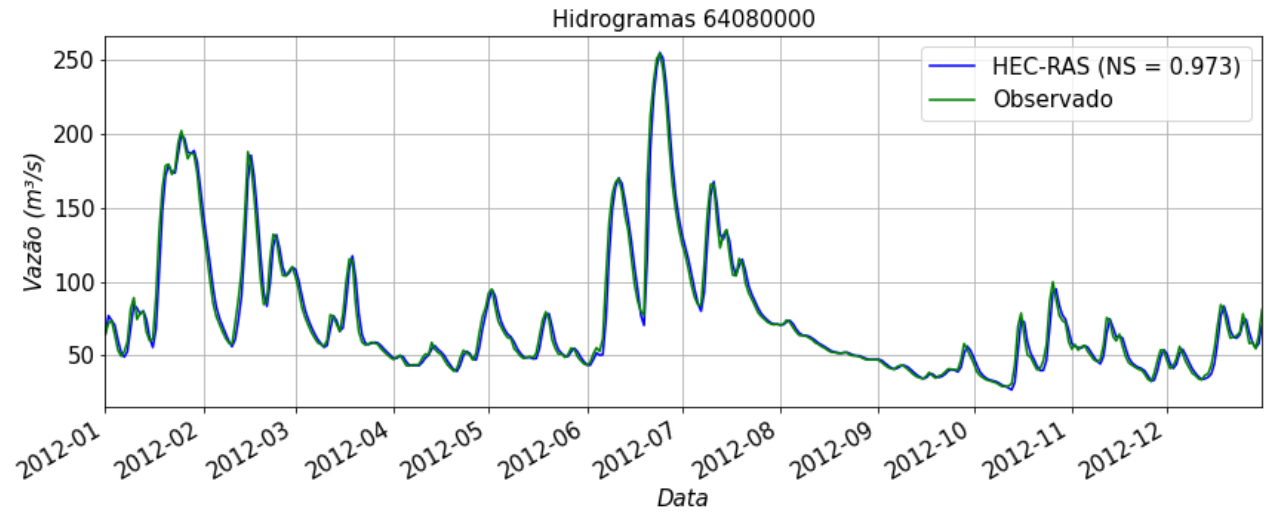

Figura 4 - Comparação dos resultados do modelo hidrodinâmico com a série de vazões observadas na 64215080.

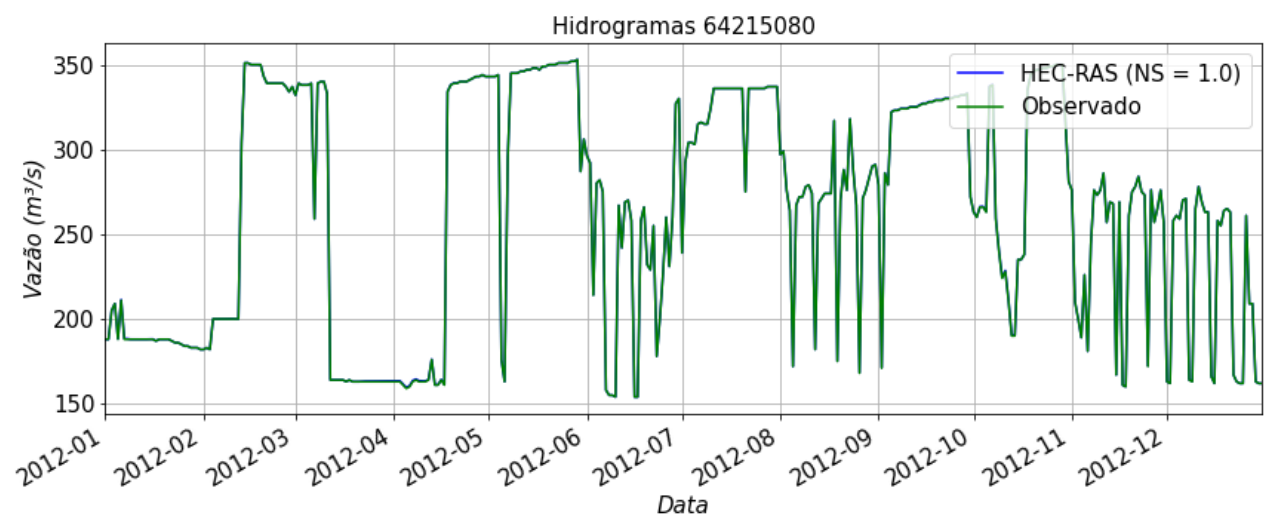


Figura 5 - Comparação dos resultados do modelo hidrodinâmico com a série de vazões observadas na 64220050.

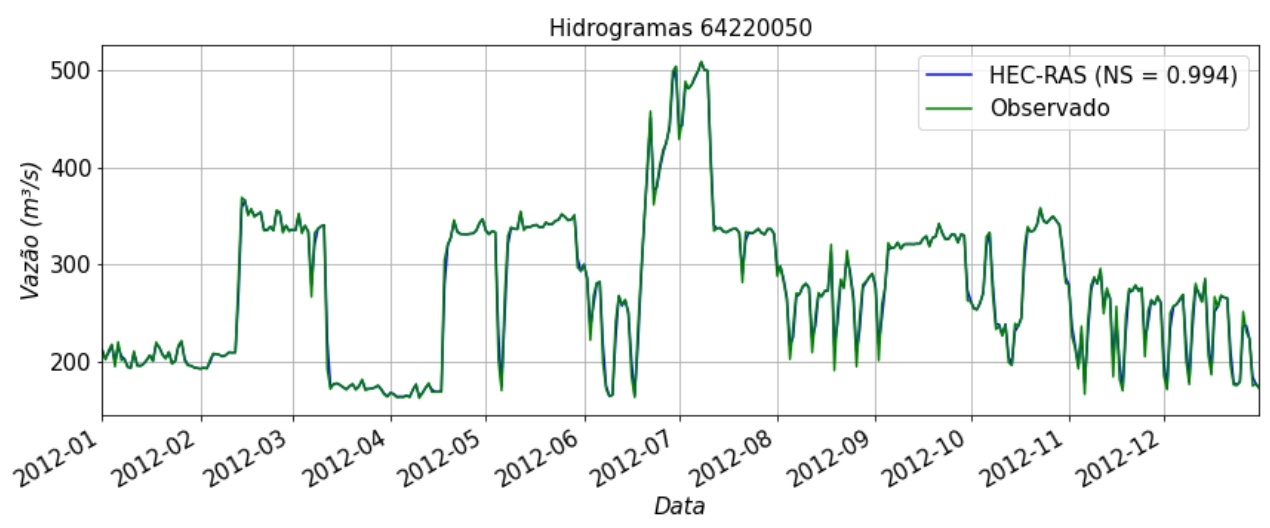

Figura 6 - Comparação dos resultados do modelo hidrodinâmico com a série de vazões observadas na 64278080.

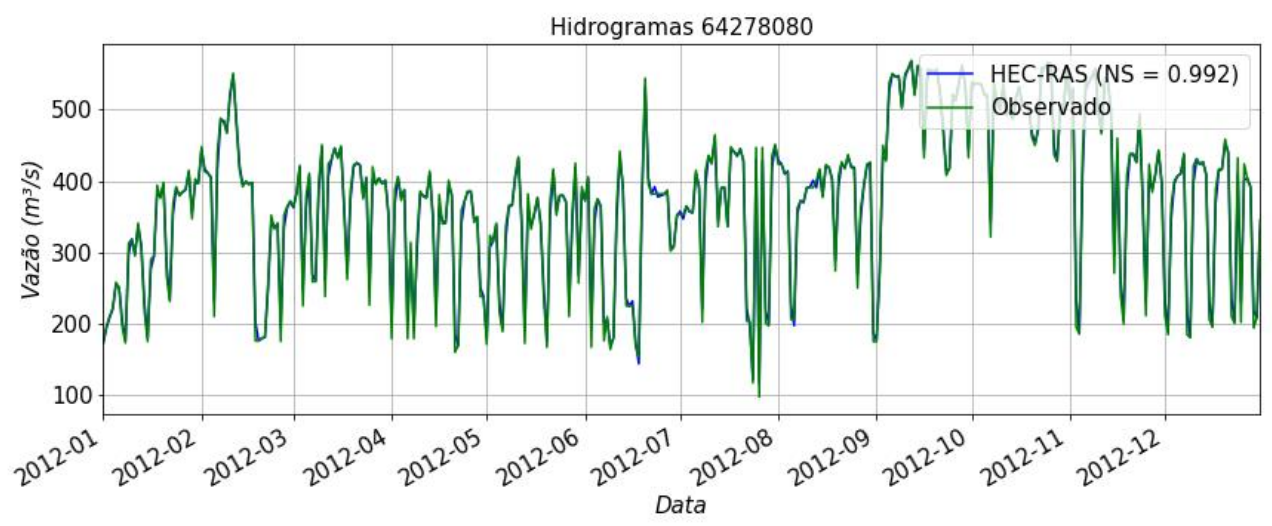

Figura 7 - Comparação dos resultados do modelo hidrodinâmico com a série de vazões observadas na 64332080.

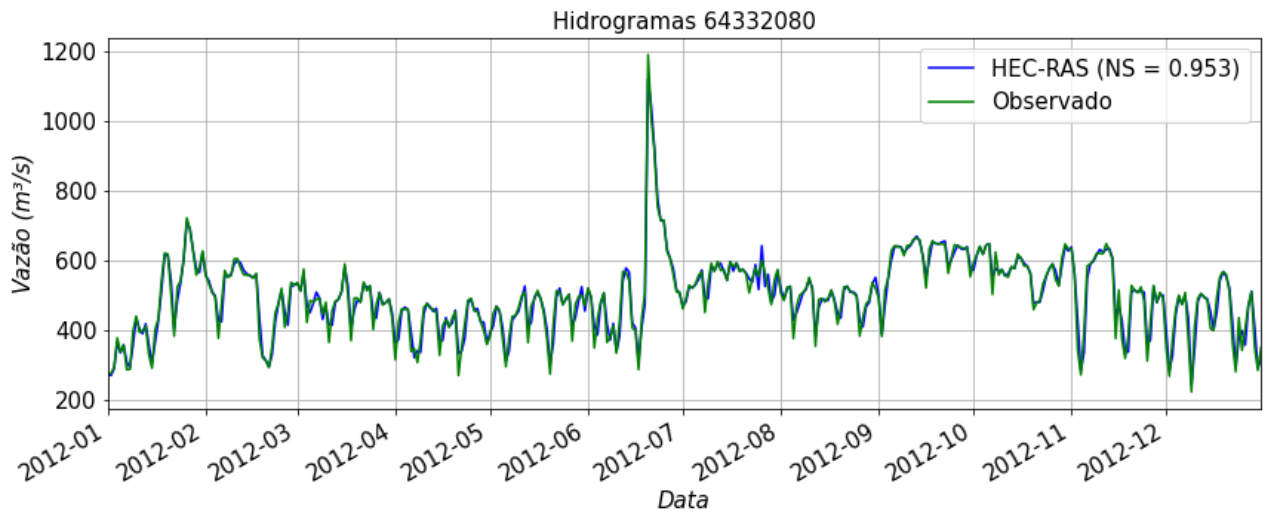

12 
Figura 8 - Comparação dos resultados do modelo hidrodinâmico com a série de vazões observadas na 64345075.

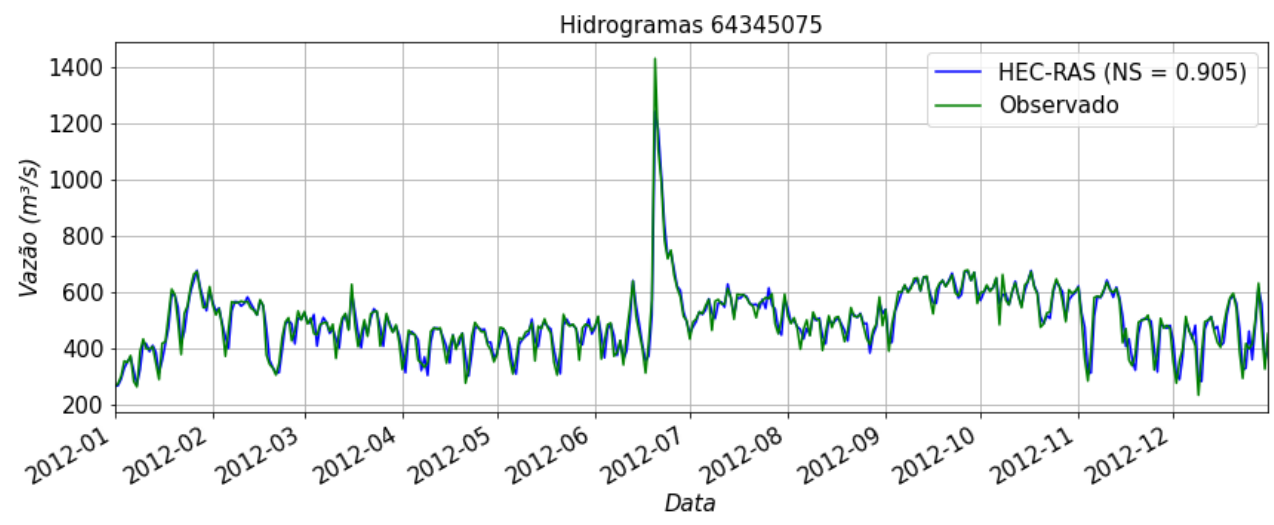

Figura 9 - Comparação dos resultados do modelo hidrodinâmico com a série de vazões observadas na 64345080.

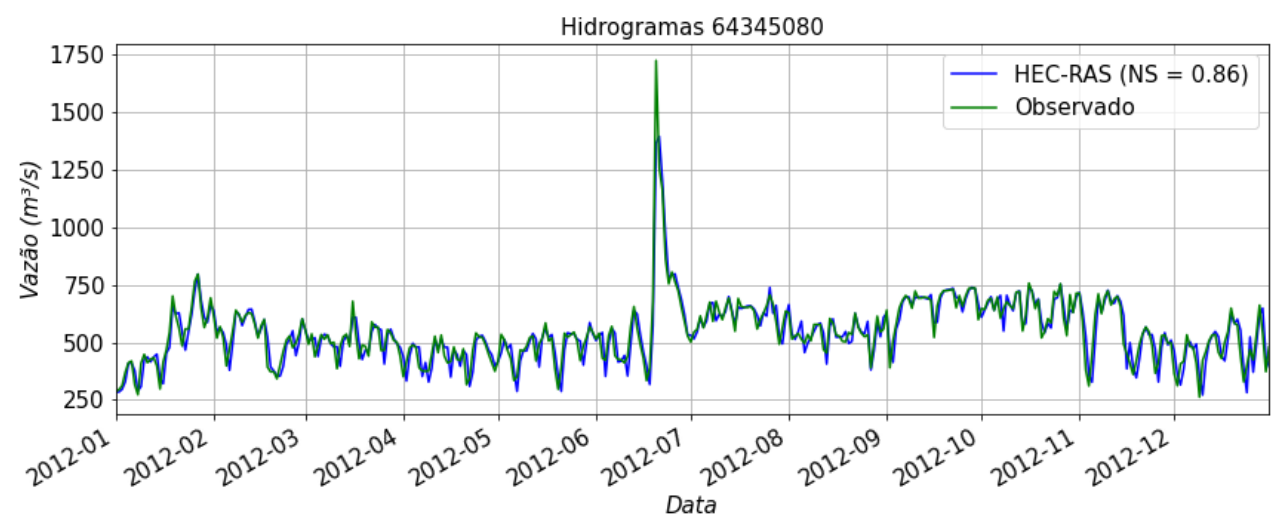

Figura 10 - Comparação dos resultados do modelo hidrodinâmico com a série de vazões observadas na 64516080.

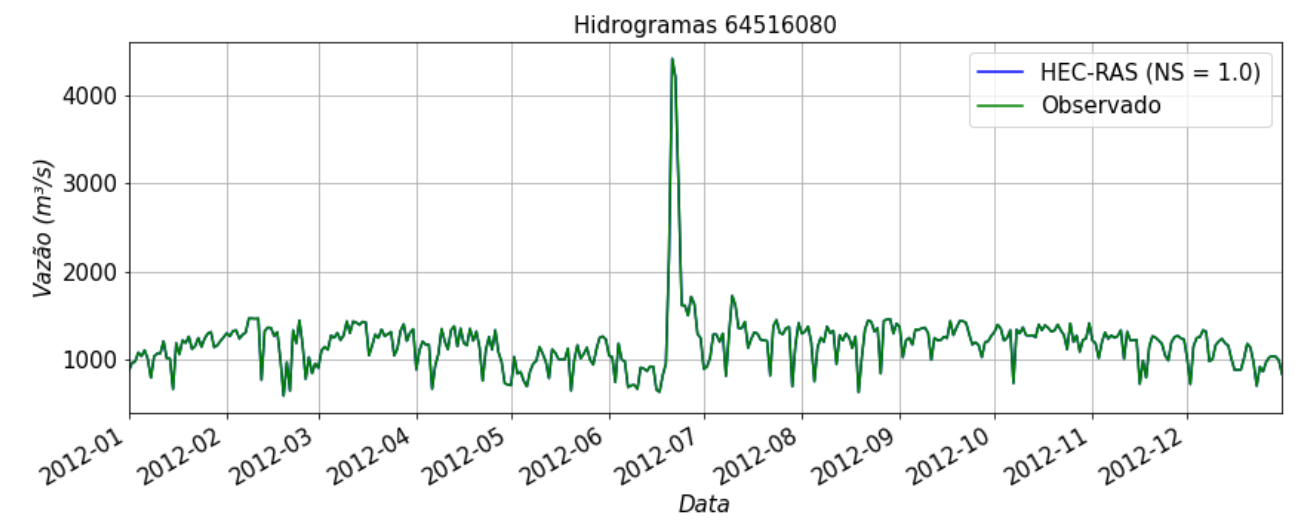

2. Rio Itararé 
Figura 11 - Comparação dos resultados do modelo hidrodinâmico com a série de vazões observadas na 64247000.

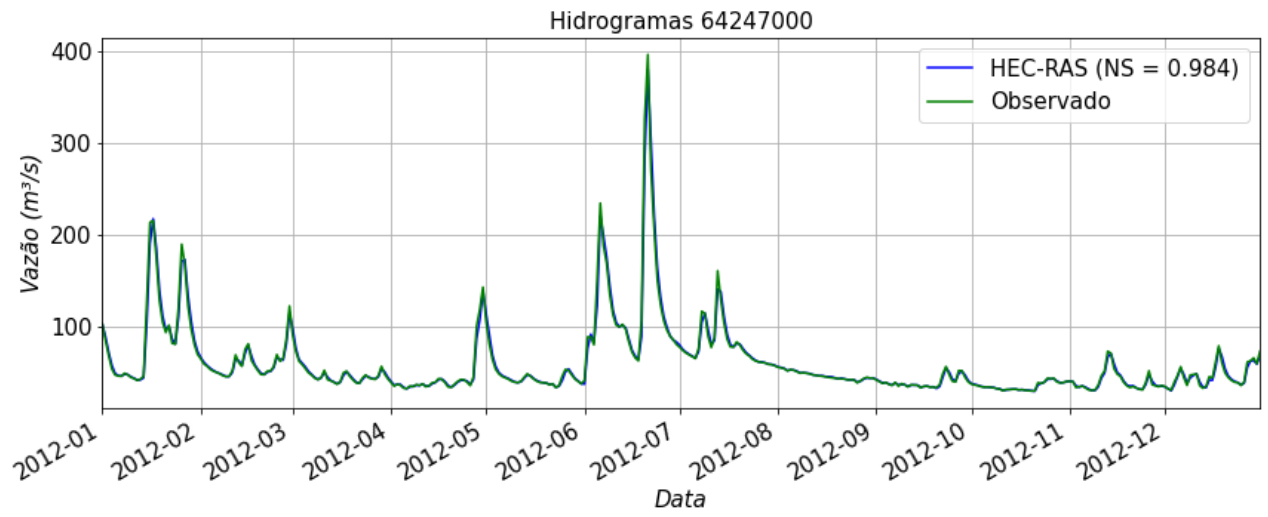

\section{Modelo de Qualidade da Água}

Os resultados das simulações de qualidade da água são apresentados para cenário base nas estações de referência, indicadas na Figura 12, no formato de boxplots.

Figura 12 - Posição das estações de referência de qualidade da água, onde os números correspondem aos códigos HIDROWEB e CETESB: $1=64081000 /$ PARP 02100; $2=$ 64214000 / JURU 02500; 3 = 64219000; 4 = 64278080; 5 = 64326000 / PARP02500; 6 = $64516900 /$ PARP 02750; $7=64571100 /$ PARP02900; $8=64245200 /$ ITAR 02500. $A=$ 64081000 e $B=64231000$. Fonte: O Autor (2021).

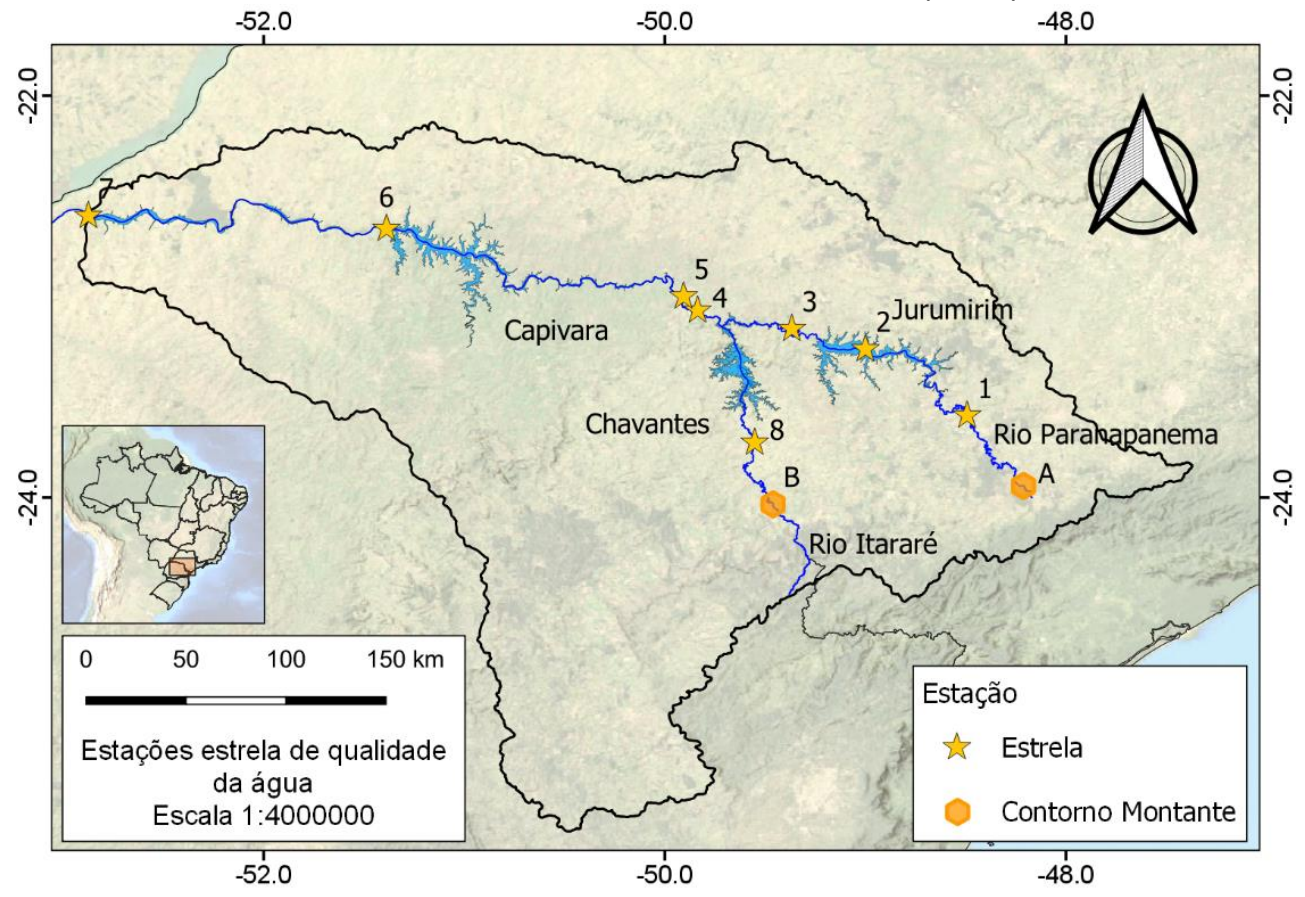




\section{Rio Paranapanema}

Figura 13 - Resultados das simulações de qualidade da água comparados com os dados observados para a estação 64081000 , em azul as concentrações limites por classe.
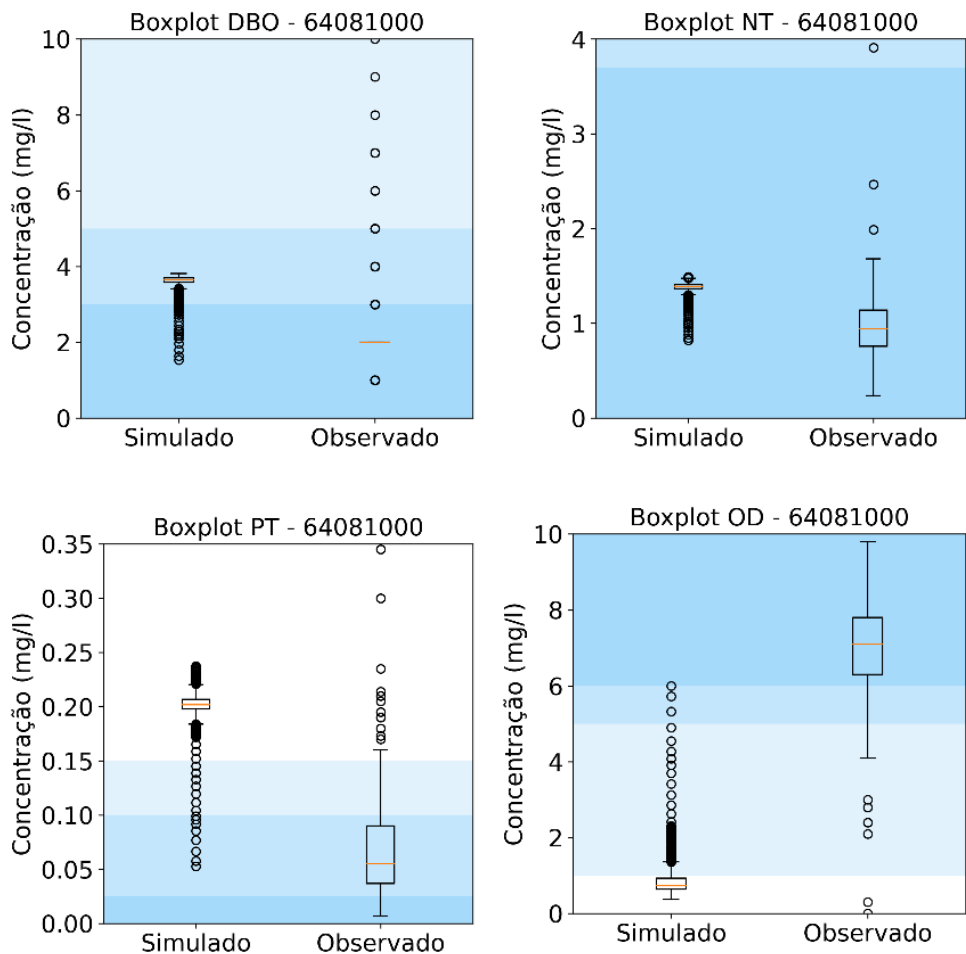

Classe $1 \square$ Classe 2

$\square$ Classe $3 \square$ Classe 4

Figura 14- Resultados das simulações de qualidade da água comparados com os dados observados para a estação 64214000 , em azul as concentrações limites por classe.
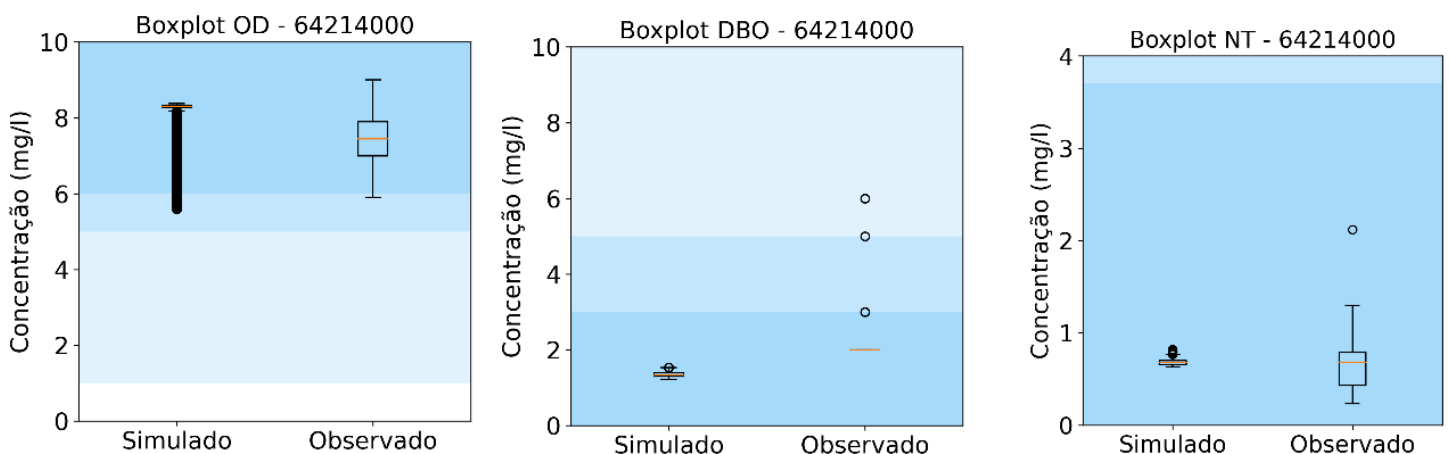

Classe 1

$\square$ Classe $2 \square$ Classe $3 \square$ Classe 4 
Figura 15 - Resultados das simulações de qualidade da água comparados com os dados observados para a estação 64219000 , em azul as concentrações limites por classe.
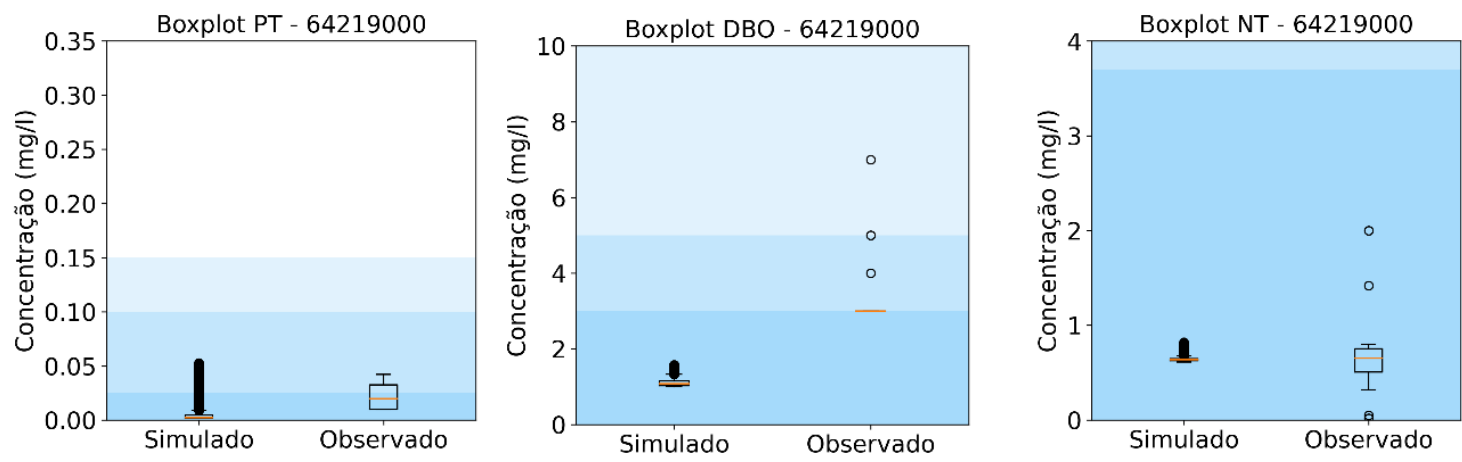

Classe $1 \quad \square$ Classe $2 \quad \square$ Classe $3 \quad \square$ Classe 4

Figura 16 - Resultados das simulações de qualidade da água comparados com os dados observados para a estação 64278080 , em azul as concentrações limites por classe.
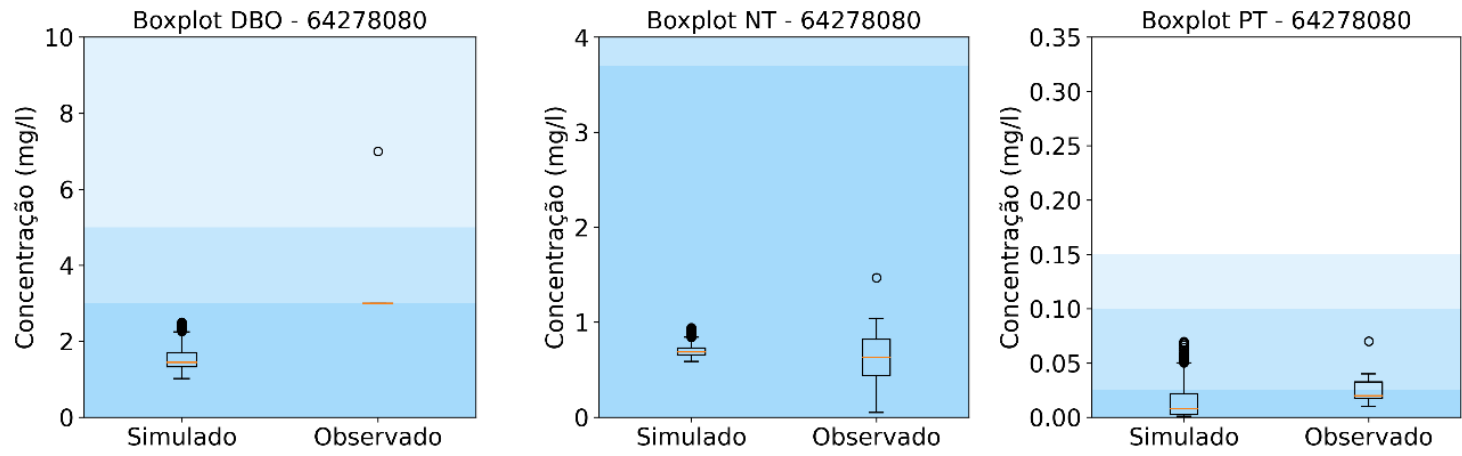

Classe 1

$\square$ Classe $2 \square$ Classe $3 \square$ Classe 4 
Figura 17 - Resultados das simulações de qualidade da água comparados com os dados observados para a estação 64326000 , em azul as concentrações limites por classe.
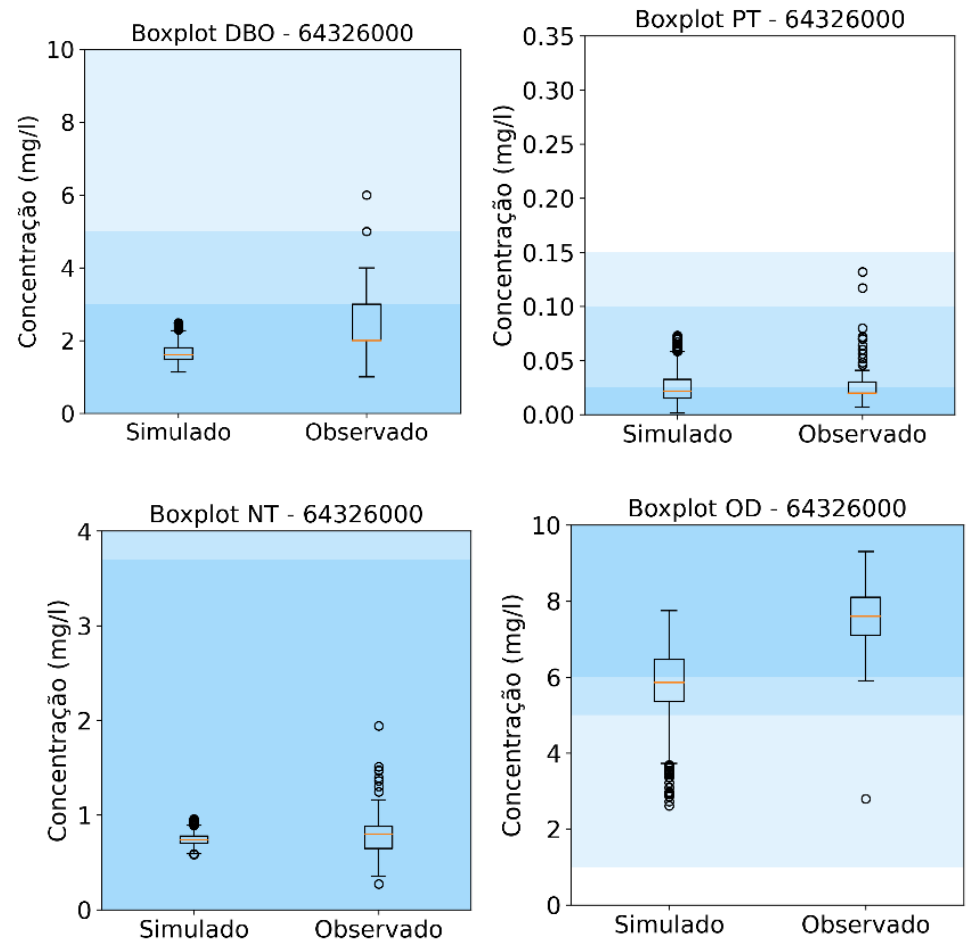

Classe $1 \square$ Classe 2

$\square$ Classe $3 \quad \square$ Classe 4

Figura 18 - Resultados das simulações de qualidade da água comparados com os dados observados para a estação 64516900 , em azul as concentrações limites por classe.
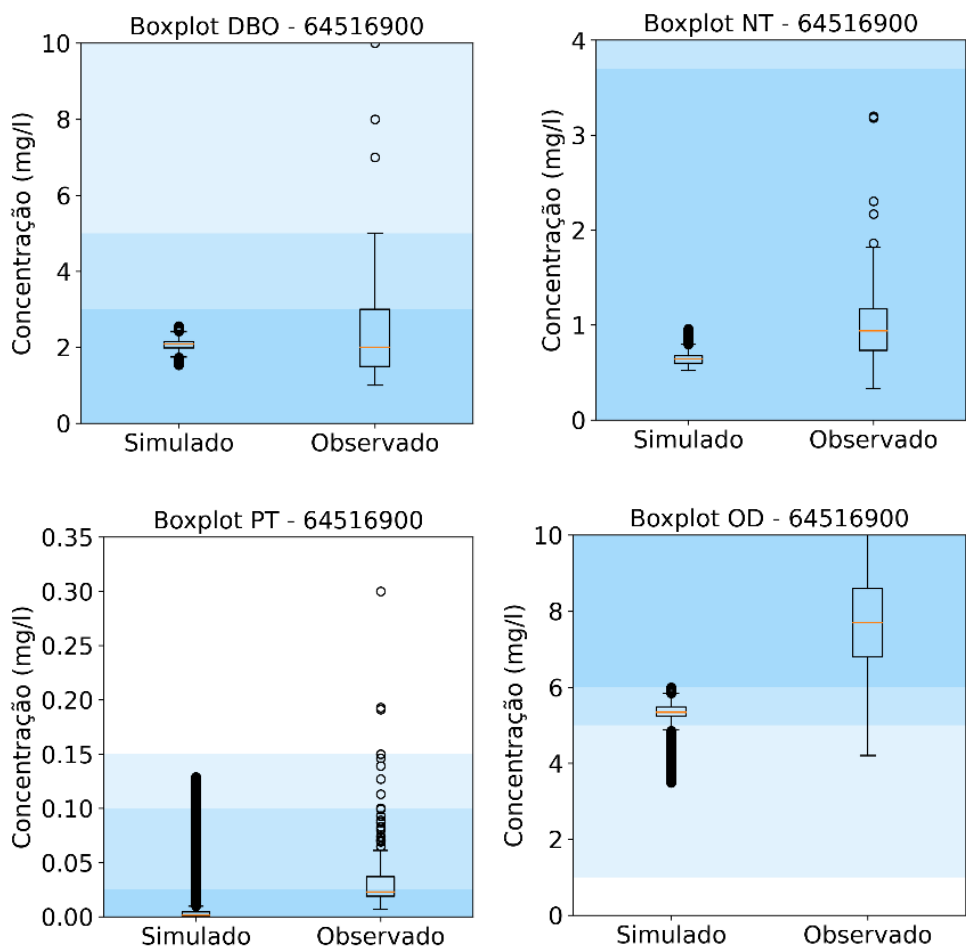

Classe $1 \square$ Classe 2

Classe $3 \square$ Classe 4 


\section{Rio Itararé}

Figura 19 - Resultados das simulações de qualidade da água comparados com os dados observados para a estação 64571100 , em azul as concentrações limites por classe.
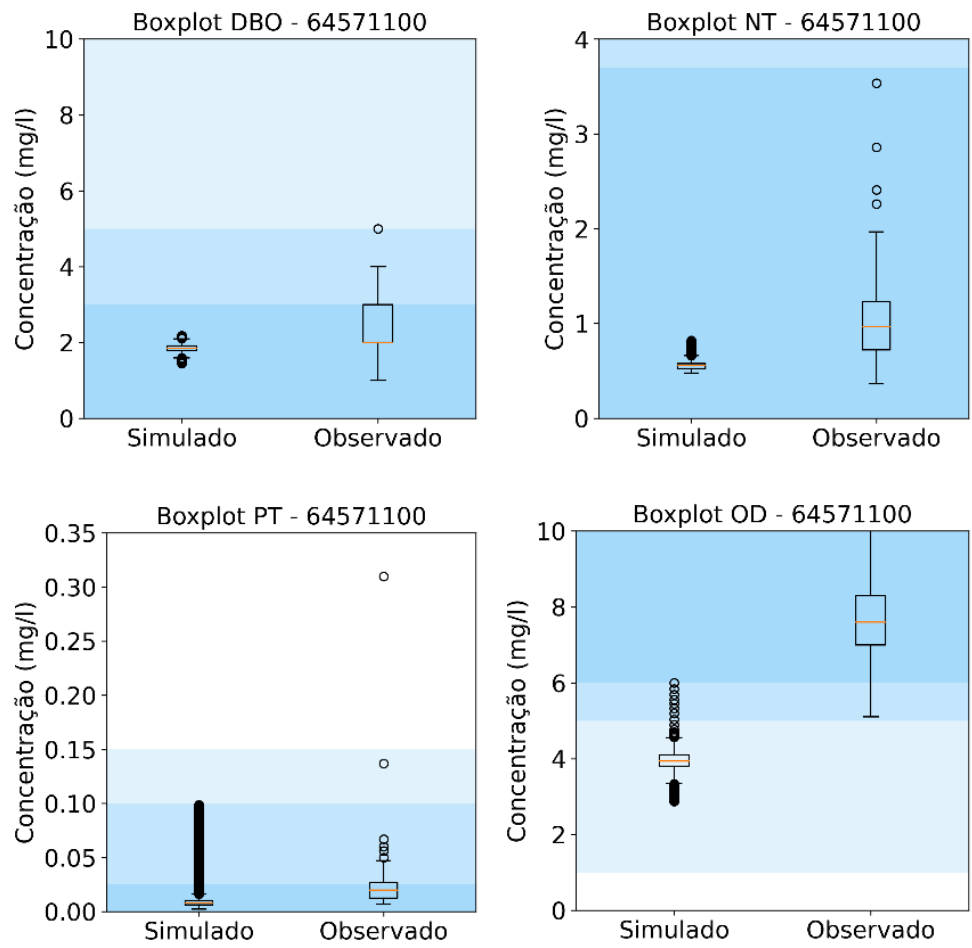

Classe $1 \square$ Classe 2

$\square$ Classe $3 \quad \square$ Classe 4

\section{Cenários Futuros}

Os cenários futuros representam o aumento no aporte de cargas no rio por conta do desenvolvimento na bacia hidrográfico. Tendo o aumento na emissão de poluentes apresentado no item 2, apresenta-se a seguir os resultados das simulações de qualidade da água para cada cenário, em cada uma das estações com dados de qualidade da água (Figura 12). 
Figura 20 - Resultados das simulações de qualidade da água para os cenários futuros de aumento no aporte de cargas apresentados na forma de frequência de permanência dentro dos limites de classe para a estação 64081000.

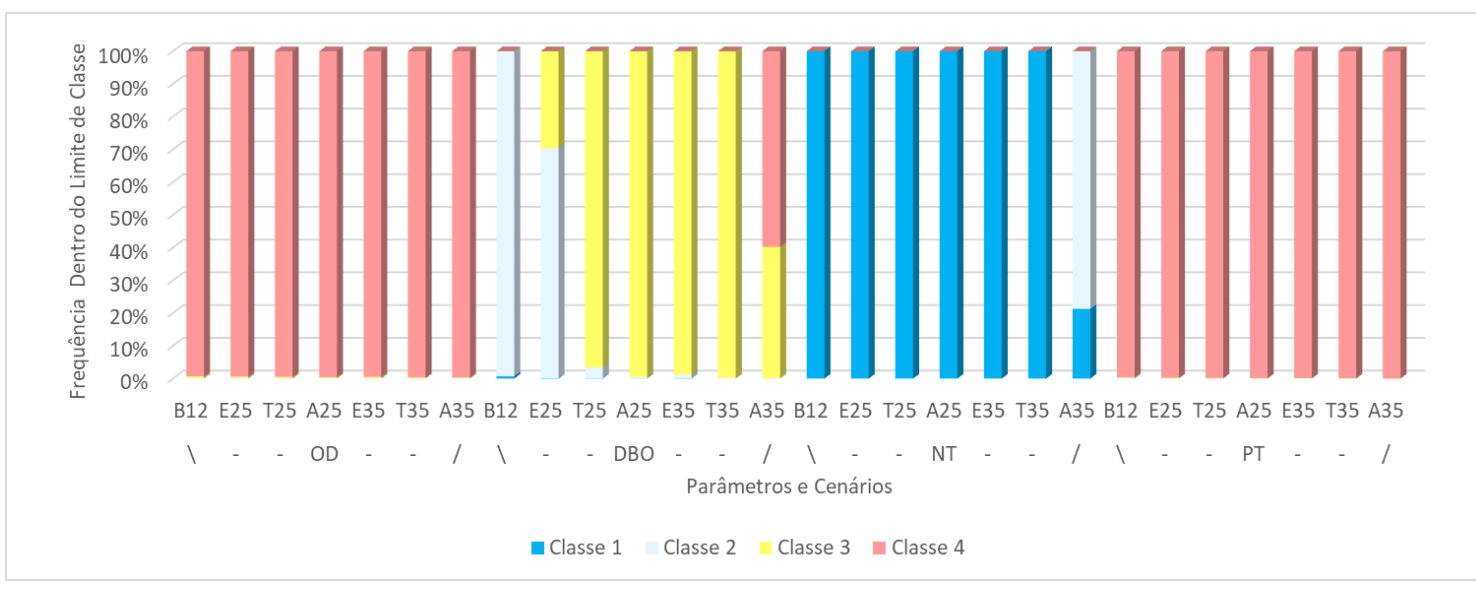

Figura 21 - Resultados das simulações de qualidade da água para os cenários futuros de aumento no aporte de cargas apresentados na forma de frequência de permanência dentro dos limites de classe para a estação 64214000.

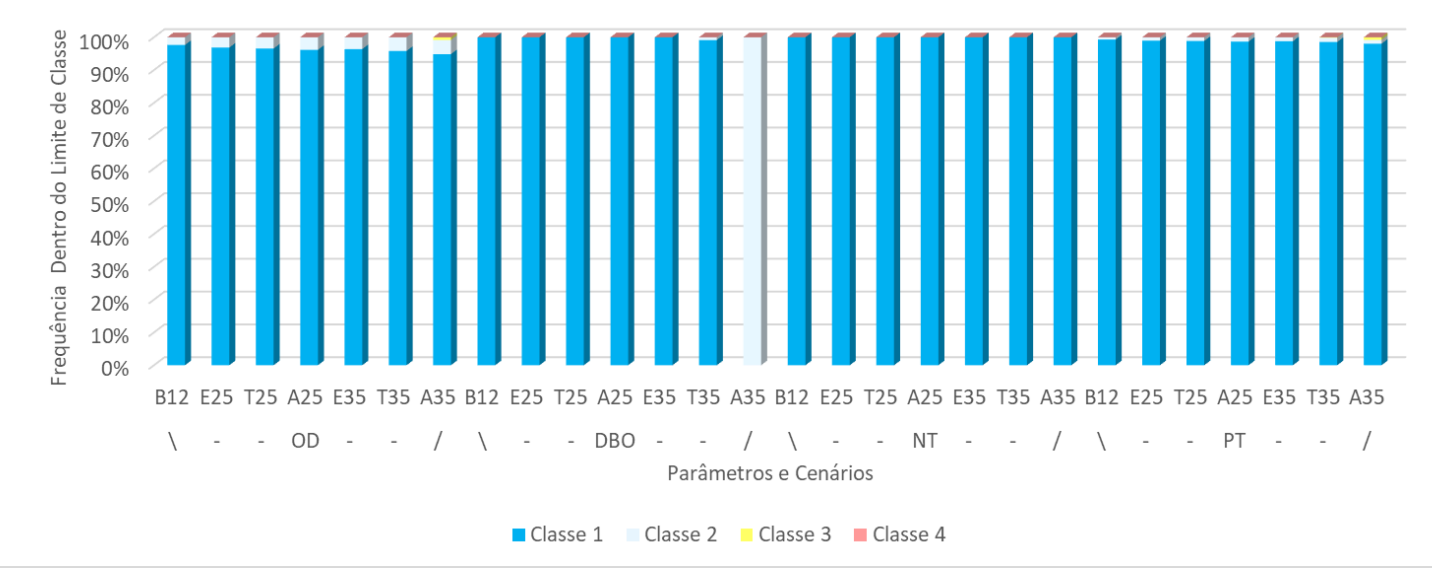

Figura 22 - Resultados das simulações de qualidade da água para os cenários futuros de aumento no aporte de cargas apresentados na forma de frequência de permanência dentro dos limites de classe para a estação 64219000 .

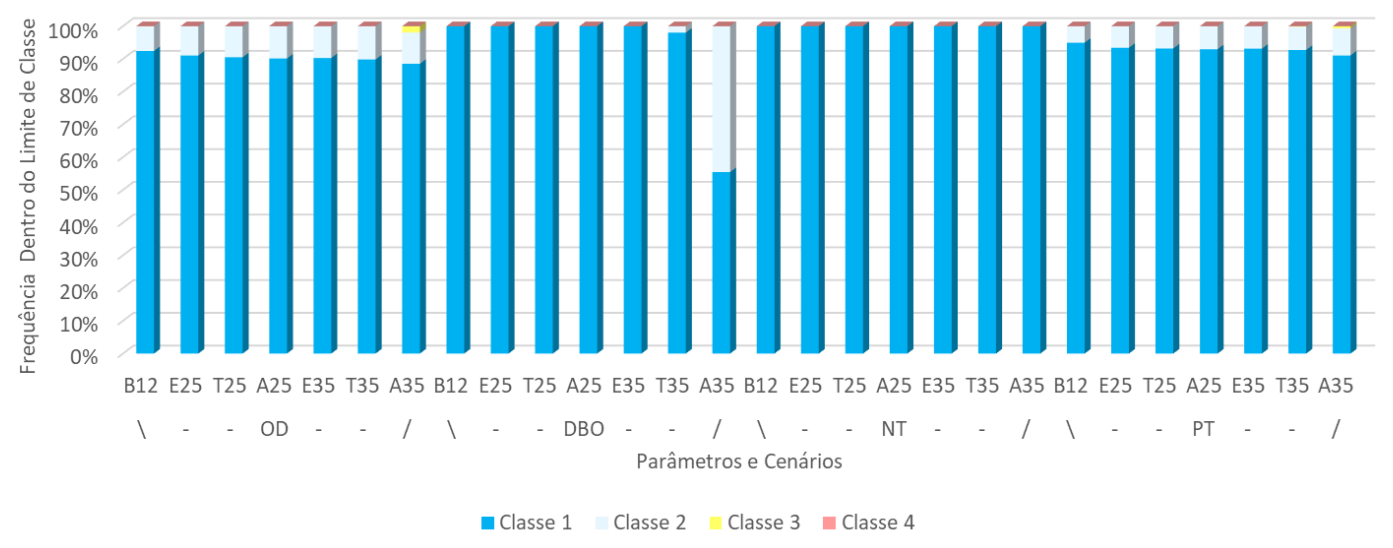


Figura 23 - Resultados das simulações de qualidade da água para os cenários futuros de aumento no aporte de cargas apresentados na forma de frequência de permanência dentro dos limites de classe para a estação 64245200.

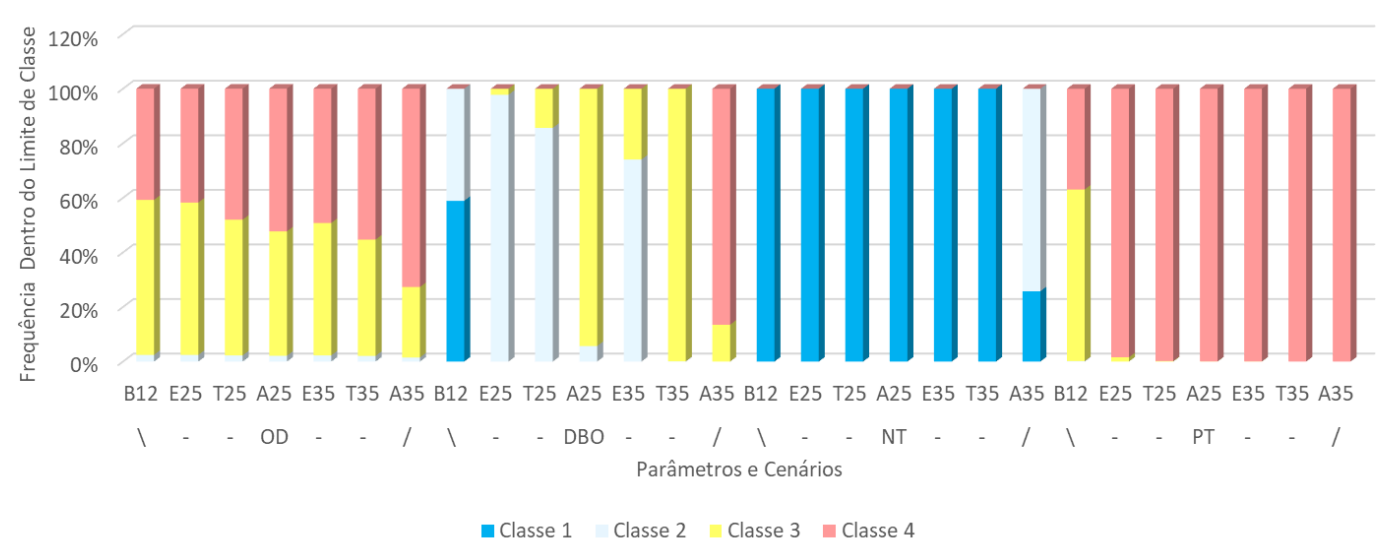

Figura 24 - Resultados das simulações de qualidade da água para os cenários futuros de aumento no aporte de cargas apresentados na forma de frequência de permanência dentro dos limites de classe para a estação 642478080.

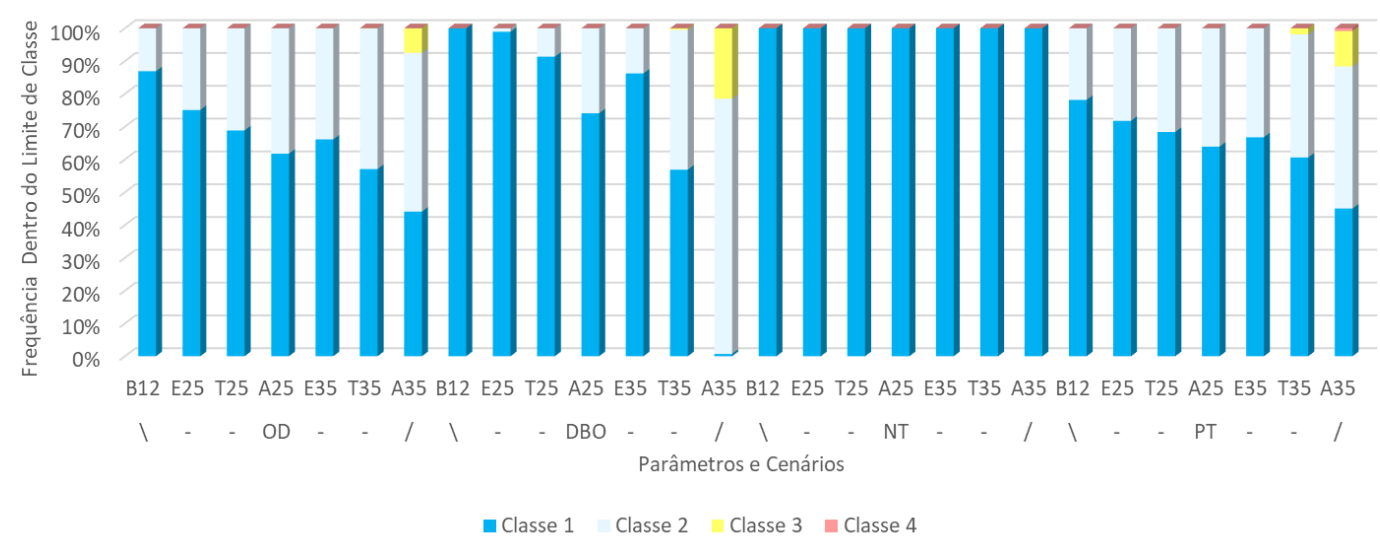

Figura 25 - Resultados das simulações de qualidade da água para os cenários futuros de aumento no aporte de cargas apresentados na forma de frequência de permanência dentro dos limites de classe para a estação 64326200.

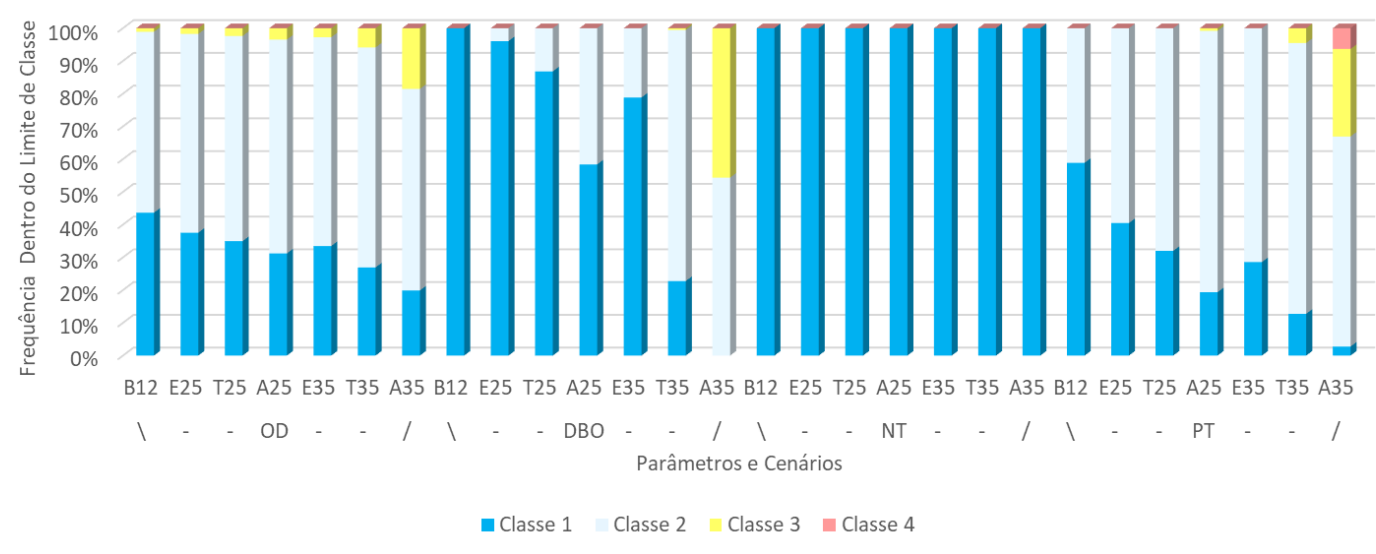


Figura 26 - Resultados das simulações de qualidade da água para os cenários futuros de aumento no aporte de cargas apresentados na forma de frequência de permanência dentro dos limites de classe para a estação 64516900.

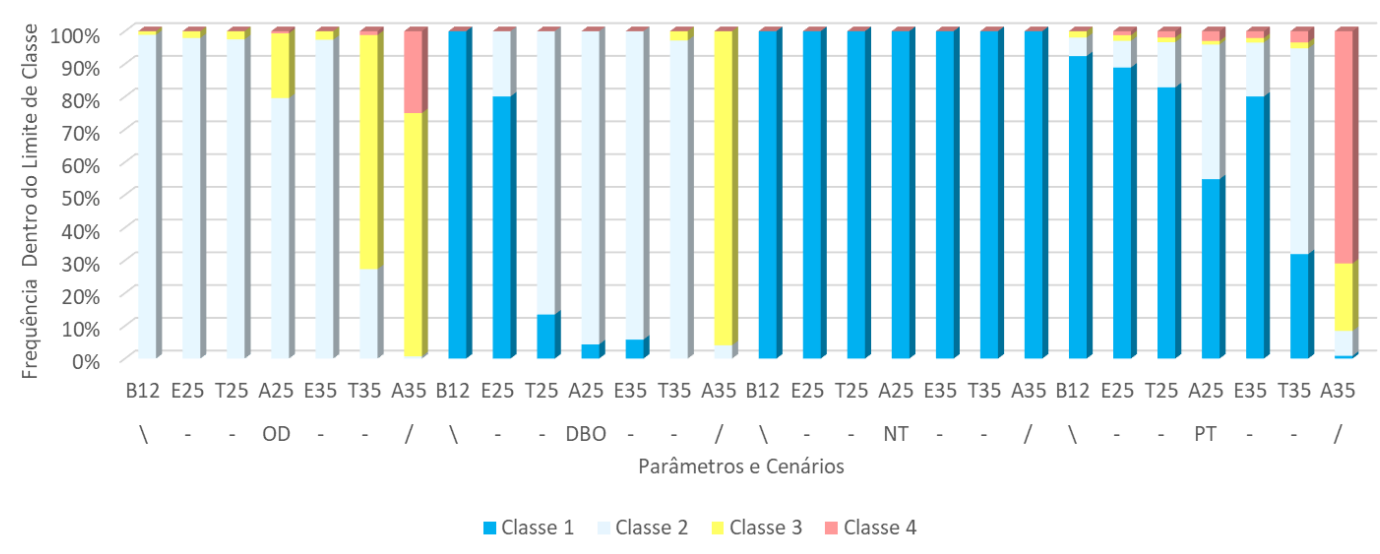

Figura 27 - Resultados das simulações de qualidade da água para os cenários futuros de aumento no aporte de cargas apresentados na forma de frequência de permanência dentro dos limites de classe para a estação 64571100 .

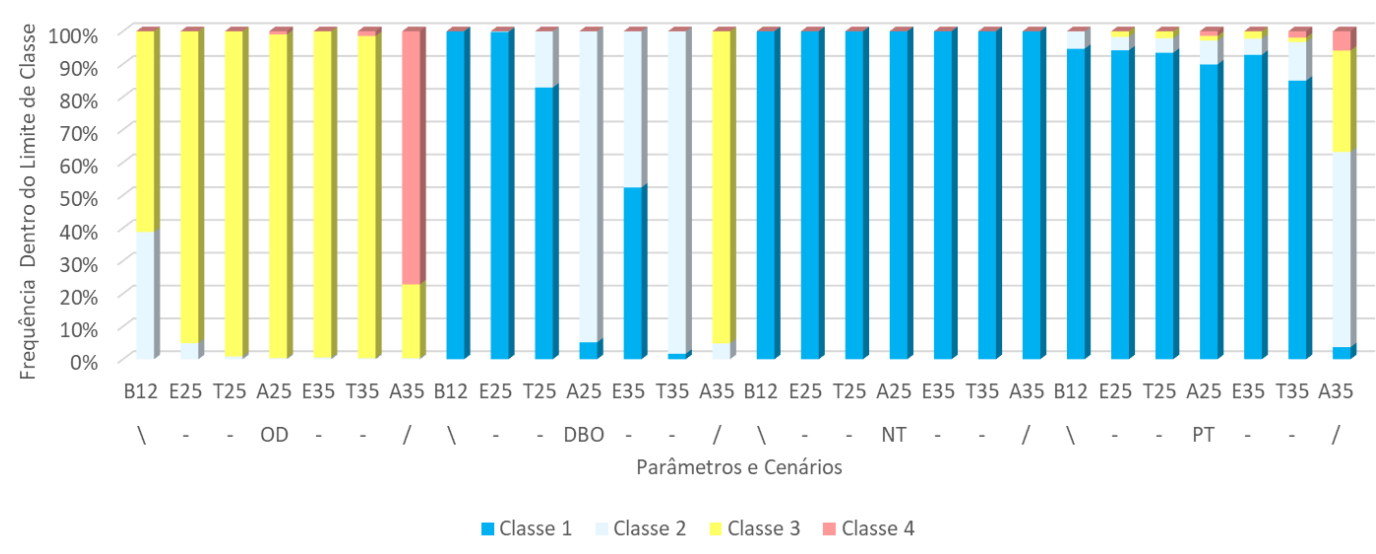




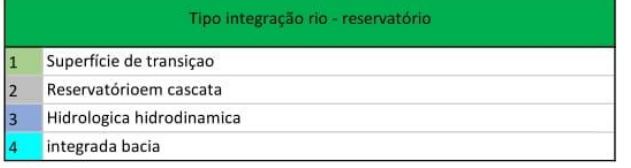

\begin{tabular}{|c|c|}
\hline \multicolumn{2}{|r|}{ Detalhes Modelagem } \\
\hline 1 & Tipo integração rio - reservatório \\
\hline 2 & Modelagem? \\
\hline 3 & Base teórica \\
\hline 4 & Ferramenta(s) de Modelagem \\
\hline 5 & Modelo Hidrológico \\
\hline 6 & Modelo Hidrodinâmico \\
\hline 7 & Qualidade da Água \\
\hline 8 & Discute resoluçăo temporal QA x Hidrograma? \\
\hline 9 & Area \\
\hline 10 & Comprimento rio \\
\hline 11 & Condiç̄es de contorno \\
\hline 12 & Resolução temporal \\
\hline 13 & Resoluçăo espacial \\
\hline 14 & Disponibilidade de dados \\
\hline
\end{tabular}

\section{Tabela de Revisão Bibliográfica}

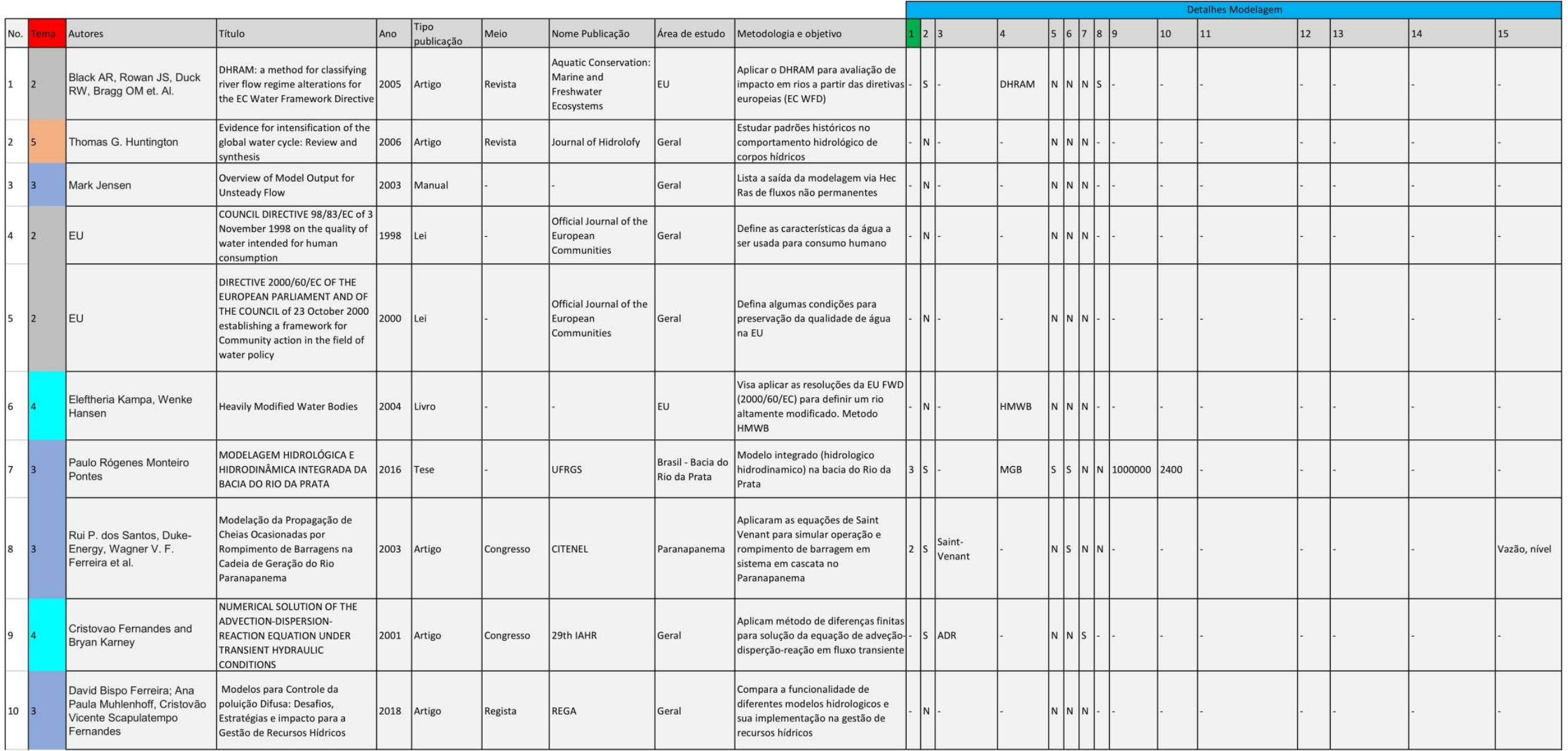




\begin{tabular}{|c|c|c|c|c|c|c|c|c|c|c|c|c|c|c|c|c|c|c|c|c|c|c|}
\hline \multirow{2}{*}{\multicolumn{2}{|c|}{ No. }} & & \multirow{2}{*}{ Titulo } & \multirow{2}{*}{ Ano } & \multirow{2}{*}{$\begin{array}{l}\text { Tipo } \\
\text { publicaçăo }\end{array}$} & \multirow{2}{*}{ Meio } & \multirow{2}{*}{ Nome Publicação } & \multirow{2}{*}{ Área de estudo } & \multirow{2}{*}{ Metodologia e objetivo } & \multicolumn{13}{|c|}{ Detalhes Modelagem } \\
\hline & & & & & & & & & & & 23 & 4 & 56 & 57 & 89 & & 10 & 11 & 12 & 13 & 14 & 15 \\
\hline 11 & 2 & Australia & $\begin{array}{l}\text { Australian Drinking Water } \\
\text { Guidelines } 62011\end{array}$ & 2013 & Lei & - & & Austrália & $\begin{array}{l}\text { Define as caracteristicas da água a } \\
\text { ser usada para consumo humano na } \\
\text { Austrália }\end{array}$ & N & s. & & $\mathrm{n} / 1$ & $\mathrm{~N}$ & & & - & & & & & \\
\hline 12 & 4 & $\begin{array}{l}\text { Paulo Sérgio Pereira, Bruno } \\
\text { Victor Veiga, Mauricio Dziedzi }\end{array}$ & \begin{tabular}{|l} 
Avaliação da Influência do Fósforo \\
e do Nitrogênio no Processo de \\
Eutrofização de Grandes \\
Reservatorios Estudo de Caso: \\
Usina Hidrelétrica foz do Areia
\end{tabular} & 2013 & Artigo & Revista & SBRH & \begin{tabular}{|l|} 
Brasil- \\
Hidrelétrica Foz \\
do Areia
\end{tabular} & $\begin{array}{l}\text { Avalia a influência do fósforo e } \\
\text { nitrogênio no processo de } \\
\text { eutrofização do reservatório e } \\
\text { qualidade da água }\end{array}$ & s & $\begin{array}{l}\text { Balanço de } \\
\text { Massa }\end{array}$ & \begin{tabular}{|l} 
FLUX, \\
Bathtub
\end{tabular} & $\sin$ & $\mathrm{s}$ & & & 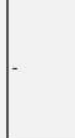 & & & & & \\
\hline 13 & 3 & Eloy et al & \begin{tabular}{|l|}
$\begin{array}{l}\text { Modelagem Hidrologica da Bacia } \\
\text { do Rio I Iuaçu entre Salto Osorio e } \\
\text { Salto Caxias }\end{array}$ \\
\end{tabular} & & Artigo & - & & \begin{tabular}{|l} 
Entre salto \\
osorio esalto \\
caxias
\end{tabular} & Descreve a modelagem no trecho & $3 \mathrm{~s}$ & \begin{tabular}{|l|} 
Chuva- \\
vazão, Saint- \\
Venant
\end{tabular} & & s s s & $\mathrm{N}$ & & & $\cdot$ & - & & & \begin{tabular}{|l|}
26 estacoes \\
pluviometrias, \\
oito \\
fluviometricas
\end{tabular} & \\
\hline 14 & 3 & $\begin{array}{l}\text { Jussara Cabral Cruz, Carlos } \\
\text { Eduardo Morelli Tucci }\end{array}$ & $\begin{array}{l}\text { Estimativa da Disponibilidade } \\
\text { Hidrica Através da Curva de } \\
\text { Permanência }\end{array}$ & 2008 & Artigo & Revista & SBRH & \begin{tabular}{|l} 
Brasil-Rio \\
Grande do Sul
\end{tabular} & $\begin{array}{l}\text { Compara o tipo de dados - ano a ano } \\
\text { e série toda - e seus resultados com } \\
\text { sua aplicabilidade na implantaçăo de } \\
\text { recursos de gestão }\end{array}$ & s & $\mid \begin{array}{l}\text { Análise } \\
\text { estatistica }\end{array}$ & & $\mathrm{N} / \mathrm{s}$ & $\mathrm{N}$ & & & - & - & & & $\begin{array}{l}13 \text { estacoes } \\
\text { fluviometricas }\end{array}$ & \\
\hline 15 & 4 & David A Chin & \begin{tabular}{|l|}
$\begin{array}{l}\text { Water-quality Engineering in } \\
\text { Natural Systems }\end{array}$ \\
\end{tabular} & 2006 & Livro & & & Geral & $\begin{array}{l}\text { Livro sobre processos em ambientes } \\
\text { aquáticos }\end{array}$ & N & v. & & n 1 & $\mathrm{~N}$ & & & - & & . & & & \\
\hline 16 & 1 & Camila A Bittencourt & \begin{tabular}{|l|} 
INTEGRAÇ̃̃O DE ANÁLISE \\
ESTATISTCA MULTIVARIADAE \\
GEOPROCESSAMENTO APLICAC̆ĀO \\
PARA ESTUDOS DE \\
ENQUADRAMENTO DE CORPOS \\
D'ÁGUA
\end{tabular} & 2018 & Dissertação & & PPGERHA & \begin{tabular}{|l|} 
Brasil - Bacia do \\
Alto Iguaçu
\end{tabular} & \begin{tabular}{|l|} 
Estuda o uso de ACP para \\
determinar quais parâmetros \\
interferem mais no enquadramento. \\
Geoprocessamento usado mais para \\
organização
\end{tabular} & s & Estatistica & & $\operatorname{nath} 1$ & $\mathrm{vs}$ & & & - & - & 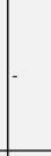 & & - & \\
\hline 17 & 4 & Daniele M. Ferreira & $\begin{array}{l}\text { SIMULAÇ̃̃̃O HIDRODINÂMICAE } \\
\text { DE QUALDADE DA ÁGUA EM RIOS } \\
\text { IMPACTO }\end{array}$ & 2015 & Dissertaçã̃o & - & PPGERHA & Geral & \begin{tabular}{|l|} 
Desenvolve modelo hidrodinamica e \\
de qualidade da água para avaliar as \\
vantagens de sua utilizaçăo sobre a \\
modelagem \\
permanente/enquadramento \\
tradicional
\end{tabular} & s & 5 & SIHQUAL & N $\mathrm{s}$ & 5 & & 3000 & 90 & Hidrogramas & 500 & 50 & $\begin{array}{l}5 \text { estaçōes } \\
\text { fluviomentrias }\end{array}$ & $\begin{array}{l}\text { Nivel, vazão, } \\
\text { DBO, OD }\end{array}$ \\
\hline 18 & 6 & USACE & Hydraulic Reference Manual & 2016 & Manual & - & - & EUA & Referencial teórico do HEC-RAS & N & 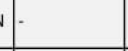 & & $n \sqrt{n}$ & $\mathrm{~N}$ & & & - & - & - & - & - & - \\
\hline 19 & 3 & Ven te Chow & Open-channel Hidraulycs & 1988 & Livro & - & & Geral & $\begin{array}{l}\text { Guia para simulação de canais } \\
\text { abertos }\end{array}$ & N & 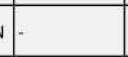 & & $\operatorname{nen} 1$ & $\sqrt{N}$ & & & - & - & - & 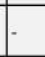 & - & - \\
\hline 20 & 3 & Tery W Sturm & Open-channel Hidraulycs & 2001 & Livro & & & Geral & $\begin{array}{l}\text { Guia para simulação de canais } \\
\text { abertos }\end{array}$ & N & 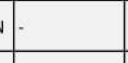 & & $\operatorname{nin} 1$ & $\mathrm{~N}$ & & & - & - & . & & & 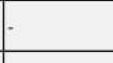 \\
\hline 21 & 3 & $\begin{array}{l}\text { L.M. Marangon Limaa, E. } \\
\text { Popovaa, P. Damienb }\end{array}$ & $\begin{array}{l}\text { Modeling and forecasting of } \\
\text { Brazilian reservoir inflows via } \\
\text { dynamic linear models }\end{array}$ & 2014 & Artigo & Revista & $\begin{array}{l}\text { International Journal } \\
\text { of Forecasting }\end{array}$ & Brasil & $\begin{array}{l}\text { Modelagem hidrológica para as } \\
\text { bacias brasileiras usando modelo } \\
\text { bayesiano }\end{array}$ & & \begin{tabular}{|l} 
Eqs. \\
Dinâmicas \\
lineares \\
(estatistica), \\
modelo \\
auoregressiv \\
0
\end{tabular} & & $\mathrm{n} h$ & $\mathrm{~N}$ & & & & & & & & $\begin{array}{l}\text { Hidrograma } \\
\text { de entrada }\end{array}$ \\
\hline 22 & 3 & $\begin{array}{l}\text { Rodrigo C.D. Paiva, Walter } \\
\text { Collischonn, Carlos E.M. } \\
\text { Tucci }\end{array}$ & \begin{tabular}{|l} 
Large scale hydrologic and \\
hydrodynamic modeling using \\
limited data and a GIS based \\
approach
\end{tabular} & 2011 & Artigo & Revista & Journal of Hidrology & \begin{tabular}{|l|}
$\begin{array}{l}\text { Brasil - Bacia do } \\
\text { Rio Purus } \\
\text { (Amazônia) }\end{array}$ \\
\end{tabular} & \begin{tabular}{|l}
$\begin{array}{l}\text { Propōes modelo } \\
\text { hidrologico/hidrodinamico para } \\
\text { modelagem de bacia com escassez } \\
\text { de dados }\end{array}$ \\
\end{tabular} & $4 \mathrm{~s}$ & $\begin{array}{l}\text { Saint- } \\
\text { Venant }\end{array}$ & GIS & $\mathrm{s}$ s & N & $\mathrm{N} 3$ & 370000 & 11000 & . & . & - & - & 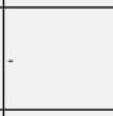 \\
\hline 23 & 1 & CONAMA & 357 & 2005 & Lei & - & - & Brasil & $\begin{array}{l}\text { Estipula as classes para } \\
\text { enquadramento }\end{array}$ & N & 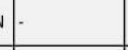 & - & & & & & - & - & - & - & - & - \\
\hline 24 & 4 & Daniele M. Ferreira & \begin{tabular}{|l|} 
INTEGRATED ANALYSIS FOR \\
MODEUING OF FLOW AND \\
TRANPPORT OF CONTAMINANTS \\
IN RIVERS
\end{tabular} & 2019 & Tese & & PPGERHA & Brasil & Desenvolve o SIHQUAL & $s$ & & SIHQUAL & $\operatorname{nat}$ & $\mathrm{vs}$ & & & - & - & & & & 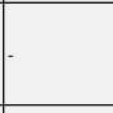 \\
\hline 25 & 4 & $\begin{array}{l}\text { MATHEUS YAGO ANTUNES } \\
\text { LUCKNER }\end{array}$ & \begin{tabular}{|l|} 
TFC ANÁLLSE DA VARIAÇĀO \\
TEMPORAL DO IOAR UTLIZZANDO \\
MODELO CE-QUAL-W2 PROPOSTA \\
DOUM INDICADOR COM BAIXA \\
RESOLUÇĀO TEMPORAL \\
\end{tabular} & 2018 & $\mathrm{TCC}$ & & PPGERHA & \begin{tabular}{|l|} 
Brasil- \\
Reservatório do \\
Vossoroca
\end{tabular} & $\begin{array}{l}\text { Modela reservatório considerando } \\
\text { certa variaçăo temporal }\end{array}$ & $s$ & & $\begin{array}{l}\text { CE-QUAL- } \\
\text { W2 }\end{array}$ & $\sin$ & $\mathrm{s}$ & & & & & & & & \\
\hline 26 & 4 & $\begin{array}{l}\text { Ana Carolina Canossa } \\
\text { Becker }\end{array}$ & \begin{tabular}{|l} 
ANÁLISE DA QUALIDADE DA ÁGUA \\
EM RESERVATÓRIOS EAVALIAÇĀO \\
DA REPRESENTATIVIDADE DO \\
IOARESTUDO DE CASO DO \\
RESERVATÓRIO VOSSOROCA, PR
\end{tabular} & 2018 & TCC & & PPGERHA & \begin{tabular}{|l|} 
Brasil- \\
Reservatório do \\
Vossoroca
\end{tabular} & $\begin{array}{l}\text { Compara a variaçăo da qualidade da } \\
\text { água (por profundidade e } \\
\text { sazonalidade) com sua } \\
\text { representatividade no IQAR }\end{array}$ & s & & & $\operatorname{nath}$ & & & & & & & & & \\
\hline
\end{tabular}




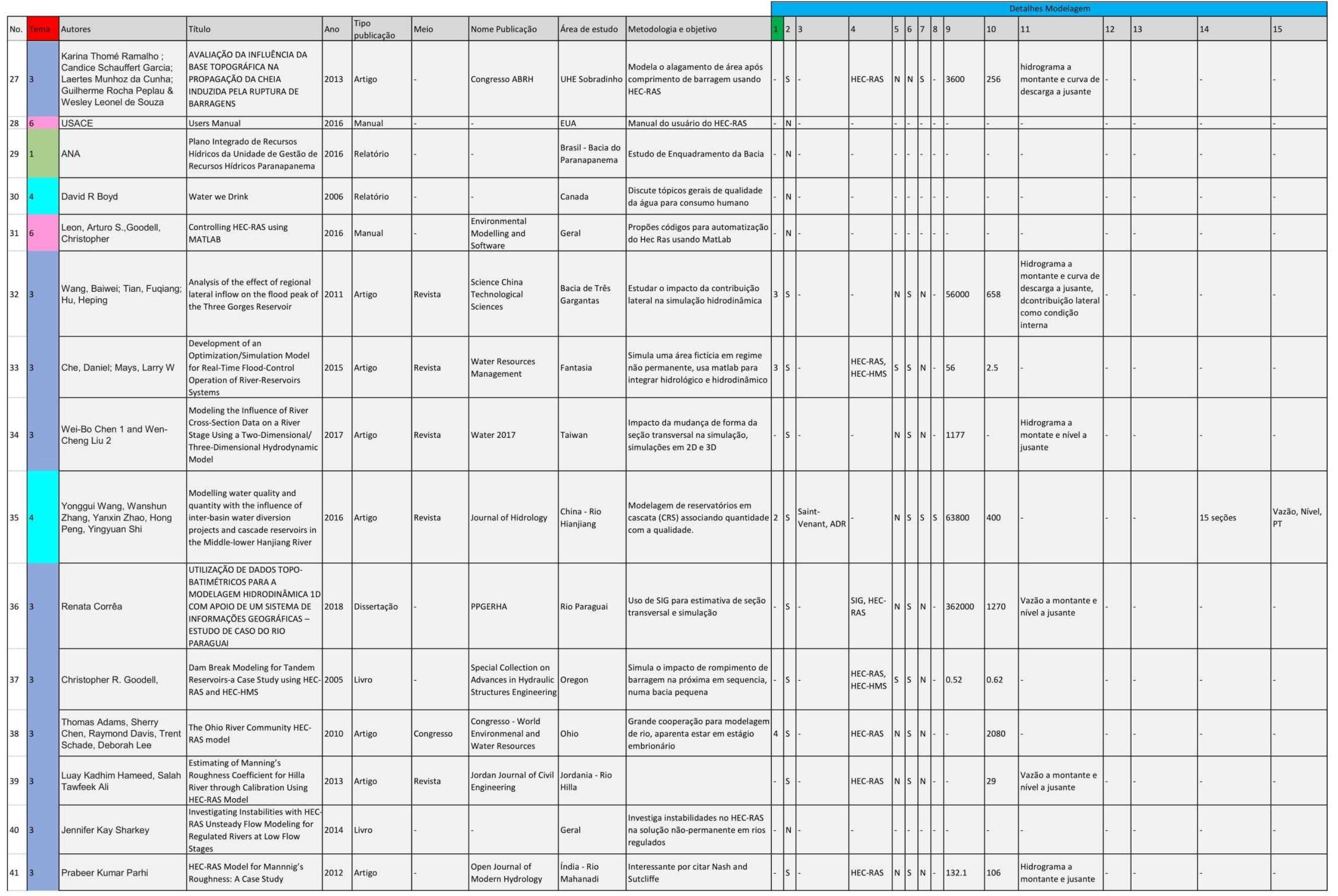




\begin{tabular}{|c|c|c|c|c|c|c|c|c|c|c|c|c|c|c|c|c|c|c|c|c|}
\hline & & & & & & & & & & & & & & & & & & & & \\
\hline No. & Tema & Autores & Titulo & Ano & \begin{tabular}{|l|}
$\begin{array}{l}\text { Tipo } \\
\text { publicação }\end{array}$ \\
\end{tabular} & Meio & Nome Publicação & Área de estudo & Metodologia e objetivo & 12 & 3 & 4 & \begin{tabular}{|l|l|l}
5 & 6 & 7 \\
\end{tabular} & 78 & & 10 & 11 & 12 & 14 & 15 \\
\hline 42 & & $\begin{array}{l}\text { Hao Wang, Xiaohui Lei, } \\
\text { Denghua Yan, Xu Wang, } \\
\text { Shyuyue Wu, Zhengijie Yin, } \\
\text { Wenhua Wan }\end{array}$ & \begin{tabular}{|l|} 
An Ecologically Oriented \\
OOeration Strategy for a Multi- \\
Reservoir System_A Case Study of \\
the Middle and Lower Han River \\
Basin, China _Elsevier Enhanced \\
Reader
\end{tabular} & f 2018 & Artigo & Revista & $\begin{array}{l}\text { Research Watershed } \\
\text { Ecology }\end{array}$ & China - Rio Han & $\begin{array}{l}\text { Estuda o impacto do represamento } \\
\text { em série, e formas de operar de } \\
\text { forma a minimizar impactos. 16 } \\
\text { reservatórios. Foco muito maior na } \\
\text { parte de operação que modelagem }\end{array}$ & $2 \mathrm{~s}$ & & & & & 159000 & 1577 & - & & & \\
\hline 43 & 3 & Daniel Che, Larry W. Mays & \begin{tabular}{|l|} 
Application of an Optimization \\
Simulation Model for Real-Time \\
Flood-Control Ioperation of River- \\
Reservoirs Systems
\end{tabular} & 2017 & Artigo & Revista & $\begin{array}{l}\text { Water Resources } \\
\text { Management }\end{array}$ & $\begin{array}{l}\text { Estados Unidos - } \\
\text { Rio Cumberland }\end{array}$ & $\begin{array}{l}\text { Usaram Hec Hms e Ras para modelar } \\
\text { sistema rio reservatório em regime } \\
\text { não permanente, visando controle } \\
\text { de cheia, com foco em eventos } \\
\text { extremos }\end{array}$ & $2 \mathrm{~s}$ & & $\begin{array}{l}\text { HEC-HMS, } \\
\text { HEC-RAS }\end{array}$ & & & 28.16 & & & & 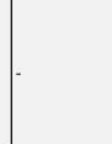 & \\
\hline 44 & & $\begin{array}{l}\text { Xinyu Wan, Lijuan Hua, } \\
\text { Shutan Yang, Hoshin V. } \\
\text { Gupta, Ping'an Zhong }\end{array}$ & $\begin{array}{l}\text { Evaluating the Impacts of a Large- } \\
\text { Scale Multi-Reservoir System on } \\
\text { Flooding Case of the Huai River in } \\
\text { China }\end{array}$ & 2018 & Artigo & Revista & $\begin{array}{l}\text { Water Resources } \\
\text { Management }\end{array}$ & China - Rio Huai & $\begin{array}{l}\text { Estuda o impacto da operacẵo de } \\
\text { reservatórios nos hidrogramas de rio } \\
\text { a jusante. } 20 \text { reservatórios em } \\
\text { sequencia }\end{array}$ & $2 \mathrm{~s}$ & & & & & 105000 & & & & & \\
\hline 45 & 6 & Tomasz Dysarz & \begin{tabular}{|l|} 
Application of Python Scripting \\
Techniques for Control and \\
Automation of HEC-RAS \\
Simulations
\end{tabular} & 2018 & Artigo & Revista & Water & Geral & $\begin{array}{l}\text { Propōes códigos para automatizaçăo } \\
\text { do Hec Ras usando Python }\end{array}$ & $\mathrm{N}$ & & & & & & & & & & \\
\hline 46 & & $\begin{array}{l}\text { Gustavo Lima Pinto, Wesley } \\
\text { Leonel De Souza }\end{array}$ & $\begin{array}{l}\text { INTEGRAÇ̄̃O ENTRE SIG, HEC-RAS } \\
\text { EHEC-HMS PARA MODELAGEM } \\
\text { DA BACIA HIDROGRAFILA DO RIO } \\
\text { BARIGUI }\end{array}$ & 2019 & TCC & & UFPR & \begin{tabular}{|l} 
Brasil-Rio \\
Barigui
\end{tabular} & $\begin{array}{l}\text { Propōes modelo } \\
\text { hidrlógico/hidrodinâmico para } \\
\text { contornar situaç̄es com falta de } \\
\text { dados. Compara hidrogramas }\end{array}$ & $\mathrm{s}$ & & $\begin{array}{l}\text { HEC-HMS, } \\
\text { HEC-RAS }\end{array}$ & 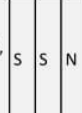 & & 279 & 67 & $\begin{array}{l}\text { Hidrograma a } \\
\text { montante e jusante }\end{array}$ & & & \\
\hline 47 & & $\begin{array}{l}\text { Danieli Mara Ferreira, } \\
\text { Cristovão Vicente } \\
\text { Scapulatempo Fernandes e } \\
\text { Eloy Kaviski }\end{array}$ & \begin{tabular}{|l|} 
Curvas de permanência de \\
qualidadeda da água como subsídio \\
para o enquadramento de corpos \\
d'água a apartir de modelagem \\
matemáticicem regime não \\
permanente
\end{tabular} & 2016 & Artigo & Revista & RBRH & \begin{tabular}{|l} 
Brasil - Rio \\
Iguaçu
\end{tabular} & $\begin{array}{l}\text { Propōes uma análise em regime não } \\
\text { permanente de rios, usandp curvas } \\
\text { de permanência ao invés de valores } \\
\text { médios }\end{array}$ & s & & SIHQUAL & $\mathrm{N} S$ & & 3000 & 90 & & & & \\
\hline 48 & & $\begin{array}{l}\text { Christopher Goodell, Brian } \\
\text { Wahlin }\end{array}$ & \begin{tabular}{|l|} 
Dynamic and Level Pool Reservoir \\
Drawdown-A Breach Modeling \\
Practical Comparison for Dam
\end{tabular} & 2009 & Artigo & Congresso & 33rd IAHR Congress & & \begin{tabular}{|l|}
$\begin{array}{l}\text { Propōe uma modelagem } \\
\text { hidrodinamica simplificada para } \\
\text { reservatórios (dynamic routing vs } \\
\text { level poop) }\end{array}$ \\
\end{tabular} & s & \begin{tabular}{|l} 
Saint- \\
Venant
\end{tabular} & $\begin{array}{l}\text { HEC-RAS, } \\
\text { HEC-HMS }\end{array}$ & s s & $N$ N & & & & & $\begin{array}{l}\text { Situação } \\
\text { hipotetica }\end{array}$ & Nivel \\
\hline 49 & & $\begin{array}{l}\text { Seidou Kane, Soussou } \\
\text { Sambou, Issa Leye, Raymond } \\
\text { Diedhiou, Seni Tamba, } \\
\text { Mouhamed Talla Cisse, } \\
\text { Didier Maria Ndione, Mousse } \\
\text { Landing Sane }\end{array}$ & $\begin{array}{l}\text { Modeling of Unsteady Flow } \\
\text { through Junction in Rectangular } \\
\text { Channels: Impact of Model } \\
\text { Junntion in the Downstream } \\
\text { Channel Hydrograph }\end{array}$ & 2017 & Artigo & Revista & $\begin{array}{l}\text { Computational Water, } \\
\text { Energy, and } \\
\text { Environmental } \\
\text { Engineering }\end{array}$ & & 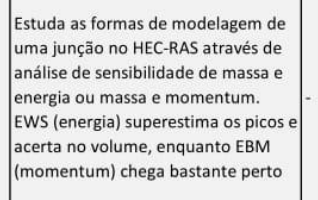 & & $\begin{array}{l}\text { Saint- } \\
\text { venant }\end{array}$ & HEC-RAS & \begin{tabular}{|l|l|l|l|l|l|l} 
n & n
\end{tabular} & $\mathrm{N} \mid \mathrm{N}$ & & & $\begin{array}{l}\text { Hidrograma a } \\
\text { montante, altura } \\
\text { normal a jusante }\end{array}$ & & $\begin{array}{l}\text { Situaçäo } \\
\text { hipotética }\end{array}$ & Nivel \\
\hline 50 & & $\begin{array}{l}\text { Chihhao Fan, Chun-Han Ko, } \\
\text { Wei-Shen Wang }\end{array}$ & $\begin{array}{l}\text { An innovative modeling approach } \\
\text { using Qual2K and HEC-RAS } \\
\text { integration to assess the impact of } \\
\text { tital effect on River Water quality } \\
\text { simulation }\end{array}$ & 2008 & Artigo & Revista & $\begin{array}{l}\text { Journal of } \\
\text { Environmental } \\
\text { Management }\end{array}$ & $\begin{array}{l}\text { Taiwan - Rio } \\
\text { Keelung }\end{array}$ & 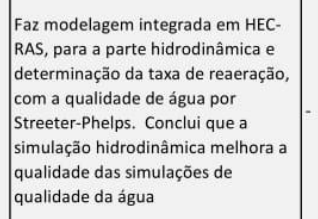 & & \begin{tabular}{|l|l|}
$\begin{array}{l}\text { Energia } \\
\text { (permanent } \\
\text { e) }\end{array}$ & \\
\end{tabular} & \begin{tabular}{|l} 
HEC-RAS, \\
Qual2R, \\
Streeter- \\
Phelps
\end{tabular} & $\mathrm{N} S \mathrm{~s}$ & & 501 & 80 & $\begin{array}{l}\text { profundidade média } \\
\text { da maté a jusante }\end{array}$ & & & $\begin{array}{l}\text { Nivel, DBO, } \\
\text { NH3-N, PT e } \\
\text { DOS } \\
\text { (demanda de } \\
\text { oxigênio do } \\
\text { sedimento) }\end{array}$ \\
\hline 51 & 6 & ANA & $\begin{array}{l}\text { Manual básico HEC-RAS 5.0.3 - } \\
\text { ruptura de barragem }\end{array}$ & 2018 & Manual & & & Geral & $\begin{array}{l}\begin{array}{l}\text { Manual de uso do HEC-RAS para } \\
\text { ruptura de barranges, publicado pela } \\
\text { ANA }\end{array} \text { - }\end{array}$ & N & & & & & & & & & & \\
\hline 52 & & $\begin{array}{l}\text { L. Cimorelli, L. Cozzolino, A. } \\
\text { D'Aniello, F. Morlando, D. } \\
\text { Pianese, V.P. Singh }\end{array}$ & \begin{tabular}{|l|} 
A new semi-lagrangian routing \\
procedure for constituent \\
transport in steady and unsteady \\
flow velocity
\end{tabular} & 2016 & Artigo & Revista & Journal of Hydrology & \begin{tabular}{|l} 
Reino Unido, \\
Nova zelândia \\
(validaçâo)
\end{tabular} & 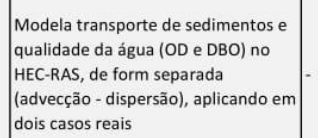 & & \begin{tabular}{|l|} 
Saint- \\
venant, $A D E$
\end{tabular} & HEC-RAS & $\begin{array}{lll}\mathrm{N} & \mathrm{S} & \mathrm{S}\end{array}$ & & & & & & & \begin{tabular}{|l} 
DBo, OD, \\
Nivel
\end{tabular} \\
\hline
\end{tabular}




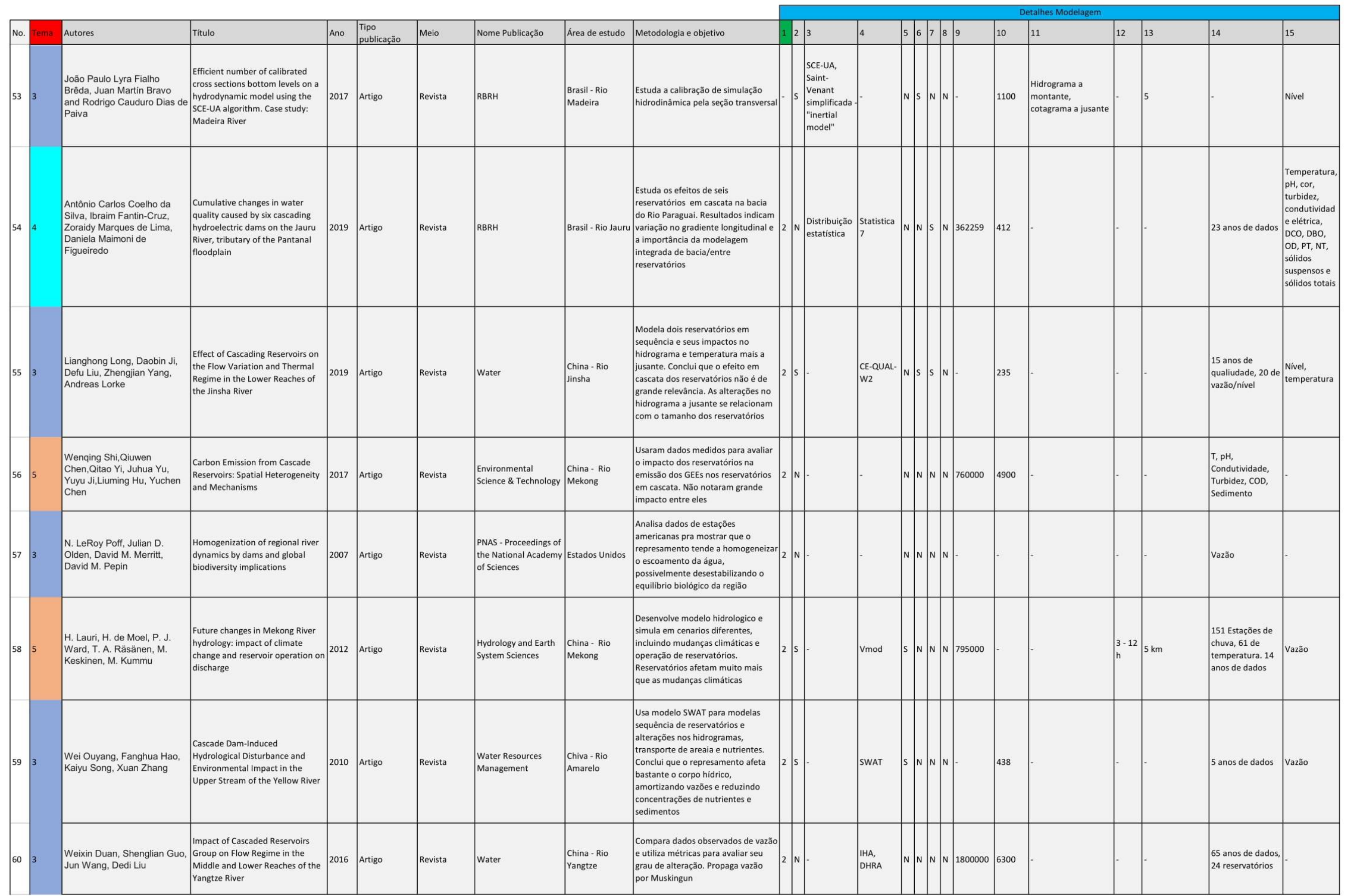




\begin{tabular}{|c|c|c|c|c|c|c|c|c|c|c|c|c|c|c|c|c|c|c|c|c|c|}
\hline & & & & & & & & & & & & & & & & & Detalhes Modelagem & & & & \\
\hline No. & & Autores & Titulo & Ano & $\begin{array}{l}\text { Tipo } \\
\text { publicacăa }\end{array}$ & Meio & Nome Publicação & Área de estudo & Metodologia e objetivo & 2 & 3 & 4 & \begin{tabular}{|l|l}
5 & 6 \\
\end{tabular} & $\begin{array}{lll}6 & 7 & 8\end{array}$ & 9 & 10 & 11 & 12 & 13 & 14 & 15 \\
\hline 61 & & $\begin{array}{l}\text { Moura, A. N.; Severiano, J. } \\
\text { S.; Tavares, N. K. A.; Dantas, } \\
\text { E. W. }\end{array}$ & $\begin{array}{l}\text { The role of a cascade of reservoirs } \\
\text { and seasonal variation in the } \\
\text { phytopplankton structure in a } \\
\text { tropical river }\end{array}$ & 2013 & Artigo & Revista & $\begin{array}{l}\text { Brazilian Journal of } \\
\text { Biology }\end{array}$ & $\begin{array}{l}\text { Brasil-Rio } \\
\text { Contas }\end{array}$ & $\begin{array}{l}\text { Medem fitoplancton em pontos do } \\
\text { rive e estudam nua variacăano } \\
\text { temporal/espacial. Concluem que os } \\
\text { reservatónios em cascata reduzem a } \\
\text { riqueza das algas }\end{array}$ & $2 / N$ & & & $\mathrm{~N}$ & \begin{tabular}{l|l|l}
$n$ & $\mathrm{n}$ \\
$\mathrm{n}$
\end{tabular} & 55000 & 700 & & & & $\begin{array}{l}3 \text { anos de coleta, } \\
28 \text { pontos }\end{array}$ & \\
\hline 62 & 3 & Ben R. Hodges & $\begin{array}{l}\text { Conservative finite-volume forms } \\
\text { of the Saint-Venant }\end{array}$ & 2019 & Artigo & Revista & $\begin{array}{l}\text { Hydrology and Earth } \\
\text { System Sciences }\end{array}$ & Geral & 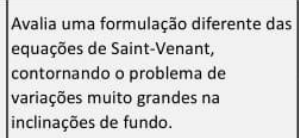 & - N & & & $|\mathrm{n}| \mathrm{N}$ & \begin{tabular}{l|l|l}
$n$ & $\mathrm{~N}$ \\
$\mathrm{n}$
\end{tabular} & 55000 & 700 & & & & $\begin{array}{l}3 \text { anos de coleta, } \\
28 \text { pontos }\end{array}$ & \\
\hline 63 & 3 & $\begin{array}{l}\text { Samuellson Lopes Cabral, } \\
\text { José Nilson B. Campos, } \\
\text { Cleiton Da Siva Siveria, } \\
\text { Francisisco Alberto De Assis } \\
\text { Teixeira }\end{array}$ & $\begin{array}{l}\text { equations for hydrology and } \\
\text { urban drainage }\end{array}$ & 2016 & Artigo & Revista & Revista Geociências & $\begin{array}{l}\text { Brasil- Rio } \\
\text { Granjeiro }\end{array}$ & $\begin{array}{l}\text { Desenvolve modelo hidrologico e } \\
\text { hidrodinamico usando as } \\
\text { ferramentas da USACE para simular } \\
\text { cheia. }\end{array}$ & $s$ & & $\begin{array}{l}\text { HEC-HMS, } \\
\text { HEC-RAS }\end{array}$ & & \begin{tabular}{l|l|l|l|l} 
& n
\end{tabular} & 18 & 7 & & & & $\begin{array}{l}\text { Uma estação, } 100 \\
\text { anos }\end{array} \mid$ & Nivel \\
\hline 64 & 3 & $\begin{array}{l}\text { Vinicius Alencar Siqueira, } \\
\text { Mino Viana Sorribas, Juan } \\
\text { Martin Bravo, Walter } \\
\text { Collischonn, Auder Machado } \\
\text { Vieira Lisboa, Giovanni } \\
\text { Gomes Villa Trinidad }\end{array}$ & $\begin{array}{l}\text { Real-time updating of HEC-RAS } \\
\text { model for streamflow forecasting } \\
\text { using an optimization algorithm }\end{array}$ & 2016 & Artigo & Revista & RBRH & $\begin{array}{l}\text { Brasil-Rio } \\
\text { Iguaçu }\end{array}$ & 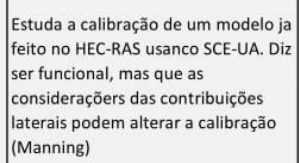 & -5 & $\begin{array}{l}\text { Saint- } \\
\text { venant }\end{array}$ & HEC-RAS & $\mathrm{N} / \mathrm{s}$ & \begin{tabular}{l|l|l}
$\mathrm{S}$ & $\mathrm{N}$ & $\mathrm{N}$ \\
\end{tabular} & & 200 & $\begin{array}{l}\text { Hidrograma a } \\
\text { montante e altura } \\
\text { normal a jusante }\end{array}$ & & & & \\
\hline 65 & 3 & André Luiz Nascentes Coelho & $\begin{array}{l}\text { GEOMORFOLOGIA FLUVIAL DE } \\
\text { RIOS IMPACTADOS POR } \\
\text { BARRAGENS1 }\end{array}$ & 2008 & Artigo & Revista & $\begin{array}{l}\text { Caminhos da } \\
\text { Geografia }\end{array}$ & & $\begin{array}{l}\text { Faz uma análise critica dos efeitos do } \\
\text { represamento, crom foco nos } \\
\text { sedimentos e a jusante do } \\
\text { reservatório }\end{array}$ & - N & & & & & & & & & & & \\
\hline 66 & 4 & $\begin{array}{l}\text { Alex Braz lacone Santos, } \\
\text { Bianca de Freitas Terra, } \\
\text { Francisco Gerson Araüjo }\end{array}$ & \begin{tabular}{|l|} 
Influence of the river flow on the \\
structure of fish assemblage along \\
the longitudinal gradient from \\
river to reservoir
\end{tabular} & 2010 & Artigo & Revista & Zoologia & & $\begin{array}{l}\text { Faz uma analise critica da } \\
\text { quantididade de peixes no rio, } \\
\text { reservatório e área de transiçăo. } \\
\text { Concluiu-se que essa area mistura os } \\
\text { peeixes que normalmente vivem nos } \\
\text { ambientes loticos e lênticos }\end{array}$ & 1 N & & & N N & $\mathrm{n} \mid \mathrm{n}$ & & 1100 & & & & $\left|\begin{array}{l}\text { Amostragem por } \\
\text { redes - 9 meses } \\
\text { entre } 2006 \text { e } 2007\end{array}\right|$ & \\
\hline 67 & 6 & \begin{tabular}{|l|} 
StefanSchmutz, \\
JanSendzimir
\end{tabular} & Riverine Ecosystem Management & 2018 & Livro & & & Geral & T. & N & & & $\mathrm{N}$ N & $\mathrm{N}$ & & & & & & & \\
\hline 68 & 4 & $\begin{array}{l}\text { João Rafael Bergamaschi } \\
\text { Tercini, Arisvaldo Vieira Méllo } \\
\text { Junior }\end{array}$ & \begin{tabular}{|l|} 
Modelo de simulaçăo de OD e \\
DBO integrando rio e reservatório \\
aplicado ao rio Tietê
\end{tabular} & 2016 & Artigo & Revista & SBRH & & $\begin{array}{l}\text { Modela OD e DBO usando Streeter- } \\
\text { Phelps para o Rio Tiête }\end{array}$ & $1 \mathrm{~s}$ & $\begin{array}{l}\text { Streeter- } \\
\text { Phelps }\end{array}$ & & N $\mid \mathrm{N}$ & \begin{tabular}{l|l|l}
$\mathrm{N}$ & $\mathrm{n}$ \\
$\mathrm{n}$
\end{tabular} & & 83 & & & & $\begin{array}{l}21 \text { a } 37 \text { anos } \mathrm{em} \\
5 \text { postos de } \\
\text { monitoramento } \\
\text { da CETESB }\end{array}$ & OD, DBO \\
\hline 69 & 6 & Chris Goodell & \begin{tabular}{|l|} 
HEC-RAS Dam Breach Theory and \\
Application
\end{tabular} & 2015 & Manual & & & Geral & Explica o funcionamento do HEC-RAS & $-\mathrm{N}$ & & & N N & N & & & & & & & \\
\hline 70 & 3 & Ralph A. Wurbs & $\begin{array}{l}\text { Modeling river/reservoir system } \\
\text { management, water allocation, } \\
\text { and supply reliability }\end{array}$ & 2005 & Artigo & Revista & Journal of Hydrology & EUA - Texas & $\begin{array}{l}\text { Modela as bacias do texas para } \\
\text { estudos de disponibilidade }\end{array}$ & 45 & $\left|\begin{array}{|l|}\text { Estatistitica, } \\
\text { Naturalizaçă } \\
\text { o de vazōes }\end{array}\right|$ & & $\mathrm{N} \mid \mathrm{N}$ & N 1 & & & & & & & \\
\hline 71 & 3 & $\begin{array}{l}\text { Xinxin Song; Yanhua Zhuang; } \\
\text { Xuelei Wang; Enhua Li }\end{array}$ & $\begin{array}{l}\text { Combined Effect of Danjiangkou } \\
\text { Reservoir and Cascade Reservoirs } \\
\text { on Hydrologic Regime } \\
\text { Downstream }\end{array}$ & 2018 & Artigo & Revista & $\begin{array}{l}\text { Jounal of Hydrologic } \\
\text { Engineering }\end{array}$ & \begin{tabular}{|l|} 
China - Hanjiang \\
River
\end{tabular} & $\begin{array}{l}\text { Faz a análise de alteraçäes no rio pós } \\
\text { represamento, usando indice iHA } \\
\text { como base de análise. }\end{array}$ & $2 \mid \mathrm{N}$ & IHA, RVS & & $\mathrm{N} \mid \mathrm{N}$ & $\mathrm{n} / \mathrm{n}$ & & & & & & & \\
\hline 72 & 4 & Mustafa M Aral & $\begin{array}{l}\text { Environmental Risk and Health } \\
\text { Risk Analysis (Acts/Risk) }\end{array}$ & 2010 & Livros & & & & \begin{tabular}{|l}
$\begin{array}{l}\text { Aspectos de modelagem } \\
\text { hidrodinâmica e qualidade da água } \\
\text { ligados à saúde humana }\end{array}$ \\
\end{tabular} & $\mathrm{N}$ & & & N N & $\mathrm{n} \mid \mathrm{n}$ & & & & & & & \\
\hline 73 & 4 & $\begin{array}{l}\text { Simona Pintilie, Loredana } \\
\text { Bránză, Camelia Betjanu, } \\
\text { Lucian Vasile Pavel, } \\
\text { Florina Ungureanu, Maria } \\
\text { Gavrilescu }\end{array}$ & $\begin{array}{l}\text { Modelling and simulation of heavy } \\
\text { metals transport in water and } \\
\text { sediments }\end{array}$ & 2007 & Artigo & Revista & $\begin{array}{l}\text { Environmental } \\
\text { engineering and } \\
\text { management journal }\end{array}$ & & $\begin{array}{l}\text { Modela aspectos do transporte de } \\
\text { metais pesados na água e sedimento }\end{array}$ & $\mathrm{s}$ & ? & & N N & n & & & & & & & \\
\hline 74 & 4 & $\begin{array}{l}\text { Kerachian, Reza Karamouz, } \\
\text { Mohammad }\end{array}$ & $\begin{array}{l}\text { A stochastic conflict resolution } \\
\text { model for water quality } \\
\text { management in reservoir-river } \\
\text { systems }\end{array}$ & 2007 & Artigo & Revista & $\begin{array}{l}\text { Advances in Water } \\
\text { Research }\end{array}$ & Iran & $\begin{array}{l}\text { Estuda impacto da operação na } \\
\text { qualidade de água do reservatório. }\end{array}$ & $25 s$ & $\left|\begin{array}{|l|}\text { ADR, } \\
\text { otimizaçāo } \\
\text { de operaçăo }\end{array}\right|$ & & $\left.n\right|^{n}$ & & & & & & & & \\
\hline
\end{tabular}




\begin{tabular}{|c|c|c|c|c|c|c|c|c|c|c|c|c|c|c|c|c|c|c|c|c|c|}
\hline & & & & & & & & & & \multicolumn{11}{|c|}{ Detalhes Modelagem } & \\
\hline No. & Ten & Autores & Titulo & Ano & $\begin{array}{l}\text { Tipo } \\
\text { publicacão }\end{array}$ & Meio & Nome Publicação & Área de estudo & Metodologia e objetivo & 2 & 3 & 4 & \begin{tabular}{|l|l|}
5 & 6 \\
\end{tabular} & \begin{tabular}{|l|l|}
7 & 8
\end{tabular} & 9 & 10 & 11 & 12 & 13 & 14 & 15 \\
\hline 75 & 4 & $\begin{array}{l}\text { Chen, Xiaoxian; Xu, Bo; Zheng, } \\
\text { Yi; Zhang, Chi }\end{array}$ & $\begin{array}{l}\text { Nexus of water, energy and } \\
\text { exosystems in the uupper Mekong } \\
\text { River: A system analysis of } \\
\text { phosphorus transport through } \\
\text { cascade reservoirs }\end{array}$ & 2019 & Artigo & Revista & $\begin{array}{l}\text { Science of the Total } \\
\text { Environment }\end{array}$ & $\begin{array}{l}\text { China - Rio } \\
\text { Mekong }\end{array}$ & \begin{tabular}{|} 
Modela o transporte de fósforo em \\
uma sequếncia de reservatorios em \\
cascata
\end{tabular} & 25 & $\begin{array}{l}\text { Balanço de } \\
\text { massa }\end{array}$ & & $\mathrm{N} \mid \mathrm{N}$ & $\mathrm{N}$ & & & & & & & PT \\
\hline 76 & 4 & $\begin{array}{l}\text { Guo, Xiaojuan } \\
\text { Zhu, Xiaosheng } \\
\text { Yang, Zhengejian }\end{array}$ & $\begin{array}{l}\text { Impacts of cascade reservoirs on } \\
\text { the longitudinal variability of fine } \\
\text { sediment characteristics: A case } \\
\text { study of the Lancang and Nu } \\
\text { Rivers }\end{array}$ & 2019 & Artigo & Revista & Journal of Hydrology & $\mid \begin{array}{l}\text { hhina - rios } \\
\text { Lancang e Nu }\end{array}$ & \begin{tabular}{|l|} 
Estuda a granulometria do \\
sedimento em dois rios: um \\
controlado por reservatórios e outro \\
natural. Conclui que o controlado \\
por reservatorios tem distribuiçăo \\
mais desigual
\end{tabular} & 2 N & & & & & & & & & & & \\
\hline 77 & 4 & 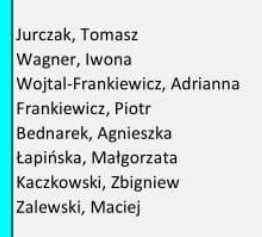 & $\begin{array}{l}\text { Comprehensive approach to } \\
\text { restoring urban recreational } \\
\text { reservoirs. Part 1 - Reduction of } \\
\text { nutrient loading through low-cost } \\
\text { and highly fffective } \\
\text { ecohydrological measures }\end{array}$ & 2019 & Artigo & Revista & Ecological Engineering & & 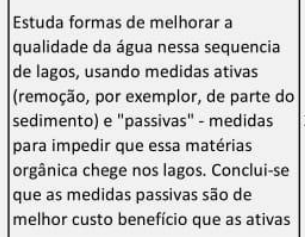 & $2{ }^{2}$ & & & N & & & & & & & & \\
\hline 78 & 4 & $\begin{array}{l}\text { Li, Dongfeng } \\
\text { Lu, Xi Xi } \\
\text { Yang, Xiankun } \\
\text { Chen, Li } \\
\text { Lin, Lin }\end{array}$ & $\begin{array}{l}\text { Sediment load responses to } \\
\text { climate variation and cascade } \\
\text { reservoirs in the Yangtze River: A } \\
\text { case study of the Jinsha River }\end{array}$ & 2018 & Artigo & Revista & Geomorphology & $\begin{array}{l}\text { China-Rio } \\
\text { Yangtze }\end{array}$ & $\begin{array}{l}\text { Estuda sedimentos em uma série de } \\
\text { reservatórios em cascata, e conclui } \\
\text { que a maior influência no seu } \\
\text { comportamento vem da operaçăo } \\
\text { dos reservatórios em cascata }\end{array}$ & $2{ }^{N}$ & & & N & & & & & & & & \\
\hline 79 & 4 & $\begin{array}{l}\text { Morales-Marin, L. A. } \\
\text { Wheater, H. S. } \\
\text { Lindenschmidt, K. E. }\end{array}$ & $\begin{array}{l}\text { Assessment of nutrient loadings of } \\
\text { alarge multipurpose prairie } \\
\text { reservoir }\end{array}$ & 2017 & Artigo & Revista & Journal of Hydrology & Canada & \begin{tabular}{|l} 
Estima a carga de matéria orgânica \\
em um reservatório es agentes \\
dessas cargas
\end{tabular} & - s s & & SPARROW & & & & & & & & & \\
\hline 80 & 4 & $\begin{array}{l}\text { Sechi, Giovanni M. } \\
\text { Sulis, Andrea }\end{array}$ & $\begin{array}{l}\text { Dynamic attribution of water } \\
\text { quality indexes in a multi-reservoir } \\
\text { optimization model }\end{array}$ & ir 2009 & Artigo & Revista & Desalination & |tália - Sardenha & $\begin{array}{l}\text { Estuda algoritmos de otimização } \\
\text { baseados no Indice de Estado Trófico } \\
\text { (IIET) em um esquema de } \\
\text { reservatórios em cascata, baseando- } \\
\text { se em um modelo que considera os } \\
\text { reservatórios como segmentados } \\
\text { verticalmente }\end{array}$ & 25 & \begin{tabular}{|l|} 
otimização \\
de operaçăo \\
linear
\end{tabular} & & N & $|n| n$ & & & & & & & \\
\hline 81 & 4 & $\begin{array}{l}\text { Cunha-Santino, Marcela B. } \\
\text { Fushita, Angela T. } \\
\text { Bianchini, Irineu }\end{array}$ & $\begin{array}{l}\text { A modeling approach for a } \\
\text { cascade of reservoirs in the Juquiá- } \\
\text { Guaçu River (Atlantic Forest, } \\
\text { Brazil) }\end{array}$ & 2017 & Artigo & Revista & Ecological Modelling & \begin{tabular}{|l} 
Bacia do Rio \\
Juquiá-Guaç̧u
\end{tabular} & 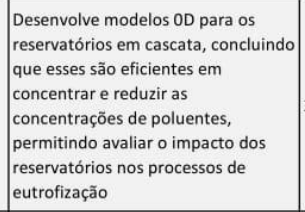 & 3 & OD & & & N & & & & & & & \\
\hline 82 & 4 & $\begin{array}{l}\text { Chen, Yihan } \\
\text { Yu, Kaifeng } \\
\text { Hassan, Muhammad } \\
\text { Xu, Cong } \\
\text { Zhang, Bo } \\
\text { Gin, Karina Yew Hoong } \\
\text { He, Yiliang }\end{array}$ & $\begin{array}{l}\text { Occurrence, distribution and risk } \\
\text { assessment of pesticides in a river- } \\
\text { reservoir system }\end{array}$ & 2018 & Artigo & Revista & $\begin{array}{l}\text { Ecotoxicology and } \\
\text { Evvironmental Safety }\end{array}$ & & $\begin{array}{l}\text { Avalia o comportamento de } \\
\text { agrotóxicos jogados em um rio, ao } \\
\text { longo da transiçăo rio-reservatório, } \\
\text { concluindo que os processos são } \\
\text { bastante afetados pelo clima }\end{array}$ & $1 \mid \mathrm{N}$ & & & & & & & & & & & \\
\hline
\end{tabular}




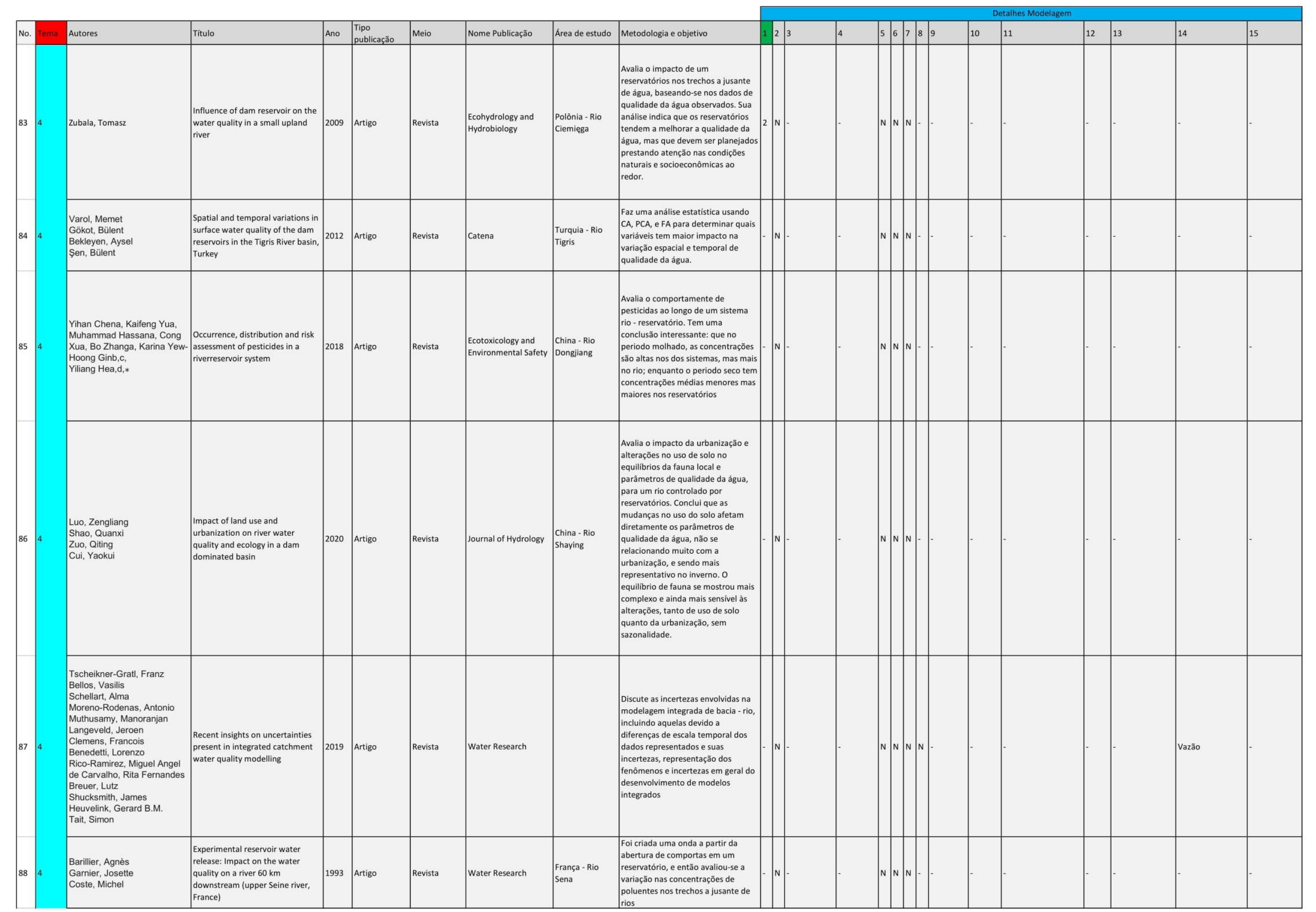




\begin{tabular}{|c|c|c|c|c|c|c|c|c|c|c|c|c|c|c|c|c|c|c|c|c|c|}
\hline & & & & & & & & & & & & & & & & & etalhes Modelagem & & & & \\
\hline No. & Tema & Autores & Titulo & Ano & $\begin{array}{l}\text { Tipo } \\
\text { publicacão }\end{array}$ & Meio & Nome Publicação & Área de estudo & Metodologia e objetivo & 2 & 3 & 4 & \begin{tabular}{l|l|l}
5 & 6 & 7
\end{tabular} & \begin{tabular}{l|l|l|}
7 & 8
\end{tabular} & 9 & 10 & 11 & 12 & 13 & 14 & 15 \\
\hline 89 & & $\begin{array}{l}\text { Chung, Se Woong } \\
\text { Ko, Ick Hwan } \\
\text { Kim, Yu Kyung }\end{array}$ & $\begin{array}{l}\text { Effect of reservoir flushing on } \\
\text { downstream river water quality }\end{array}$ & 2008 & Artigo & Revista & \begin{tabular}{|l} 
Journal of \\
Environmental \\
Management
\end{tabular} & $\begin{array}{l}\text { Korea - Rio } \\
\text { Geum }\end{array}$ & 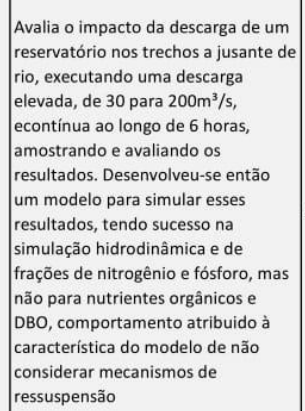 & & & & & & & & & & & & \\
\hline 90 & 3 & $\begin{array}{l}\text { Passaia, Otávio } \\
\text { Siqueira, Vinicius Alencar } \\
\text { Brêda, João Paulo } \\
\text { Fleischmann, Ayan Santos } \\
\text { Paiva, Rodrigo Cauduro Dias } \\
\text { de }\end{array}$ & $\begin{array}{l}\text { Impact of large reservoirs on } \\
\text { simulated discharges of Brazilian } \\
\text { rivers }\end{array}$ & 2020 & Artigo & Revista & RBRH & Brasil & 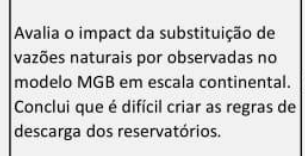 & $\begin{array}{ll}3 & 5 \\
\end{array}$ & MGB & MGB & $s|n| n$ & & & & & & & & Vazão, Nivel \\
\hline 91 & 4 & $\begin{array}{l}\text { Tranmer, Andrew W. } \\
\text { Weigel, Dana } \\
\text { Marti, Clelia L. } \\
\text { Vidergar, Dmitri } \\
\text { Benjankar, Rohan } \\
\text { Tonina, Daniele } \\
\text { Goodwin, Peter } \\
\text { Imberger, Jörg }\end{array}$ & $\begin{array}{l}\text { Coupled reservoir-river systems: } \\
\text { Lessons from an integrated } \\
\text { aquatic ecosystem assessment }\end{array}$ & 2020 & Artigo & Revista & $\begin{array}{l}\text { Journal of } \\
\text { Environmental } \\
\text { Management }\end{array}$ & \begin{tabular}{|l} 
EUA - Rio \\
Deadwood
\end{tabular} & 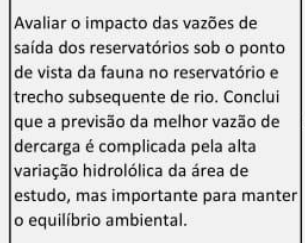 & & \begin{tabular}{|l|} 
"3D \\
Reynolds \\
averaged \\
Navier- \\
Stokes", \\
Saint- \\
Venant, ADR
\end{tabular} & $\begin{array}{l}\text { AEM3D, } \\
\text { Mike11 }\end{array}$ & $\mathrm{N} / \mathrm{s}$ & & 614 & 38 & \begin{tabular}{|l} 
Vazão de saida e \\
temperatura do \\
reservatório \\
(jusante)
\end{tabular} & & $\begin{array}{l}100 \times 100 \times 1 \text { (grid } \\
\text { reservatório), } \\
30 \mathrm{M} \text { (MDE rio) }\end{array}$ & & \\
\hline 92 & 3 & Yevdjevich, Vujica M & $\begin{array}{l}\text { Bibliography and Discussion of } \\
\text { Flood-Routing Methods and } \\
\text { Unsteady Flow in Channels }\end{array}$ & 1964 & Livro & & & - & $\begin{array}{l}\text { Avalia métodos de propagação de } \\
\text { onda }\end{array}$ & N & & & n $\mid$ n & $\mathrm{N} N$ & & & & & & & \\
\hline 93 & 4 & Steven C Chapra & \begin{tabular}{|l|}
$\begin{array}{l}\text { Surface Water-Quality Modeling- } \\
\text { Waveland Press }\end{array}$ \\
\end{tabular} & 2008 & Livro & & & & Base teórica & N & & & $|\mathrm{n}| \mathrm{n}$ & $N \mid N$ & & & & & & & \\
\hline 94 & 3 & $\begin{array}{l}\text { Gichamo, T. Z. } \\
\text { Popescu, I. } \\
\text { Jonoski, A. } \\
\text { Solomatine, D. }\end{array}$ & $\begin{array}{l}\text { River cross-section extraction from } \\
\text { the ASTER global DEM for flood } \\
\text { modeling }\end{array}$ & 2012 & Artigo & Revista & $\begin{array}{l}\text { Environmental } \\
\text { Modelling and } \\
\text { Software }\end{array}$ & $\begin{array}{l}\text { Húngria- Rio Rio } \\
\text { Tisza }\end{array}$ & 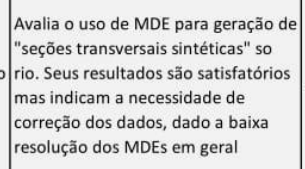 & & \begin{tabular}{|l} 
Saint- \\
venant
\end{tabular} & $\begin{array}{l}\text { HEC-RAS, } \\
\text { GEORas }\end{array}$ & $\mathrm{N} S$ & $\mathrm{~N}$ & & 88.4 & $\begin{array}{l}\text { Hidrogama } \\
\text { (montante) e nivel } \\
\text { (jusante }\end{array}$ & & & & Vazão, nivel \\
\hline 95 & 3 & $\begin{array}{l}\text { Pramaniik, Niranjan } \\
\text { Panda, Rabindra Kumar } \\
\text { Sen, Dhrubajyoti }\end{array}$ & $\begin{array}{l}\text { One dimensional hydrodynamic } \\
\text { modeling of river flow using DEM } \\
\text { extracted river cross-sections }\end{array}$ & 2010 & Artigo & Revista & $\begin{array}{l}\text { Water Resources } \\
\text { Management }\end{array}$ & $\begin{array}{l}\text { India - Bacia } \\
\text { Brahmani }\end{array}$ & 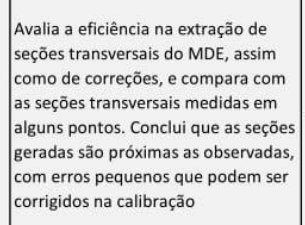 & & $\begin{array}{l}\text { Saint- } \\
\text { venant }\end{array}$ & Mike11 & & $n\left|\frac{1}{n}\right|$ & 39.269 & & Hidrogama, nivel & & & & Vazão, nivel \\
\hline 96 & 3 & Steinstrasser, Carlos Eduardo & \begin{tabular}{|l|}
$\begin{array}{l}\text { Método difusivo de Lax aplicado } \\
\text { na solução das equaçoes de Saint } \\
\text { venant }\end{array}$ \\
\end{tabular} & 2005 & Tese & & PPGERHA & & $\begin{array}{l}\begin{array}{l}\text { Estuda o método de Lax para } \\
\text { solução das equaçōes de Saint- } \\
\text { Venant }\end{array} \\
\text { Vent }\end{array}$ & & & & & & & & & & & & \\
\hline
\end{tabular}




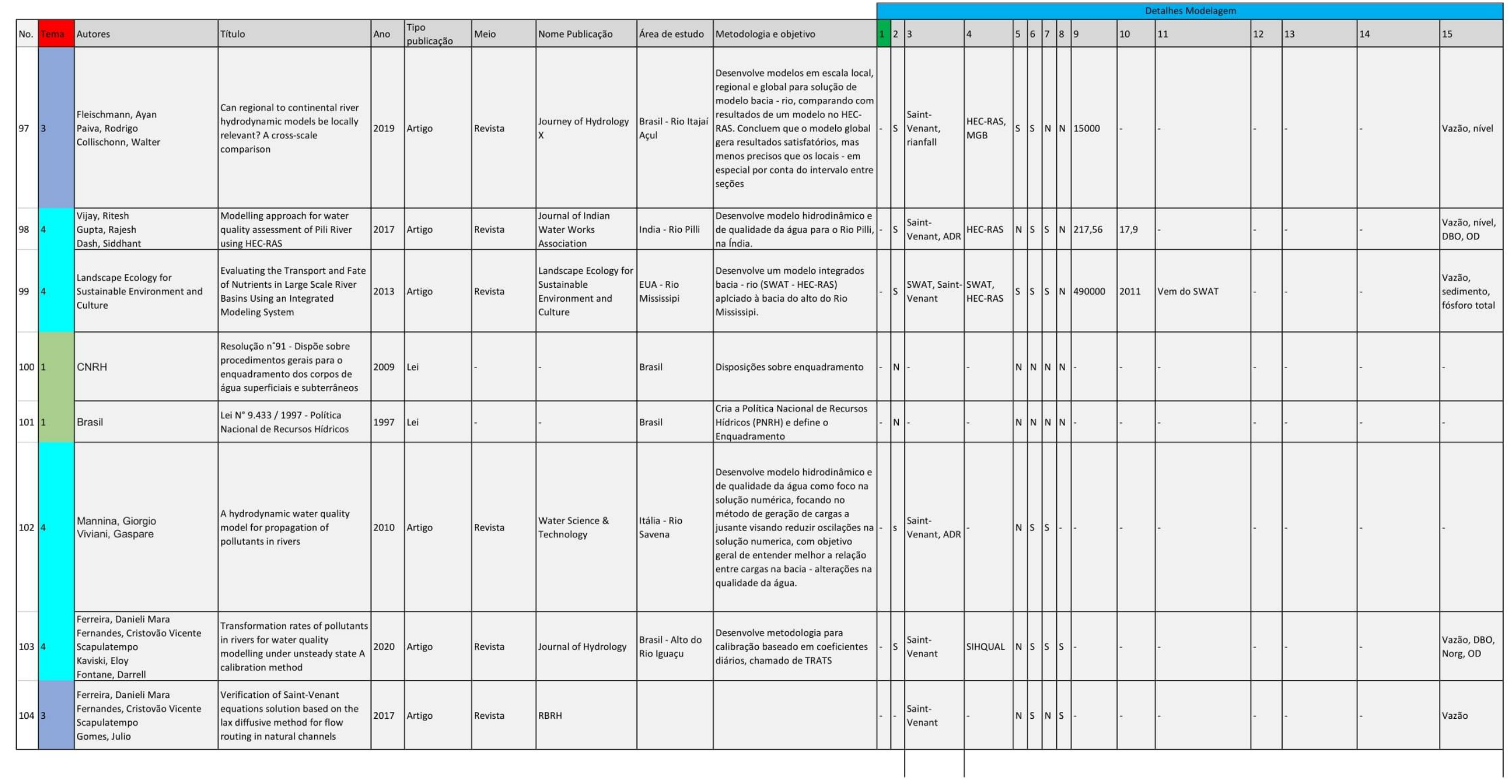

